\title{
THE THEORY OF ABUSE IN GOOGLE SEARCH: A POSITIVE AND NORMATIVE ASSESSMENT UNDER EU COMPETITION LAW
}

Pinar Akman $\dagger$

\begin{abstract}
In its investigation into Google's search practices, Google Search, the Commission alleges that Google abuses its dominant position on the web search market by giving systematic favourable treatment to its "comparison shopping product" (namely, "Google Shopping") in its general search results pages. This Article analyses whether the conduct in question in Google Search can be an abuse under Article 102TFEU (prohibiting the abuse of a dominant position in the EU) and, if so, under what conditions. This Article proceeds by first providing a positive assessment of the application of Article 102TFEU and the relevant case law to the issues involved in Google Search on the assumption that the Commission may seek to place the facts under an existing category of abuse. Three categories of abuse are analysed to this end: refusal to deal (including the essential facilities doctrine), discrimination, and tying. The article then proceeds to a normative assessment of the circumstances under which Article 102TFEU should be applied in Google Search under a principled conceptualisation of "abuse," one which requires exploitation, exclusion, and a lack of an increase in efficiency. The Article finds that the facts in Google Search do not meet the requirements of the existing law to be found abusive unless the established frameworks for the types of abuse examined are unjustifiably disrupted. It also finds that under the principled conceptualisation of abuse adopted in this Article, the facts in Google Search do not represent the type of conduct that should be found abusive either.
\end{abstract}

$\dagger$ Professor of Law, School of Law, University of Leeds. The research for this Article has been supported by Google but the views expressed therein represent solely those of the Author. The research was not undertaken on behalf of the University of Leeds and therefore the University owes no responsibilities or liability in relation to this work. The Author would like to thank Peter Whelan and an anonymous referee for helpful comments and suggestions. The usual disclaimer applies. The Author can be contacted at pinarakmanleeds@gmail.com. After this article was finalized the Commission found Google to have infringed Article 102TFEU and levied a record fine of $€ 2.42$ billion for the infringement. As of the time of the article going into press, the text of the Commission decision is unavailable. 


\section{TABLE OF CONTENTS}

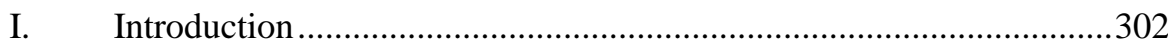

II. Positive Assessment of the Alleged Abuse ............................................307

A. Refusal to Deal and the Essential Facilities Doctrine....................307

1. The Relevant Input .............................................................309

2. The Requirements for Refusal to Deal to be Abusive ............311

a. Refusal to Provide Access to Physical Property...............311

b. Refusal to Provide Access to Intangible Property Including Property Protected by IP Rights .......................317

c. Estoppel Abuse ..............................................................323

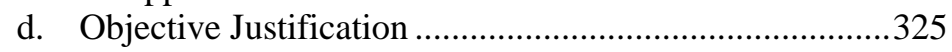

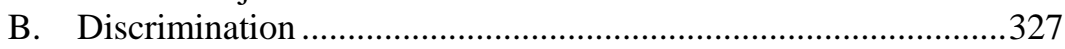

1. Transactions with Other Trading Parties .................................329

2. Competitive Disadvantage.....................................................332

3. Applying Dissimilar Conditions to Equivalent Transactions 334

4. The Relevance of a Downstream/Upstream Market and

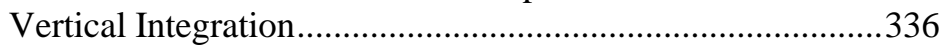

5. Objective Justification and Exclusionary Effect.....................343

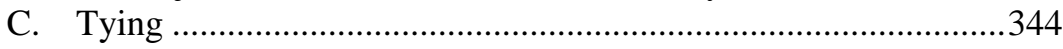

1. Two Separate Products/Services ..............................................346

2. Lack of Customer Choice to Obtain the Tying Product

Without the Tied Product ..........................................................349

3. Foreclosure of Competition ......................................................352

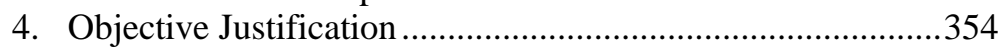

III. Normative Assessment of the Alleged Abuse.......................................355

A. The Concept of Abuse and its Requirements ...............................357

B. Application of the Framework to the Facts in Google Search......359

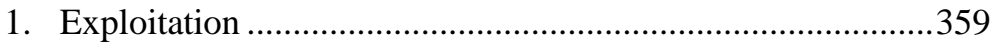

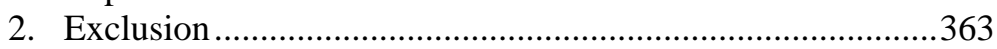

3. Lack of an Increase in Efficiency .........................................364

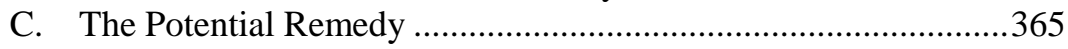

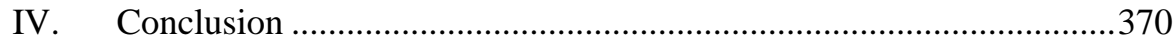

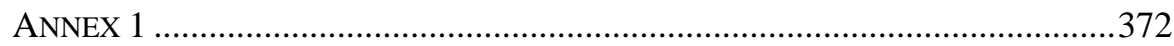

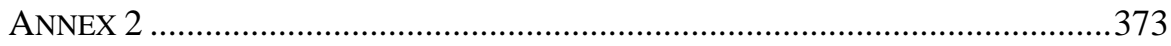

\section{INTRODUCTION}

The European Commission started investigating Google in November 2010 for allegedly abusing a dominant position, contrary to Article 102TFEU. Despite pursuing negotiations with Google, which culminated in commitments that officially "address the Commission's concerns," the Commission issued a

1. See European Commission Press Release IP/14/116, Antitrust: Commission Obtains from Google Comparable Display of Specialised Search Rivals (Feb. 5, 2014) (discussing then-Commissioner Almunia's statement that the commitments address the competition concerns of the Commission). Under Regulation 1/2003 
Statement of Objections (SO) to Google in April 2015, followed by a Supplementary SO in July 2016. ${ }^{2}$ The preliminary conclusion of the Commission's investigation is that Google gives systematic favourable treatment to its "comparison shopping product" (currently called "Google Shopping") in its general search results pages, e.g., by showing Google Shopping more prominently on the screen. " "Comparison shopping products" allow consumers to search for products on online shopping websites and compare prices between different merchants. ${ }^{4}$ The Commission alleges that when a consumer enters a shopping-related query in Google's search engine ("Google Search"), Google Shopping is "systematically displayed prominently at the top of the search results" irrespective of whether it is the most relevant response to the query. ${ }^{5}$ The Commission interprets this to suggest that Google's Commercial Product ("Google Shopping Commercial Unit"), which is the group of Product Listing Ads on general result pages, is not subject to the same algorithms as other comparison shopping services. ${ }^{6}$

According to the Commission, Google's conduct may artificially divert traffic from rival comparison shopping services, hindering their ability to compete. ${ }^{7}$ Further, the Commission suggests that Google's conduct has a

where the Commission intends to adopt a decision requiring that an infringement be brought to an end and the undertakings concerned offer commitments to meet the concerns expressed to them by the Commission in its preliminary assessment, the Commission may, by decision, make those commitments binding on the undertakings. Council Regulation 1/2003, art. 9, 2002 O.J. (L 1$) 1$ (EC).

2. European Commission Press Release IP/16/2532, Antitrust: Commission Takes Further Steps in Investigations Alleging Google's Comparison Shopping and Advertising-Related Practices Breach EU Rules (July 14, 2016).

3. European Commission Press Release IP/15/4780, Antitrust: Commission Sends Statement of Objections to Google on Comparison Shopping Service; Opens Separate Formal Investigation on Android (Apr. 15, 2015) [hereinafter Press Release IP/15/4780].

4. Id.

5. European Commission Statement 15/4780, Statement by Commissioner Vestager on Antitrust Decisions Concerning Google (Apr. 15, 2015) [hereinafter Statement 15/4780].

6. Id. In response to a search query, Google displays free search results that are sometimes accompanied by ads that are paid for by advertisers. The revenue from these ads enables Google to provide the search engine services to the users for free. Product Listing Ads provide merchants with an alternative to text ads by including images, prices, and merchant information. See also, infra note 15 (containing background information). Santiago Andrigo, Google Shopping Now Available in 8 New Countries, Google Inside Adwords (Nov. 7, 2013), http://adwords.blogspot.be/2013/11/google-shopping-now-available-in-8-new.html; Dan Friedman, Announcing Product List Ads, GoOGLE InSIDE ADWORDS (Nov. 11, 2009), http://adwords.blogspot.be/2009/ 11/announcing-product-listing-ads.html; Sameer Samat, Building a Better Shopping Experience, GoOGLE COM.: BLOG (May 31, 2012), https://commerce.googleblog.com/2012/ 05/building-better-shopping-experience.html; Sameer Samat, Connect, Click and Convert Around the World with Google Shopping, GooGLE INSIDE ADWORDS (June 11, 2013), http://adwords.blogspot.be/2013/ 05/shoppingglobal.html; Sameer Samat, Google Shopping Global Transition Is Underway, GoOGLE COM.: BLOG (Feb. 21, 2013), https://commerce.googleblog.com/2013/ 02/google-shopping-global-transition-is_21.html.

7. Press Release IP/15/4780, supra note 3. More specifically, the Commission's preliminary conclusions in its SO are that: (i) Google systematically positions and prominently displays its comparison shopping service in its general search results pages, irrespective of its merits; (ii) Google does not apply to its own comparison shopping service the system of penalties which it applies to other comparison shopping services on the basis of defined parameters, and which can lead to the lowering of the rank in which they appear in Google's general search results pages; (iii) Froogle, Google's first comparison shopping service, did not benefit from any favourable treatment, and performed poorly; (iv) as a result of Google's systematic favouring of its subsequent comparison shopping services "Google Product Search" and "Google Shopping," both experienced higher rates of growth, to the detriment of rival comparison shopping services. European Commission Fact Sheet, Antitrust: 
negative impact on consumers and innovation. ${ }^{8}$ For the Commission, users arguably do not necessarily see the most relevant comparison shopping results in response to their queries, and incentives to innovate from rivals are lowered as they know that however good their product may be, they will not benefit from the same prominence as Google's product. ${ }^{9}$ The Commission's preliminary view is that Google's favourable treatment of Google Shopping is an abuse of Google's dominant position in general Internet search. ${ }^{10}$

The SO's discussion of remedies adopts the preliminary view that in order to remedy the conduct, Google should treat its own comparison shopping service and those of rivals in the same way. ${ }^{11}$ The Commission argues that this remedy would not interfere with Google's algorithms or how it designs its search results pages. ${ }^{12}$ The Commission suggests that it would mean that when Google shows comparison shopping services in response to a user's query, the most relevant service(s) would be selected to appear in Google's search results pages. ${ }^{13}$

The Commission appears to be using Google Search as a test case since it has indicated that "[i]f an infringement is proven, a case focusing on comparison shopping could potentially establish a broader precedent for enforcing EU competition rules in other instances of Google favouring [sic] its own services over competing services." 14 The possibility of such further intervention arises due to the fact that Google Search (like other search engines) has moved from displaying "ten-blue-links" in response to search queries to generating a list of results that integrates specialist (vertical) results such as news, video, image, local, shopping, etc. in one search result (known as "Universal Search"). ${ }^{15}$ Consequently, there is a possibility that these integrated search features other than shopping may give rise to similar cases if Google Search sets a precedent by finding an infringement. The importance of reaching the right decision in Google Search, therefore, cannot be overemphasised since the case will potentially set a precedent not just for other Google services similar to shopping, but also for other businesses in similarly innovative technology markets which provide services with multiple features on multi-sided markets. The case is also of fundamental importance as it represents an ideal opportunity for the Commission to demonstrate that it wishes to protect competition (and thereby the interests of consumers) rather than protect competitors. Concerns have already been voiced that an adverse finding in Google Search may protect

Commission Sends Statement of Objections to Google on Comparison Shopping Service (Apr. 15, 2015), http://europa.eu/rapid/press-release_MEMO-15-4781_en.htm [hereinafter Fact Sheet].

8. Fact Sheet, supra note 7 .

9. Id.

10. Statement $15 / 4780$, supra note 5 .

11. Fact Sheet, supra note 7.

12. Id.

13. Id.

14. Statement $15 / 4780$, supra note 5 .

15. See Our History in Depth, GoOGLE, https://www.google.com/about/company/history (explaining that Google introduced Froogle in 2002 and grouped product results in 2003 and Universal Search in 2007. In 2008, Google introduced advanced ad formats for promoting merchant product offers. These evolved into the Google Shopping Commercial Unit that Google shows today and that is the subject matter of the Commission's investigation. Froogle became Google Shopping in 2012.) (last visited Oct. 14, 2017). 
competitors and disadvantage consumers due to chilling innovation and competition. $^{16}$

The assessments of market definition and dominance are early hurdles in reaching the correct outcome in Google Search. First, there is the issue of what the correctly identified, relevant market is for the purposes of the investigation. Second, there is the issue of determining whether Google holds market power in a properly defined market, which — despite apparent high market shares - is far from a foregone conclusion. In its investigation, the Commission has identified three separate markets (namely: the markets for web search, search advertising, and comparison shopping) reaching the preliminary finding that Google is dominant on the first two of them. ${ }^{17}$ Several commentators have argued that: first, the markets that the Commission has identified in this context are unlikely to be the relevant markets, and, at the least, are too narrowly defined; and, second, on a correctly identified relevant market, Google is unlikely to be dominant. ${ }^{18}$ A finding that Google is not dominant on the correctly identified relevant market would clearly be the end of the Commission's case against Google. ${ }^{19}$ An incorrect definition of the relevant market and/or an incorrect finding of dominance would also suffice for the annulment of the Commission's decision in case of an appeal since it is inconceivable that the remainder of such a decision could survive such a finding.

This Article aims to analyse whether the conduct in question in Google Search can be an abuse under Article 102TFEU, and if so, under what conditions. This Article is, thus, limited to the assessment of the potential theory of abuse, alongside the discussion of a potential remedy. For the sake of full engagement with the conduct aspect of the case, the remainder of this Article bases its discussion on the relevant markets identified by the Commission and the market power allegedly held by Google over them.

The Commission's accusations do not reveal what type of abuse the Commission considers Google's conduct to fall under. This has led to different interpretations by commentators of the type of abuse the investigated conduct might constitute. At one level, how the conduct is categorised is legally

16. See, e.g., Geoffrey A. Manne \& Joshua D. Wright, Google and the Limits of Antitrust: The Case Against the Case Against Google, 34 HARV. J. L. \& PUB. POL'Y 171, 178 (2011) (discussing the U.S. context); Andrea Renda, Searching for Harm or Harming Search?, CEPS Special Report, No. 118/Sept. 2015, https://www.ceps.eu/system/files/AR\%20Antitrust\%20Investigation\%20Google.pdf (2015); Florian Wagnervon Papp, Should Google's Secret Sauce be Organic?, 16 MelBOURnE J. INT’L L. 609, 646-47 (2015).

17. European Commission Memo 13/383, Commission Seeks Feedback on Commitments Offered by Google to Address Competition Concerns-Questions and Answers (Apr. 25, 2013); Statement 15/4780, supra note 5 .

18. See, e.g., Wagner-von Papp, supra note 16, at 639-40; Renda, supra note 16, at 31-32; Christian Kersting \& Sebastian Dworschak, Does Google Hold a Dominant Market Position?-Addressing the (Minor) Significance of High Online User Shares, 16 IFo ScHNELLDIENST 7 (Sept. 12, 2014), http://papers.ssrn.com/sol3/ papers.cfm?abstract_id=2495300; Marina Lao, Search, Essential Facilities, and the Antitrust Duty to Deal, 11 Nw. J. TeCh. \& INTELL. Prop. 275, 292 (2013); James D. Ratliff \& Daniel L. Rubinfeld, Is There a Market for Organic Search Engine Results and Can Their Manipulation Give Rise to Antitrust Liability?, 10 J. CoMP. L. \& ECON. 517, 518-19 (2014); Florence Thépot, Market Power in Online Search and Social Networking: A Matter of Two-Sided Markets, 36 WORLD COMPETITION: L. \& ECON. REV. 195, 217-18 (2013).

19. See, e.g., Wagner-von Papp, supra note 16, at 624. 
irrelevant since Article 102TFEU only lists examples of abuse and it is not necessary for a given conduct to fall within one of the listed categories of conduct to be found abusive. ${ }^{20}$ Given the illustrative nature of the list of practices in Article 102TFEU, what matters is how one interprets the concept of "abuse" and whether the conduct under investigation constitutes an abuse under that relevant interpretation. ${ }^{21}$ Commentators, in seeking to assess Google's conduct under one of the established categories of abusive conduct, have also tried to examine the practice on the basis of existing case law on these different types of abusive conduct. ${ }^{22}$ This is clearly a valuable and important exercise in terms of assessing the potential application of the case law on Article 102TFEU in Google Search. However, at some level, this is also not authoritative for two reasons: first, the concept of "abuse" covers practices not yet found abusive in a case, including novel practices due to the non-exhaustive nature of the provision; and, second, there is no rule of precedent in EU law. ${ }^{23}$ It is therefore possible for the EU Commission (and, should there be an infringement decision and an appeal, for the EU Courts) to not apply any of the existing case law to the facts involved in Google Search or to change the parameters of the existing case law concerning their application in Google Search. ${ }^{24}$ This underlines the importance of a normative assessment of the issues in Google Search and of the examination of how the law should be applied to the facts. Consequently, this Article conducts two separate assessments. It proceeds by first providing a positive assessment of the application of Article 102TFEU and the relevant case law to the issues involved in Google Search on the assumption that the Commission may seek to place the facts under an existing category of abuse. It then proceeds to a normative assessment of the circumstances under which Article 102TFEU should be applied in Google Search under a particular principle of "abuse." Its novel contribution is thus provided in its containing both a thorough assessment

20. For the non-exhaustive list of examples of abuse in Article 102TFEU, see e.g., Case 6/72, Europemballage Corporation and Continental Can Company Inc. v. Comm'n, 1973 E.C.R. 215, If 26. Whether the conduct is a novel type of abuse may be relevant for the imposition of a fine. Although the fact that the Commission and the EU courts have not yet had the opportunity to rule specifically on certain conduct does not, in itself, prevent the Commission from imposing a fine. See Commission Decision, Case AT.39985, 2014 O.J. (L 344) 57, II 560, http://ec.europa.eu/competition/antitrust/cases/dec_docs/39985/39985_928_16.pdf (citing Case C-457/10 P, AstraZeneca v. Comm'n E.C.R., If 164 (Dec. 6, 2012)). Occasionally, the novelty of the abuse has led to the imposition of a symbolic fine, a reduced fine or no fine at all. See, e.g., Case AT.39985, If 561; see also 2014 O.J. (C 344) 6 (summarizing Motorola-Enforcement of GPRS Standard Essential Patents); Case C-62/86, AKZO Chemie BV v. Comm'n, 1991 E.C.R. I-3359, II 163; Commission Decision COMP/C-1/36.915, 2001 O.J. (L 331) 40, II 193.

21. Case 6/72, Europemballage Corp. and Cont'l Can Co. Inc. v. Comm'n, 1973 E.C.R. 215, 254.

22. Renato Nazzini, Google and the (Ever-Stretching) Boundaries of Article 102, 6 (5) J. EuR. COMPETITION L. \& PRAC. 301 (2015); Ioannis Lianos \& Evgenia Motchenkova, Market Dominance and Search Quality in the Search Engine Market, 9 J. COMPETITION L. \& ECON. 419 (2013); Nicolas Petit, Theories of SelfPreferencing under Article 102TFEU: A Reply to Bo Vesterdorf (2015), http://dx.doi.org/10.2139/ssrn.2592253.

23. For there being no rule of precedent, see e.g., Anthony Arnull, Owning Up to Fallibility: Precedent and the Court of Justice, 30 COMMON MKT. L. Rev. 247, 248, 262 (1993); PAUL LASOK, LAW \& InSTITUTIONS OF THE EuRopean Union 171 (7th ed. 2001); PAUl CRAIG \& GráinNe De BúrCa, EU LaW: TEXT, CASES, AND MATERIALS 63 (5th ed. 2011) (showing why the exercise is not authoritative).

24. See Arnull, supra note 23 (demonstrating the lack of precedent in European Union Law). 
of the positive law, as well as a normative analysis of the relevant issues under one interpretation of the concept of "abuse."

To achieve its two objectives, this Article comprises two parts. Section II examines the most likely existing categories of abusive conduct under which Google's conduct might fall. It has been argued that the alleged abuse in Google Search does not squarely fit any of the established categories of abuse. ${ }^{25}$ The closest types of abuse to the allegedly abusive conduct in Google Search are refusal to deal (including the essential facilities doctrine), discrimination, and tying. Thus, Section II is divided into three parts examining each of these abuses and their application in Google Search. Underlying all of these possible types of conduct is a theory that Google leverages its market power on the search engine market to another market, namely the market for comparison shopping sites. ${ }^{26}$ Section III presents a normative legal assessment of the circumstances under which Article 102TFEU should apply to the facts of Google Search. The particular conceptualisation of abuse on which this normative assessment is based would require there to be exploitation, exclusion, and a lack of an increase in efficiency resulting from the dominant undertaking's conduct before a finding of abuse can be made. ${ }^{27}$ This normative assessment is complemented by the discussion of the potential remedy in Google Search. Section IV concludes by finding that the facts in Google Search do not meet the requirements of the existing law to be found abusive unless the established frameworks for the types of abuse examined are unjustifiably disrupted. It also finds that under the conceptualisation of abuse adopted in this article, the facts in Google Search do not represent the type of conduct that should be found abusive.

\section{Positive Assessment of THE AlLEGEd Abuse}

\section{A. Refusal to Deal and the Essential Facilities Doctrine}

Many commentators have associated the alleged abuse in Google Search with refusal to deal and accordingly, have discussed whether Google Search is in fact an "essential facility." 28 Moreover, considering the remedy that the Commission appears to be seeking, namely that of applying the same algorithm that Google applies to Google Shopping to all comparison shopping sites ${ }^{29}$ one could argue that the remedy (and therefore the alleged abuse) concerns the access of comparison shopping sites to Google's product (the search engine) and the conditions of that access, namely, how these websites appear on the general

\footnotetext{
25. Nazzini, supra note 22, at 313.

26. See Statement $15 / 4780$, supra note 5.

27. For a detailed explanation and justification of the conceptualisation of abuse, developed by this Author, see PinAR AKMAN, The CONCEPT of ABUSE IN EU COMPETITION LAW: LAW AND ECONOMICS APPROACHES (2012) (developing the concept particularly in Chapter 8).

28. See, e.g., Lao, supra note 18; Bo Vesterdorf, Theories of Self-Preferencing and Duty to Deal-Two Sides of the Same Coin?, 1 Competition L. \& PoL'y Debate 4 (2015); Petit, supra note 22; Lisa Mays, The Consequences of Search Bias: How Application of the Essential Facilities Doctrine Remedies Google's Unrestricted Monopoly on Search in the United States and Europe, 83 GEO. WASH. L. REV. 721 (2015).

29. See Statement 15/4780, supra note 5 (demonstrating the Commission's desire to use the remedy).
} 
result pages. ${ }^{30}$ Taking this argument to its logical conclusion, the question at issue in Google Search can be restated as whether Google has a duty to deal with the operators of websites, such as comparison shopping sites, that provide competing services to Google's own services by providing them access to Google Search on certain terms which ensure that their services are subject to the same rules that Google applies to the display of its own services (such as shopping results) on Google Search (i.e., Google's own, proprietary product).

As acknowledged by the Commission, generally speaking, any undertaking, including a dominant one, should have the right to choose its trading partners and to freely dispose of its property. ${ }^{31}$ Intervention on competition law grounds where the application of Article 102TFEU would impose an obligation of supply on the dominant undertaking therefore requires careful consideration, not least because of its potential to undermine both the dominant undertaking's and its rivals' incentives to invest and innovate, something which would not be in the interests of consumers. ${ }^{32}$ Competition concerns typically arise when the dominant undertaking competes on the "downstream market" with the buyer whom it refuses to supply. ${ }^{33}$ In this context, the term "downstream market" refers to the market on which the refused input is needed to manufacture a product or produce a service. ${ }^{34}$ This is indeed the only type of refusal to deal that the Commission discusses in its Guidance, which suggests that it is the only type of refusal to deal that is a priority in terms of the Commission's enforcement. ${ }^{35}$ This type of refusal to deal covers a broad range of practices including refusal to grant access to an "essential facility" or a network. ${ }^{36}$ An "essential facility," in turn, is defined as "a facility or infrastructure, without access to which competitors cannot provide services to their customers." 37

In Google Search, the Guidance's conceptualisation of refusal to deal faces the problem that, as discussed below, Google is unlikely to be a vertically integrated undertaking which is active on the "upstream" market of search and which provides an "input" necessary to provide a service on the "downstream" market of comparison shopping where it is also present. ${ }^{38}$ However, given that much of the commentary to date suggests that this may indeed be the theory of harm underlying the allegations, this Subsection will assume that the market positioning of Google Search and comparison shopping sites could be considered to fit into the categorisation of upstream and downstream levels of

\footnotetext{
30. Id.

31. European Commission, Communication from the Commission-Guidance on the Commission's Enforcement Priorities in Applying Article 82 of the EC Treaty to Abusive Exclusionary Conduct by Dominant Undertakings, 2009 O.J. (C 45) 7, If 75 [hereinafter Commission Guidance].

32. Id.

33. Id. II 76 .

34. $I d$.

35. Id.

36. Id. I 78

37. Commission Decision 94/19 of December 21, 1993, Relating to a Proceeding Pursuant to Article 86 of the EC Treaty, 1993 O.J. (L 15) II 66 (EC).

38. See infra text after note 220 for the discussion of vertical integration. Vertical integration is considered to be more immediately relevant and fundamentally important for the abuse of discrimination, which explains why it is discussed under discrimination below.
} 
production or a similar positioning. Nevertheless, the separate question of whether Google provides an "input" which is needed in order to provide the service on the other, neighbouring market and the supply of which is refused by the dominant undertaking is one that has to be further examined. After a brief inquiry into what this "input" might be immediately below (i), this Subsection will turn to the requirements for refusal to deal to be abusive under the case law (ii). This assessment will specifically examine the requirements for such an abuse concerning refusal to supply physical property (ii.a), the requirements for such an abuse concerning refusal to supply intangible property including property that is protected by IP rights (ii.b), the so-called "estoppel abuse" which concerns the conditions of supply where supply has been provided voluntarily (ii.c), and, finally, "objective justification" which can justify conduct that would otherwise be found abusive (ii.d).

\section{The Relevant Input}

The first issue that needs to be explored is identifying the relevant "input" that is not being supplied. This is not obvious from the Commission's allegations, which focus on the argument of "self-favouring," without much detail. ${ }^{39}$ The closest explanation of what the input can be is found in a statement by Commissioner Vestager, who remarked that " $[t]$ he commercial importance of appearing prominently in Google's general search results is obvious." ${ }^{40}$ Therefore, the input could be (i) the free traffic to comparison shopping sites that being displayed on Google's general result pages provides to these sites, or, (ii) a particular positioning and ranking on Google's general result pages (e.g., appearing on the first page of results). ${ }^{41}$ Although the value of a particular position in the results is also linked to the traffic that this position and ranking would provide to the comparison shopping sites, "being ranked prominently" is a more specific type of input than "receiving free traffic" and would have different implications in the context of remedies. ${ }^{42}$ The question in Google Search, therefore, is whether either receiving free traffic or being displayed in a certain position on Google's general result pages is a necessary input to provide a service, namely, comparison shopping.

It has been argued that at face value, there is no abusive refusal to supply in Google Search because-as will be argued below concerning discrimination - there is no trading relationship between a search engine and specialist (vertical) search sites or any other site from which information is obtained to respond to a user's query. ${ }^{43}$ Moreover, Google is displaying rival specialist search websites (such as comparison shopping sites) in its own search

39. Press Release IP/15/4780, supra note 3.

40. Statement 15/4780, supra note 5.

41. See, e.g., Lianos \& Motchenkova, supra note 22, at 436 (suggesting the possibility that the refusal concerns the refusal to grant access to the highest ranking in the search engine or to being ranked on the first page of results).

42. Id. at 435-36.

43. Nazzini, supra note 22 , at 307. 
results. ${ }^{44}$ Furthermore, there is no contractual or technological coercion of consumers to choose results higher up on the search result pages. ${ }^{45}$ These comments suggest that the refusal to deal theory would only work if the "input" being necessary for competing on the comparison shopping market is not just appearing in Google's general search results, but appearing in a certain position and ranking in these results: provided that the comparison shopping sites appear somewhere on the list of results, one cannot argue that the supply of the "input" is being refused if the "input" is simply that of appearing in Google's general search results rather than appearing in a particular way in those results. ${ }^{46}$ If the "input" is that of being positioned or displayed in a certain way, this would imply that to remedy the conduct, Google would have to ensure that the comparison shopping sites appear prominently in the general search results, i.e., in a certain position and ranking. Despite the Commissioner's statement that "[they] would not want to interfere with Google's design choices or how its algorithms work, ${ }^{47}$ it is difficult to envisage how the conduct could be remedied without imposing on Google the use of an algorithm that would ensure that certain display conditions are satisfied such as prominent display. Yet, such an imposition would not only interfere with the core of Google's business model and business judgment, it would also constitute the protection of the commercial interests of the competitors irrespective of the benefits or otherwise of such an intervention for users of the search engine. ${ }^{48}$ This is because underlying such a remedy is the assumption that consumers would benefit from the prominent display of such competitors more than they do from, for example, the current, or indeed future, configurations of the result pages. ${ }^{49}$ However, this reflects a value judgment by the Commission and is arguably paternalistic. ${ }^{50}$ In fact, it has been posited that not being able to access a market because the dominant player is impeding access to distribution channels or forms of supply is very different from when a dominant player fails to actively promote competing services through its own service. ${ }^{51}$ It is noteworthy that the Commission itself has held that there is no obligation placed on a dominant producer to subsidize competition to itself. ${ }^{52}$ All in all, the lack of clarity concerning what exactly might be the "input" being refused by Google and the implications of identifying the input in certain ways for the business model of Google inevitably raises questions concerning the legal feasibility and appropriateness of a theory based on a refusal-to-deal-type abuse in Google Search. However, the rest of this Subsection will assume that there is such an "input" that Google could but fails

44. Id.

45. Wagner-von Papp, supra note 16, at 643.

46. Id.

47. Statement $15 / 4780$, supra note 5 .

48. Wagner-von Papp, supra note 16, at 646.

49. Id. at 633 .

50. Id. at 646 .

51. Renda, supra note 16 , at 33 .

52. Commission Decision 87/500/EEC, 1987 O.J. (L 286) 36 II 19. 
to provide, and will examine the conditions under which such a failure would constitute an abusive refusal to deal under Article 102TFEU.

\section{The Requirements for Refusal to Deal to be Abusive}

As refusal to deal is not an abuse explicitly stipulated in Article 102TFEU, its legal assessment inevitably involves examination of the relevant case law. ${ }^{53}$ That case law can be categorised as that concerning the refusal to supply/provide access to physical property or the refusal to supply/provide access to intangible property, including that protected by IP rights. ${ }^{54}$ There is debate whether the duty to deal should differ depending on the type of property, with some arguing that both the refusal to deal in physical property and the refusal to deal in IPprotected property should be subject to the same rules. ${ }^{55}$ The jurisprudence has developed different conditions for these different types of refusal to deal; ${ }^{56}$ the following Section will therefore examine refusal to provide access to physical property separately from refusal to provide access to intangible property including property protected by IP rights.

\section{a. Refusal to Provide Access to Physical Property}

The EU refusal to supply case law is generally deemed to start with Commercial Solvents, where the input whose supply was refused was a raw material necessary to produce a derivative, ethambutol (a type of antituberculosis drug). ${ }^{57}$ After having supplied a downstream customer with the raw material for some years, Commercial Solvents discontinued the supply when it started competing on the downstream market. The Court of Justice $(\mathrm{CoJ})$ found this to be abusive. ${ }^{58}$ Importantly, the CoJ indicated that if on the raw material market, there was another raw material that could be substituted without difficulty for the raw material being refused, then this could have invalidated the argument that Commercial Solvents had a dominant position on the market for the raw material in the first place. ${ }^{59}$ Applying this to Google Search, if the input allegedly being refused is traffic to a website, then it is questionable that the case falls within the scope of the refusal to deal case law, since there are clearly

53. Joined Cases $6 \&$ 7/73, Istituto Chemioterapico Italiano S.p.A. and Commercial Solvents Corp. v. Comm'n, 1974 E.C.R. 223; Case C-7/97, Oscar Bronner GmbH \& Co. KG v. Mediaprint Zeitungs-und Zeitschriftenverlag GmbH \& Co. KG, 1998 E.C.R. I-7791; see also PinAR AKMAN, THE CONCEPT OF AbUSE IN EU COMPETITION LAW: LAW AND ECONOMICS APPROACHES (2012).

54. Joined Cases $6 \& 7 / 73$, Istituto Chemioterapico Italiano S.p.A. and Commercial Solvents Corp. v. Comm'n, 1974 E.C.R. 223; Case C-7/97, Oscar Bronner GmbH \& Co. KG v. Mediaprint Zeitungs-und Zeitschriftenverlag GmbH \& Co. KG, 1998 E.C.R. I-7791; see also PINAR AKMAN, THE CONCEPT OF ABUSE IN EU COMPETITION LAW: LAW AND ECONOMICS APPROACHES (2012).

55. See Robert O’Donoghue \& Jorge Padilla, The LaW And EConomics of ARTicle 102TFEU 529 (2d ed. 2013); Nazzini, supra note 21, at 309.

56. See Commercial Solvents, 1974 E.C.R. 223 (demonstrating that jurisprudence has developed conditions for refusal to deal); Bronner, 1998 E.C.R. I-7791.

57. Commercial Solvents, 1974 E.C.R. 223.

58. Id. I[ 25.

59. Id. II 15 
available alternatives to Google for generating traffic to a website. ${ }^{60}$ This would and does indeed raise the question whether Google can be dominant on the relevant market for the purposes of a theory of harm based on refusal to supply free traffic to certain websites. ${ }^{61}$ But as noted above, for present purposes, it is assumed that it can be established that Google is dominant on a properly defined relevant market.

Some other cases of refusal to deal in physical property involved the duty to provide access to physical infrastructure and ports. ${ }^{62}$ However, it was not until Bronner that the legal conditions under which access could be ordered were clarified by the EU Courts. ${ }^{63}$ In Bronner, a preliminary reference ruling, the CoJ was asked to rule whether the conduct of Mediaprint, a press undertaking holding a very large share of the daily newspaper market in Austria and which also operated the only nationwide newspaper home delivery scheme, in refusing to provide access to Bronner, the publisher of a rival newspaper with a small circulation, was an abusive delivery scheme. ${ }^{64}$ Despite the fact that Mediaprint had provided such access to another newspaper as part of a package of services, the CoJ suggested that Mediaprint's refusal to provide access to Bronner was not abusive. ${ }^{65}$ In clarifying the conditions for such conduct to be abusive, the Court emphasised that it is not just necessary to prove that the refusal of the service is likely to eliminate all competition in the daily newspaper market on the part of the person requesting access and that the refusal cannot be objectively justified, it is also necessary to prove that the service in itself is indispensable to carry on that person's business and that there is no actual or potential substitute in existence for the relevant service. ${ }^{66}$ Moreover, regarding indispensability, it is not enough for a party seeking access to argue that it is not economically viable for it to create an alternative due to its small scale. ${ }^{67}$ In establishing whether there are substitutes or not, it is also not relevant that some of these substitutes may be "less advantageous" for the competitor in question than using the service of the dominant undertaking. ${ }^{68}$ For access to be deemed indispensable, it would be necessary "at the very least" that it is not economically viable to create a second delivery scheme for an undertaking that has similar scale to the undertaking that has developed the existing scheme. ${ }^{69}$ In other words, the

\footnotetext{
60. Traffic to these websites can be generated, inter alia, through advertising on search engines, offering of mobile apps, offline advertising, repeat visits from satisfied customers, etc.

61. Wagner-von Papp, supra note 16, at 642.

62. See, e.g., Commission Decision 94/19, supra note 37, If 66 (EC); Commission Decision No. 94/119 of December 21, 1993 Concerning a Refusal to Grant Access to the Facilities of the Port of Rødby, 1994 O.J. (L 55) 52 (EC), http://eur-lex.europa.eu/legal-content/EN/TXT/?uri=CELEX:31994D0119; Commission Decision No. 92/213/EEC, (British-Midland v. Aer Lingus), 1992 O.J. (L 96) 34, http://eur-lex.europa.eu/legalcontent/EN/TXT/ ?uri=CELEX:31992D0213.

63. O'DONOGHUE \& PADILLA, supra note 55, at 529.

64. Bronner, 1998 E.C.R. I-7791 II 11.

65. Id. $\llbracket 47$

66. Id. II 41 .

67. Id. \ 45 .

68. Id. $\llbracket 42$

69. Id. $\llbracket 46$
} 
standard is an objective one based on an equally efficient entrant. ${ }^{70}$ The Advocate General's Opinion in Bronner is also noteworthy in pointing out that allowing access to a company's facilities too easily would disincentivise both the competitor gaining access and the dominant undertaking allowing access from investing in such facilities. ${ }^{71}$ Moreover, "the mere fact that by retaining a facility for its own use a dominant undertaking retains an advantage over a competitor cannot justify requiring access to it."72 Applying Bronner to the facts of Google Search suggests that, as comparison shopping sites have many ways of receiving traffic other than appearing prominently in the results on Google's general result pages, it cannot be said that there are no actual or potential alternatives to Google's service for the comparison shopping sites to carry on their business. ${ }^{73}$ In Google Search, there are both current and potential substitutes to receiving (free) traffic from Google Search, such as receiving (free) traffic from other search engines, mobile apps, social media or direct (e-) mail campaigns, or online and offline advertising campaigns to increase brand

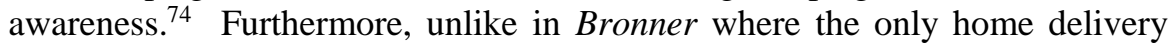
scheme in the country was owned by Mediaprint-which allegedly had a dominant position in "the market for services constituted by that scheme or of which it forms part," "75 — in Google Search there are actual, existing competitors of Google's search engine such as Bing and Yahoo!, which have their own comparison shopping features. ${ }^{76}$ Thus, the factual context of Google Search is even less likely to require the imposition of a duty to deal than the specific factual context of Bronner.

It has been argued that there are two prongs to the test of indispensability in Bronner. ${ }^{77}$ Petit believes that these are the "substitutability prong" and the "replicability prong." The former relates to whether there are any alternatives to the service to which access is sought, whereas the latter relates to whether it is economically viable to create an alternative service. ${ }^{78}$ A further argument is that subsequent case law has focused more on the replicability prong rather than the substitutability prong, which occupies a "marginal role in the assessment."79 This argument is used to suggest that in the context of Google Search, even if the substitutability test could be satisfied due to availability of alternative routes

\footnotetext{
70. O’DONOGHUE \& PADILLA, supra note 55, at 530.

71. Bronner, 1998 E.C.R. I-7791】[ 57.

72. Id.

73. Wagner-von Papp, supra note 16, at 642.

74. Bronner, 1998 E.C.R. I-7791 II 57.

75. Id. $\llbracket 42$

76. Id.

77. Petit, supra note 22 , at $12-13$.

78. Id. at 12.

79. Id . at 13. Petit also suggests that the Commission's Guidance similarly "confirms the predominance of the replicability prong in the indispensability test." Id. However, the cited footnote in support of this argument is limited to an explanation of what replicability means without any indication that this is the more important aspect of indispensability. In fact, in the very same paragraph, the Commission states that "an input is indispensable where there is no actual or potential substitute on which competitors in the downstream market could rely ....” Id.; Commission Guidance No. 2009/C 45/7/02 (Art. 82), 2009 O.J. (C 45) 7, II 83. Thus, it is
} clear that also for the Commission the key to whether the input is indispensable is substitutability. 
to the market for comparison shopping sites, it also has to be established that it would be "economically viable" for another undertaking to replicate Google's search engine. ${ }^{80}$ This Author respectfully disagrees with the argument that there are two separate prongs to indispensability and that later case law has emphasised the replicability prong of Bronner's test. ${ }^{81}$ For a start, linguistically, the CoJ does not seem to have introduced separate elements to the issue of whether a service is indispensable; the Court has explicitly suggested that substitutability is what indispensability means in stating that "the service in itself [is] indispensable to carrying on that person's business, inasmuch as there is no actual or potential substitute in existence . . .." 82 The use of the words "inasmuch as" suggests that the second part of the statement explains what the first part of the statement means. According to the Court, indispensability is about whether or not there are actual or potential substitutes to the service to which access is sought to carry on the business for which access is sought. ${ }^{83}$ The rest of the judgment does not introduce a "replicability prong" to the test of indispensability; it simply explains what might be "potential" substitutes as opposed to "actual" substitutes. ${ }^{84}$ After noting that "other methods" of distribution "exist and are used" (i.e., there are actual substitutes), ${ }^{85}$ the Court states that moreover, there are not any technical, legal or economic obstacles that would prevent the creation of alternative schemes (i.e., there are potential substitutes). ${ }^{86}$ The rest of the relevant parts of the judgment explain that this understanding of potential substitutes is based on economic viability of creating these for an undertaking that has similar scale to the one refusing access and not one that has similar scale to the one seeking access. ${ }^{87}$ This explanation of how to establish the existence of potential substitutes cannot be interpreted to suggest that the replicability of the service is a separate prong to the substitutability prong of "indispensability"; the entire test of "indispensability" in Bronner is based on the concept of substitutability alone. ${ }^{88}$ Regarding Google Search, as there are actual, existing substitutes to Google, a further investigation into "replicability" is neither legally required nor meaningful. ${ }^{89}$

The case law subsequent to Bronner has not emphasized "replicability" over "substitutability" as a separate and more important aspect of indispensability either. ${ }^{90}$ In European Night Services, one of the subsequent

\footnotetext{
80. Petit, supra note 22, at 12-13.

81. Id.

82. Case C-7/97, Oscar Bronner GmbH \& Co. KG v. Mediaprint Zeitungs-und Zeitschriftenverlag GmbH \& Co. KG, 1998 E.C.R. I-7791 (emphasis added).

83. Id. II 45 .

84. Id. ITI 43-46.

85. Id. II 43 .

86. Id. II 44

87. Id. III $45-46$.

88. Id.

89. $I d$.

90. Joined Cases T-374-375, 384 \& 388/94, European Night Services Ltd (ENS) v. Comm'n, 1998 E.C.R. II-3141 (expressing that the statement in 9209 is used to explain what "substitutability" means in the given context is clear from the fact that the paragraph starts with the word "consequently" which follows If 208
} 
cases cited in this respect, ${ }^{91}$ the General Court (GC) held that a facility cannot be considered necessary or essential unless there is no real or potential substitute. ${ }^{92}$ The reference in European Night Services to the prohibitive cost of reproducing the facility is again an explanation of what might constitute "viable alternatives available to potential competitors" in terms of explaining "substitutability." 93 Microsoft and IMS Health are the two other cases cited in support of "replicability" being more important than "substitutability." 94 The argument is that in Microsoft the GC ruled that the key question in the indispensability test was the "economic viability" of rival companies..$^{95}$ However, in Microsoft the cited reference to "economic viability" appears to have been made not in the context of the economic viability of replicating the product/service to which access is sought, but the economic viability of rivals as businesses if the sought access is not provided. ${ }^{96}$ These are two different issues and Bronner already noted that "indispensability" related to the indispensability of the access "to carry on that person's [i.e. the person seeking access] business." ${ }^{97}$ In fact, there was no factual point about replicability in Microsoft since the refusal to deal aspect of the case concerned disclosure of interoperability information which the rivals on the work group server operating systems market needed and replicability of client PC operating systems (i.e., the market over which Microsoft was dominant) was never an issue in the case..$^{98}$ The question was whether there were alternatives (i.e., substitutes) to Microsoft's disclosure of information that would have enabled the rivals to remain economically viable on the server market. ${ }^{99}$ Thus, Microsoft does not appear to have emphasised the replicability of the service over the substitutability of the service, not least because the factual issue related to substitutability. ${ }^{100}$ Similarly, in IMS Health, "indispensability" again seems to have been expressed only in terms of the existence of substitutes (actual or potential) rather than through a distinction between substitutability and replicability of the service to which access is sought. ${ }^{101}$ Furthermore, in a factual scenario as in Google Search, where there are already actual substitutes to the service to which access is sought, logically, there would be no need to consider

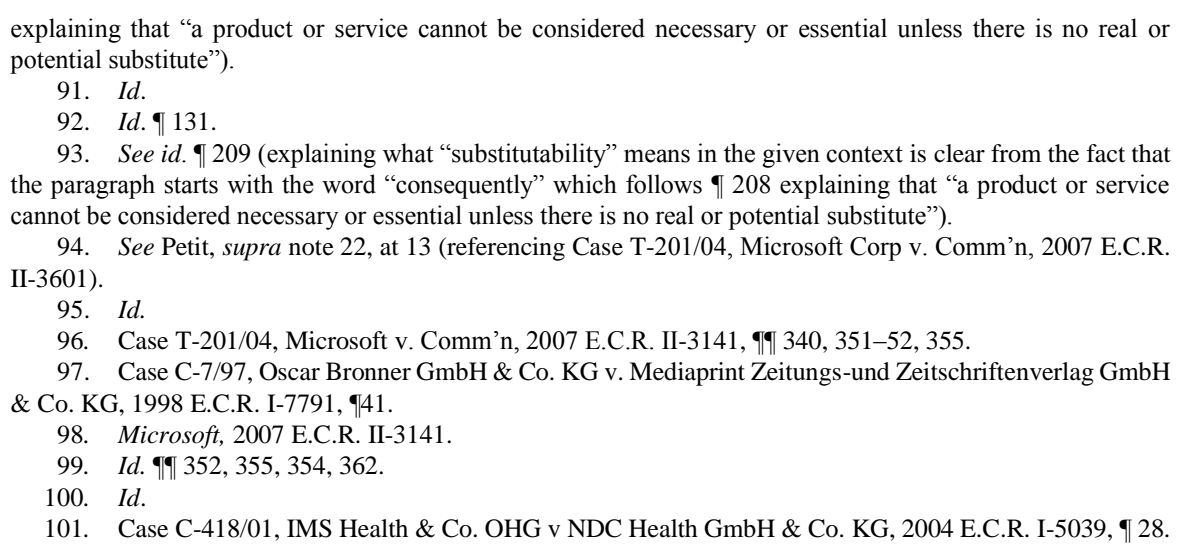

93. See id. $\mid 209$ (explaining what "substitutability" means in the given context is clear from the fact that the paragraph starts with the word "consequently" which follows \ 208 explaining that "a product or service cannot be considered necessary or essential unless there is no real or potential substitute").

94. See Petit, supra note 22, at 13 (referencing Case T-201/04, Microsoft Corp v. Comm'n, 2007 E.C.R. II-3601).

95. Id.

96. Case T-201/04, Microsoft v. Comm'n, 2007 E.C.R. II-3141, IITI 340, 351-52, 355.

97. Case C-7/97, Oscar Bronner GmbH \& Co. KG v. Mediaprint Zeitungs-und Zeitschriftenverlag GmbH \& Co. KG, 1998 E.C.R. I-7791, I[41.

98. Microsoft, 2007 E.C.R. II-3141.

99. Id. IITI $352,355,354,362$.

100. Id.

101. Case C-418/01, IMS Health \& Co. OHG v NDC Health GmbH \& Co. KG, 2004 E.C.R. I-5039, II 28. 
whether the service could be replicated since the existence of actual alternatives makes that inquiry into potential alternatives redundant.

Regarding the abuse of refusal to supply and the application of the case law to the facts of Google Search, a key issue is indeed the indispensability of the input that Google allegedly provides to websites such as comparison shopping sites. It has been noted that vertical foreclosure and the consequent duty to be imposed to assist rivals may only be justified when the dominant undertaking controls an indispensable input that cannot be replicated. ${ }^{102}$ In terms of indispensability of Google Search or a certain type or position of display on the general result pages for comparison shopping sites, some commentators have suggested that it is possible to conceive Google Search as an indispensable distribution tool, a "sort of essential facility" to which competing specialist search engines and websites should have access. ${ }^{103}$ They note that Google's search engine has a cost structure that resembles that of natural monopolies (important fixed costs and low marginal costs), making it theoretically possible for a plaintiff to prove that creating a search engine is not a realistic potential alternative and that access to the existing system is therefore indispensable in the sense of Bronner. ${ }^{104}$ However, the same commentators also remark that such evidence will be particularly difficult to produce, and requires concrete empirical analysis. ${ }^{105}$ Moreover, the theory of the search engine being a natural monopoly and providing an indispensable output without substitutes is directly challenged by the existence of competitors of Google providing search engines such as Bing, Yahoo!, DuckDuckGo, and some local competitors such as Yandex, etc. ${ }^{106}$

For some, such as the German Monopolies Commission, it is doubtful whether search engines meet the legal prerequisites of an "essential facility."107 Arguably, regardless of its market share, a single search engine is unlikely to constitute an essential facility if there are alternative search engines making it possible to find websites. ${ }^{108}$ Content which does not appear at the top of the search results remains accessible for Internet users, as a matter of principle, via other channels; this suggests that a search engine is neither an essential facility nor a gatekeeper. ${ }^{109}$ Even if network effects were a relevant consideration due to, for example, enabling Google to offer the best services among search engines as a result of performing the largest number of search queries, Google is still subject to competitive pressure from other search engines. The latter would immediately exploit any shortcomings of Google in order to attract users and

102. Nazzini, supra note 22, at 309.

103. Lianos \& Motchenkova, supra note 22, at 434; see also Mays, supra note 28, at 751 (arguing that Google Search should be regulated as an essential facility).

104. Lianos \& Motchenkova, supra note 22, at 435.

105. Id.

106. YAHOO!, http://www.yahoo.com (last visited Oct. 14, 2017)

107. German Monopolies Commission, Competition Policy: The Challenge of Digital Markets, 2015 Special Report 68, 58, http://www.monopolkomission.de/images/PDF/SG/s68_fulltext_eng.pdf.

108. Id. at 58 .

109. Id. at 61 . 
reduce the degree to which they lag behind Google. ${ }^{110}$ User behaviour also suggests that individual search engines do not act as gatekeepers of the Internet, since well-known websites (in Germany) with a large share of Internet traffic do not rely on search engines as they are navigated to directly. ${ }^{111}$

Other commentators argue that even if one assumed that Google simply refused to list the competitor's business in the organic search results, considering a potential vertical foreclosure theory, the only impact that Google's conduct would have on the unaffiliated competitor would be to deprive it of a particular source of free promotion. ${ }^{112}$ There is no need to consider the antitrust implications of Google's organic results being the only mechanism by which competitors in the vertical-search relevant market could promote their businesses, because that is counterfactual. ${ }^{113}$ Thus, while the assumed refusal to deal by Google may hurt the excluded competitor, it is difficult to conceive how the assumed refusal to deal would harm the unaffiliated competitor's ability to compete or harm competition in the assumed vertical search-relevant market. ${ }^{114}$

All in all, neither the provision of free traffic by Google nor certain display conditions relating to the general result pages can be deemed to be indispensable for operating a website, such as a comparison shopping site, given the alternatives available for both potential inputs.

b. Refusal to Provide Access to Intangible Property Including Property Protected by IP Rights

In addition to cases concerning refusal to provide (access to) physical property, there are also cases that have concerned a dominant undertaking's refusal to provide access to intangible property, including property that is protected by IP rights. Given that the input in question in Google Search does not concern physical property, this line of case law is more relevant to the application of a refusal to deal theory in Google Search.

An early case concerning access to intangible property is Télémarketing, where the CoJ found that the ruling in Commercial Solvents also applies to an undertaking holding a dominant position on the market in a service which is indispensable for the activities of another undertaking on another market. ${ }^{115}$ This case concerned the TV broadcaster holding a legal monopoly in Luxembourg for running the RTL TV station refusing to sell CBEM (a telemarketing company) television time on RTL for telephone marketing operations using a telephone number other than that of RTL's exclusive agent for TV advertising. ${ }^{116}$ The Court held that if telemarketing activities constitute

\footnotetext{
110. Id. at 59 .

111. Id.

112. Ratliff \& Rubinfeld, supra note 18 , at 540.

113. Id.

114. Id. at 541 .

115. Case 311/84, Centre belge d'études de marché-Télémarketing (CBEM) v. SA Compagnie luxembourgeoise de télédiffusion (CLT) and Information publicité Benelux (IPB), 1984 E.C.R. 3261, II 26. 116. Id. \I 2.
} 
a separate market from that of television advertising and the telemarketing activities mainly consist in making available to advertisers the telephone lines and telephonists of the telemarketing undertaking, to subject the sale of broadcasting time to the condition that the telephone lines of an advertising agent belonging to the same group as the TV station should be used amounts in practice to a refusal to supply the services of that station to any other telemarketing undertaking. ${ }^{117}$ If that refusal is not justified by technical or commercial requirements relating to the nature of the television, but it is intended to reserve to the agent any telemarketing operation broadcast by the station, with the possibility of eliminating all competition from another undertaking, such conduct amounts to an abuse under Article 102TFEU, provided that the other conditions of that provision are satisfied. ${ }^{118}$ Thus, the Court held that it is an abuse where, without any objective necessity, an undertaking dominant on a particular market reserves to itself or to an affiliated undertaking an ancillary activity which might be carried out by another undertaking as part of its activities in a neighbouring but separate market, with the possibility of eliminating all competition from such undertaking. ${ }^{119}$

Applying the findings of Télémarketing to Google Search reveals that the facts are too different to make the conduct in Google Search abusive under Télémarketing. Other than it being questionable whether comparison shopping constitutes a separate market in itself, the dispute in Télémarketing ultimately involved contractual tying (in the manner of a constructive refusal to supply) since RTL tied the supply of advertising time on TV to the condition that the TV company's own telemarketing agency was used. ${ }^{120}$ In Google Search there is no such (contractual) tying (i.e., there is no supplementary obligation imposed on comparison shopping sites for their websites to be displayed in Google's general result pages). There is also no legal (or factual) monopoly, unlike Télémarketing. More importantly, the ratio of the case is not applicable to the facts in Google Search since that ratio involves an undertaking holding a monopoly on the market in a service which is indispensable for the activities of another undertaking on another market reserving to itself an ancillary activity with the possibility of eliminating all competition from another undertaking which could carry out that activity without objective necessity and without technical or commercial justifications. ${ }^{121}$ As noted above, Google's search engine cannot be deemed indispensable to provide comparison shopping services, since a website providing such services can technically and commercially be started and operated with no input from Google or its search engine. ${ }^{122}$ Similarly, Google could not reserve to itself the ancillary activity of comparison shopping since technically-unlike in Télémarketing - it cannot stop any users from visiting the comparison shopping sites just like it cannot

117. Id. $\llbracket 26$

118. Id.

119. Id. $\mathbb{I} 27$

120. Id. $\llbracket 26$.

121. Id. IIII 26-27.

122. Rand Fishkin, How Search Engines Work, MOZ, https://moz.com/beginners-guide-to-seo/howsearch-engines-operate (last visited Oct. 14, 2017). 
prevent any other website from entering the alleged comparison shopping market. The fact that (free) traffic from Google Search might make a given site more profitable cannot in itself imply that Google Search is indispensable to operate that site, with the implication that if Google does not provide such traffic, it would mean that it reserves to itself that separate activity. As noted above, in European Night Services, the GC held, in the context of essential facilities, that a facility cannot be considered necessary or essential unless there is no real or potential substitute. ${ }^{123}$ In other words, mere advantage to the competitor is not enough. ${ }^{124}$ Furthermore, objective necessity as well as technical or commercial justifications have been provided by the $\mathrm{CoJ}$ as grounds which would render the conduct legitimate. ${ }^{125}$ In Google Search, the technical and commercial nature of the services of a search engine involves the ranking of search results on the basis of relevance as determined by the search engine's algorithm. This suggests that if certain websites do not appear in certain rankings which are occupied instead by other websites in the general result pages because they are more relevant to a query, this in itself can constitute a justification, even a necessity since it is necessary to rank results and there can only be one link to one website displayed in a given ranking in the results.

The case law on refusal to supply also involves cases dealing with refusal to supply access to intangible property/services that are protected by IP rights. A number of commentators have suggested that Google Search is not an IPrelated case. ${ }^{126}$ For some authors, this means that these cases are irrelevant, ${ }^{127}$ whereas for others, all cases involving refusal to deal should be subject to the higher intervention threshold established in cases concerning IP-related cases since the rationale that justifies the threshold to be high is similarly applicable to all types of property. ${ }^{128}$ This Author posits that Google Search is not necessarily a case outside the realm of the case law concerning refusal to deal in IP-protected property/services, for the following reasons.

Despite the fact that neither the complainants nor the Commission are seeking the disclosure of Google's algorithm in Google Search, the case can still be deemed to fall within the scope of the refusal to deal case law concerning IP rights. ${ }^{129}$ This is because although in Google Search the remedy sought may not be the compulsory disclosure or licensing of a product/service protected by IP rights, the alleged abuse and the remedy sought concern the conditions of access to a product/service aspects of which are protected by IP rights. ${ }^{130}$ This is

123. Joined Cases T-374-375, 384 \& 388/94, European Night Services Ltd (ENS) v. Comm'n, 1998 E.C.R. II-3141, II 208; Case T-504/93, Tiercé Ladbroke v. Comm'n, 1997 E.C.R. II-923, II 131, http://eurlex.europa.eu/legal-content/EN/TXT/?uri=CELEX:61993TJ0504.

124. Alison Jones \& BRENDA SuFrin, EU COMPETITION LAW: TEXT, CASES \& MATERIALS 518 (5th ed. 2014).

125. See European Night Services, 1998 E.C.R. II-3141, II 132 (discussing justifications).

126. See, e.g., Nazzini, supra note 22, at 310; Petit, supra note 22, at 14.

127. Petit, supra note 22, at 14.

128. Nazzini, supra note 22, at 309.

129. See, e.g., id. at 310; Petit, supra note 22, at 14 (demonstrating how the case can fall within the scope of refusal to deal).

130. Nazzini, supra note 22, at 310; Petit, supra note 22, at 14. 
because the claim is that Google diverts traffic in its general search results from comparison shopping sites to its own comparison shopping service. ${ }^{131}$ This diversion allegedly occurs through the use of Google's algorithm since the results displayed are generated by the algorithm. ${ }^{132}$ Certain aspects of Google's algorithm are patent-protected and some have suggested that the entire algorithm itself may be patent-protected as a process. ${ }^{133}$ Moreover, the algorithm may be copyright-protected as a computer program. ${ }^{134}$ Furthermore, the remedy sought concerns conditions of rivals' access to Google's general search result pages regarding display, ranking, etc. ${ }^{135}$ These pages are again the outcome of the application by Google of its algorithm to a given query. ${ }^{136}$ A comparison with Microsoft further reveals the relevance of the case law concerning IP-related refusals to deal for Google Search.

In Microsoft, the access sought never concerned the compulsory disclosure of the source code for the Windows Operating System (OS), but the case was still dealt with as a case concerning IP rights. ${ }^{137}$ By analogy, the algorithm of Google Search can be deemed to be the equivalent of the code for Windows OS. In Microsoft, the abusive refusal to deal concerned the refusal to provide interoperability information by Microsoft (which held a virtual monopoly in the market for client PC operating systems) to its rivals on the separate market for work group operating systems. ${ }^{138}$ Consequently, if in Microsoft the interface information that enabled interoperability between Microsoft's operating system and competitors' operating systems was deemed to be protected by copyright, it is at least arguable that the results of the application of Google's algorithm to a query-which have been held to be an "opinion" protected by the First Amendment by some U.S. courts - may similarly be protected by IP rights (e.g., copyright). ${ }^{139}$ If there is any possibility that IP rights are involved in Google

131. Jim Edwards, Europe Accuses Google of Antitrust Violations and Launches a Massive Investigation into Android, Bus. InsIDER (Apr. 15, 2015, 6:07 AM), http://www.businessinsider.com/europe-accuses-googleof-antitrust-violations-2015-4.

132. Id.

133. See Method for Node Ranking in a Linked Database, U.S. Patent No. 6,285,999 (filed Jan. 9, 1988) (issued Sept. 4, 2001) (describing the PageRank patent); see also Bill Slawski, The Google Hummingbird Patent?, SEO BY THE SEA (Sept. 27, 2013), http://www.seobythesea.com/2013/09/google-hummingbird-patent/ (suggesting Google's entire algorithm may be patent-protected as a process).

134. Directive 2009/24/EC, of the European Parliament and of the Council of 23 April 2009 on the Legal Protection of Computer Programs, 2009 O.J. (L 111) 16.

135. Slawski, supra note 134.

136. Id.

137. Case T-201/04, Microsoft v. Comm'n, 2007 E.C.R. II-3141, IIII 40, 203, 241, 286.

138. Id. III $24-25,36$.

139. See Search King v. Google Tech., No. CIV-02-1457-M, 2003 WL 21464568 at *4 (W.D. Okla. May 27, 2003) (holding that PageRank, a component of Google's algorithm, represents an "opinion" of the significance of a particular website as it corresponds to a search query and also holding that rankings, as statements of relative significance, are inherently subjective in nature); see, e.g., KinderStart.com, LLC v. Google, Inc., 2007 WL 831806 at *24 (N.D. Cal. Mar. 16, 2007); Copyright, Designs and Patent Act 1988, c. $48 \S \S 9(3), 12(7), 178$ (stating the Designs and Patents Act 1988 expressly protects works created by a computer where there is no human author and work created using a computer); Directive 96/9/EC of the European Parliament and Council of 11 March 1996 on the Legal Protection of Databases, 1996 O.J. (L 77) 20 (explaining that databases are protected by copyright and by a sui generis database right in the EU under the Database Directive since a database is defined as a collection of independent works, data or other materials arranged in a 
Search, then similar to Microsoft, the Commission and EU Courts would have to treat the case as one involving IP rights since this would be the most favourable interpretation to Google. In Microsoft it was indeed questionable whether the interface information was copyright protected, but it was assumed that it was and the Commission and the GC both took their decisions accordingly, because this interpretation was more favourable to Microsoft than the alternative. ${ }^{140}$ Thus, it is not necessary for the remedy sought to be the disclosure of the algorithm for Google Search to be treated as a case concerning IP rights. ${ }^{141}$ Therefore, one can argue that the applicable refusal to deal case law in Google Search is that concerning refusal to provide access to IP-protected products/services, with its higher threshold for intervention. This Article will now consider this line of case law.

Across various cases, the EU Courts have established the conditions under which refusals to supply IP-protected products/services may be abusive. This jurisprudence first suggests that only in "exceptional circumstances" could the exercise of an exclusive right (e.g., the exercise of using Google's algorithm) involve abusive conduct. ${ }^{142}$ In IMS Health, the CoJ clarified that, for the refusal by an undertaking which owns an IP right to give access to a product or a service indispensable for carrying on a particular business to be treated as abusive, three cumulative conditions must be satisfied: (i) that refusal prevents the emergence of a new product for which there is a potential consumer demand; (ii) the refusal is unjustified, and; (iii) the refusal excludes any competition on a secondary market. ${ }^{143}$ Regarding condition (i), the CoJ held that where the product/service to which access is sought is indispensable to operate on a separate market, the refusal to provide that access may only be abusive if the undertaking requesting access does not intend to limit itself essentially to duplicating the products/services already offered on the secondary market by the owner of the IP right, but intends to produce new products/services not offered by the owner of the right and for which there is a potential consumer demand. ${ }^{144}$ Regarding condition (iii), in Microsoft, the GC held that this meant not the elimination of all competition, but the elimination of all effective competition. ${ }^{145}$ This has been

\footnotetext{
systematic or methodical way and individually accessible by electronic or other means); see TANYA APLIN \& JenNifer Davis, Intellectual Property Law: Text, CASes, AND Materials 242 (2d ed. 2013) (arguing that Google's index constitutes a database and a given search result is a subset of that database; whilst copyright protects the selection or arrangement of the contents in a database, the sui generis right for databases protects the contents of the database as a whole); see generally James Grimmelmann, The Structure of Search Engine Law, 93 IowA L. REv. 50, 59 (2007) (explaining how search results themselves may be protected by copyright since the results of a search are generated by the algorithm through a mechanical process, because subjectivity enters the algorithm when it is programmed, and what emerges at the end are the subjective judgments made by Google programmers about a webpage and quality).

140. Microsoft, 2007 E.C.R. II-3141 IIIT 277, 280-85, 287.

141. Id.

142. Case C-418/01, IMS Health \& Co. OHG v NDC Health GmbH \& Co. KG, 2004 E.C.R. I-5039, If 35; Cases C-241-242/91 P, RTE \& ITP v. Comm'n (Magill), 1995 E.C.R. I-743, If 50; Case 238/87, AB Volvo v. Erik Veng, 1988 E.C.R. 6211, If 9.

143. IMS Health, 2004 E.C.R. I-5039, II 38.

144. Id. II 49

145. Microsoft, 2007 E.C.R. II-3141 II 563.
} 
suggested to be a response to earlier developments of the case law which had inhibited the applicability of the essential facilities doctrine since the requirement of eliminating all competition is a more demanding one than the requirement of eliminating effective competition. ${ }^{146}$ Although the substance of this interpretation may be correct on the basis of the wording of the judgment in Microsoft, it is noteworthy that Microsoft is a judgment of the GC whilst the cases stipulating the requirement to be that of eliminating all competition involve judgments of the CoJ. ${ }^{147}$ Thus, had the Microsoft judgment been appealed, the CoJ may have had an issue with the GC's interpretation; without a recent judgment of the CoJ after Microsoft the law on this requirement ultimately remains debatable. It is also noteworthy that the GC in Microsoft does not use "essential facilities" terminology. ${ }^{148}$ Moreover, it is argued that in Microsoft, the GC appeared to suggest that the criteria in Magill and IMS Health were satisfied anyway since the non-disclosure of interoperability information was likely to prevent new and innovative products from emerging and to eliminate effective competition. ${ }^{149}$ In Microsoft, the GC also provided an interpretation of the requirement that the refusal to deal prevents the emergence of a new product as stipulated in Magill and IMS Health that goes beyond the stipulations of the CoJ in these cases. ${ }^{150}$ The GC in Microsoft held that this could not be the only parameter which determines whether the refusal is capable of prejudicing the interests of consumers since that can also be the case where the refusal limits technical development. ${ }^{151}$ Again, this finding has not been challenged before the CoJ and in any case does acknowledge that the relevant criterion is whether or not there is damage to the interests of consumers. ${ }^{152}$

One commentator argued that to prove that Google is abusing its position due to a refusal to supply, it would need to prove that: (i) achieving a certain ranking and/or being displayed in a certain way in Google Search is indispensable to compete effectively; (ii) Google lowers the ranking of competitors in searches or manipulates the way in which they are displayed in search results to their detriment, in a way that cannot be justified as being responsive to users" queries; (iii) as a result of the conduct, all effective competition in specialist (vertical) searches is likely to be eliminated; (iv) users are consequently harmed in that the quality of search results and users" experience are materially worse than it would otherwise be the case. ${ }^{153}$ To this list of conditions, this Author would add that if the conduct in Google Search is to be treated as a refusal to supply, then the Commission would also have to prove that this refusal prevents the emergence of a new product/service for which there is potential consumer demand and the rivals seeking access do not intend to limit themselves essentially to duplicating the products/services

\footnotetext{
146. Petit, supra note 22, at 14.

147. Magill, supra note 142; IMS Health, 2004 E.C.R. I-5039.

148. Magill, supra note 142; IMS Health, 2004 E.C.R. I-5039.

149. O'DonOGHUE \& PADILLA, supra note 55, at 535.

150. Microsoft, 2007 E.C.R. II-3141; Cf. Magill, supra note 142.

151. Microsoft, 2007 E.C.R. II-3141, II 647.

152. Id. भाषा 646-47.

153. Nazzini, supra note 22, at 310.
} 
already offered on the secondary market by the dominant undertaking. In Google Search this would require proving that the comparison shopping sites seeking certain display and access conditions concerning Google's search result pages are intending to provide new services (e.g., new websites, websites with new features, etc.) for which there is potential consumer demand and that are not already provided by the dominant undertaking. It is highly debatable whether this can be satisfied on the facts in Google Search, particularly in the presence of merchant platforms such as Amazon that already offer arguably more convenient and attractive alternatives to consumers for product search. In this context, it is also noteworthy that the Commission in its Guidance on Enforcement Priorities has expanded the use of the criterion whether the refusal prevents the emergence of a new product or service for which there is potential consumer demand to all cases of refusal to supply as part of the assessment of whether the refusal causes consumer harm. ${ }^{154}$ Therefore, even if it were held that Google Search does not involve any IP rights, this condition still remains an important part of the assessment of abuse, at least according to the Commission's own expressions of its approach to Article 102TFEU. As the facts in Google Search are unlikely to support the finding of an indispensable input which the rivals are seeking to introduce a new product/service for which there is potential consumer demand, the abuse of refusal to supply cannot be established under the existing case law.

\section{c. Estoppel Abuse}

Some commentators have discussed the possibility of there being an "estoppel abuse" in the context of the dealings of a dominant undertaking with others. ${ }^{155}$ The suggestion is that in cases where the dominant undertaking does not have a duty to deal, it is not sensible to argue that there should nevertheless be certain terms of supply or that the terms of supply can be abusive. ${ }^{156}$ However, one could still suggest, so the argument goes, that once the dominant undertaking has unilaterally chosen to supply, it must supply on terms that would make it at least possible to compete. This is based on the idea of estoppel since the premise is that the customer will have taken certain commercial decisions relying on the existing offer of supply and such reliance should be protected. ${ }^{157}$ This approach has been interpreted as a possible reading of TeliaSonera which, according to some, has vacated the requirements of the case law on refusal to deal (including indispensability or the essential nature of the facility to which

154. Commission Guidance, supra note 31, II 87

155. Kevin Coates, The Estoppel Abuse, 21st Century Competition Blog (Oct. 28, 2013), http://www.twentyfirstcenturycompetition.com/2013/10/the-estoppel-abuse/; Petit, supra note 22, at 8.

156. Coates, supra note 155.

157. See Roger Halson, Contract Law 176 (2d ed. 2013) (explaining that the concept of estoppel related to a person being prevented or estopped from going back on a promise, representation, or assumption); see also Coates, supra note 155 (explaining the equitable doctrine of estoppel covers different types of estoppel such as estoppel by convention, proprietary estoppel, and promissory estoppel). 
access is sought). ${ }^{158}$ However, with respect, it is difficult to understand how TeliaSonera might be relevant for the interpretation of indispensability in the context of refusal to deal, if this is what is being suggested by commentators. Whatever the merits of the judgment in TeliaSonera, the Court's findings relate to a margin-squeeze abuse and not a refusal to supply. ${ }^{159}$ The only relevance of refusal to deal for TeliaSonera is the Court's finding that for margin squeeze to be abusive, it is not necessary that the dominant undertaking has a duty to supply the product/service (the price of which leads to squeezing the margins of the downstream competitors) in the first place. ${ }^{160}$ In other words, margin squeeze "may, in itself, constitute an independent form of abuse distinct from that of refusal to supply."161 It follows that if a duty to supply the product/service in question is not necessary for the relevant prices to constitute abusive margin squeeze, argumentum a fortiori it is not relevant whether the input sought is indispensable or essential since this is only a relevant concern if the abuse is that of refusal to deal. ${ }^{162}$ This does not imply that indispensability of the input is no longer necessary for cases concerning refusal to supply since a judgment that explicitly states that the case is not about refusal to deal cannot be interpreted to have changed the conditions established in the case law concerning refusal to deal. ${ }^{163}$ The judgment in TeliaSonera that margin squeeze is an abuse independent of refusal to supply is a reflection of the interpretation that margin squeeze is an abuse that falls under Article 102(a)TFEU, which explicitly prohibits the imposition of unfair purchase or selling prices or other unfair trading conditions. ${ }^{164}$ This Author is not aware of any interpretation of Article 102(a)TFEU that suggested that before a price could be deemed unfair for being, for example, excessive, or before a contract clause could be "unfair," it has to be established that the dominant undertaking had a duty to supply the product/service or a duty to enter into a contract in the first place. Article 102(a)TFEU occupies itself with the terms and conditions of the dealings of a dominant undertaking with its customers and suppliers as an exploitative abuse

158. See Petit, supra note 22, at 7-8 (arguing that the Court's refutation of the essential facilities threshold in Case C-52/09, Konkurrensverket v. TeliaSonera Sverige AB, 2011 E.C.R. I-527 is not strictly confined to margin squeeze cases); Case C-52/09, Konkurrensverket v. TeliaSonera Sverige AB, 2011 E.C.R. I-527; see also Lianos \& Motchenkova, supra note 22, at 435-36 (suggesting that after TeliaSonera, proving the "indispensability" of access to the input controlled by the dominant company might not be such a difficult condition to fulfil and it might not even be required for the application of Article 102TFEU to discriminatory practices of a dominant undertaking. Lianos and Motchenkova argue that the indispensability condition does not work outside a clear refusal to deal framework and it seems unclear how Google's practices might be qualified as a refusal to deal since Google does not refuse to provide access to its search engine, but arguably only avoids listing vertical competitors' at the first positions in the ranking); see Nazzini, supra note 22, at 309 (suggesting that TeliaSonera is relevant - and wrong - regarding the condition of indispensability).

159. TeliaSonera, 2011 E.C.R. I-527.

160. Id.

161. Id. If 56; but see Pac. Bell Tel. Co. v. Linkline Comm. Inc., 555 U.S. 438 (2009) (finding that for margin squeeze to be abusive, there first must be an antitrust duty to deal with the plaintiff at wholesale, and second, the price at retail level must be predatory; see also Verizon Comm. Inc. v. Law Offices of Curtis V. Trinko, 549 U.S. 398 (2004) (establishing that where there is no antitrust duty to deal with competitors at wholesale, there is no duty to deal under terms and conditions that the rivals find commercially advantageous).

162. TeliaSonera, 2011 E.C.R. I-527, II 56.

163. Id.

164. See, e.g., id. II 25; Petit, supra note 22, at 8. 
irrespective of whether there is a duty to enter into a contract on the part of the dominant undertaking. ${ }^{165}$ TeliaSonera simply explains that this is the case also for margin squeeze without any implications for the requirements of refusal to deal as a separate abuse from margin squeeze. ${ }^{166}$

Regarding Google Search, adopting such an approach of "estoppel” abuse would imply that Google could never innovate and improve its service to users, namely the provision of relevant results for a search query. If a given website appears on Google's general result pages at a given ranking in response to a given query and this creates reliance on the part of that website (e.g., reliance that there will be a certain amount of traffic to that website, etc.), then Google would be bound to display the same set of results in response to the same query indefinitely. This clearly goes against the business model of a search engine which regularly updates its algorithm to provide better results to users, and would be a huge impediment to innovation that would ultimately constitute a detriment to consumers. Establishing a duty on the part of Google to supply a service to certain websites could open up the possibility of creating such an estoppel abuse, which would bring to a halt any innovation that could increase choice and any improvement in existing technologies for the sake of protecting the interests of certain undertakings. It should, therefore, be avoided.

\section{d. Objective Justification}

An objective justification provided by a dominant undertaking for an allegedly abusive conduct can prevent the finding of an infringement under Article 102TFEU. ${ }^{167}$ Such objective justification can take the form of proving that the dominant undertaking's conduct is either objectively necessary or is justified due to the efficiencies that it produces which counterbalances or outweighs any anticompetitive effects and also benefit consumers. ${ }^{168}$ Although commentators have argued that any such justifications should be taken into account by the Commission before a finding of abuse is made (rather than constitute a "defence"), currently, the burden to prove an objective justification by providing all the necessary evidence is on the dominant undertaking. ${ }^{169}$

165. Thus, margin squeeze should be both exploitative and exclusionary for it to be considered abusive. See AKMAN, supra note 27, at 307-16 (arguing that for exploitation to be prohibited under Article 102TFEU it should also be the case that the exploitation leads to the exclusion of an as efficient undertaking since otherwise, it is unclear what the harm to competition is from pure exploitation of customers).

166. TeliaSonera, 2011 E.C.R. I-527, II 56.

167. See, e.g., Télémarketing, supra note 115, If 27; Case 27/76, United Brands Company \& United Brands Continentaal BV v. Comm'n, 1978 E.C.R. 207, I 184 (describing objective justification); Case C-95/04P, British Airways v. Comm'n, 2007 E.C.R. I-2331, IIII 69, 86.

168. Case C-209/10, Post Danmark A/S v. Konkurrenceradet, 2012 EUR-Lex CELEX LEXIS 172, q 41(Mar. 27, 2012); British Airways, 1978 E.C.R. 207, II 86; TeliaSonera, 2011 E.C.R. I-527, II 76; Commission Guidance, supra note 31, II 28.

169. See, e.g., Post Danmark I, 2012 EUR-Lex CELEX LEXIS 172, II 42 (Mar. 27, 2012); see Guidance, supra note 31, If 26. In the context of enforcement at EU level, the Commission would make the ultimate assessment of whether the conduct is not objectively necessary or whether the anticompetitive effects outweigh any efficiencies. See, e.g., Pinar Akman, Searching for the Long-Lost Soul of Article 82EC, 29 OXFORD J. LEGAL STUD. 267, 288-89 (2009) (arguing that any efficiencies and other justifications should be taken into consideration before a finding of abuse is made); Denis Waelbroeck, The Assessment of Efficiencies under 
Consequently,

[I]t is for the dominant undertaking to show that the efficiency gains likely to result from the conduct under consideration counteract any likely negative effects on competition and consumer welfare in the affected markets, that those gains have been, or are likely to be, brought about as a result of that conduct, that such conduct is necessary for the achievement of those gains in efficiency and that it does not eliminate effective competition, by removing all or most existing sources of actual or potential competition. ${ }^{170}$

As with all categories of abuse, even if there was a refusal to deal with competitors in Google Search, a defence of objective justification would still be available. In fact, in IMS Health the CoJ held that the finding of refusal not being justified is one of the cumulative conditions that has to be satisfied before the refusal can be found abusive in the first place. ${ }^{171}$ In Google Search, it is in the nature of the search engine business model to list results and to rank them applying a particular algorithm. ${ }^{172}$ Thus, one can argue that if certain websites are not displayed or ranked in certain ways as a result of the application of Google's algorithm, then provided that, for example, there is no arbitrary noninclusion on the web index or deletion of a website from the index where inclusion was technically possible and customary, ${ }^{173}$ the business model itself justifies the fact that not every site is displayed equally in the results, since this is neither technically possible nor desirable. ${ }^{174}$ Consequently, the conduct can satisfy both the requirement of being objectively necessary and also generating efficiencies due to the nature of the business model of a search engine. In fact, the FTC has found that Google's "prominent display of its own vertical search results" had the primary goal of quickly answering and better satisfying "its

Article 102TFEU and the Commission's Guidance Paper, COMPETITION L. \& THE ENFORCEMENT OF ARTICLE 102 115, 121-22 (Federico Etro \& Ioannis Kokkoris eds, 2010); AKMAN, supra note 27, at 282-83, 316; O'Donoghue \& PADIlla, supra note 55, at 283. Part of the problem with accepting efficiencies to be an "objective justification" and therefore a defence is that, as expressed by Advocate General Jacobs in Syfait, the two-stage analysis suggested by the distinction between "abuse" and "objective justification" is somewhat artificial: the more accurate view is that "certain types of conduct on the part of a dominant undertaking do not fall within the category of abuse at all"); see A.G. Jacobs Opinion in Case 53/03, Synetairismos Farmakopoion Aitolias \& Akarnanias (Syfait) and Others v. GlaxoSmithKline AEVE, 2005 E.C.R. I-4609, II 72.

170. Post Danmark I, 2012 EUR-Lex CELEX LEXIS 172, II 42 (Mar. 27, 2012); see Pinar Akman, The European Commission's Guidance on Article 102TFEU: From Inferno to Paradiso?, 73 MODERN L. REv. 605, 621 (2010); see also Commission Guidance, supra note 31, I[ 30. This Author has previously argued that this position of the EU Courts and the Commission essentially involves a reversal of the burden of proving abuse in cases where the Commission has not proven harm to consumers/consumer welfare as it requires the dominant undertaking to rebut a position that the Commission has not established (i.e., the existence of harm to consumers/consumer welfare, which is not necessary for a finding of abuse by the Commission) in the process of trying to establish that efficiencies are a valid justification because they benefit consumers.

171. Case C-418/01, IMS Health \& Co. OHG v NDC Health GmbH \& Co. KG, 2004 E.C.R. I-5039, If 38.

172. How Search Algorithms Work, GoOGLE SEARCH, https://www.google.com/search/howsearchworks/ algorithms/ (last visited Oct. 14, 2017).

173. Monopolies Comm'n, supra note 107, at 61.

174. How Search Algorithms Work, supra note 172. 
users" search queries by providing directly relevant information. ${ }^{175}$ According to the FTC, the evidence that it examined is largely consistent with the conclusion that Google likely benefitted consumers by prominently displaying its specialist (vertical) content. ${ }^{176}$ This is supported by evidence on FTC's file that Google would typically test, monitor, and carefully consider the effect of introducing its specialist (vertical) content on the quality of its general search results and demote its own content to a less prominent location when a higher ranking adversely affected the user experience. ${ }^{177}$ The German Monopolies Commission appears to share the same view as the FTC. ${ }^{178}$ For it, the inclusion of specialised services in the results of a horizontal search constitutes a refining of the search platform and is therefore a product innovation, not least because many search queries cannot be sensibly answered until other services are incorporated in this way. ${ }^{179}$ The search platform's additional functions not only make it more attractive to users, it also offers users added value if relevant content is shown directly, allowing the user to avoid inconvenient further searches on other websites. ${ }^{180}$

Finally, the conduct does not eliminate effective competition either. Merchant platform sites like Amazon, retailer sites, and the sites of retailers which carry the product in a given product search as well as comparison shopping sites appear in the organic results on Google Search, in addition to relevant sponsored links from any sites which have purchased advertisements to display in the space on the result page in response to a search for that item. All of these sites are also accessible by navigating to their websites without the need to conduct a search for them on Google, which is an additional factor that supports the finding that effective competition is not eliminated.

\section{B. Discrimination}

Discrimination is the second type of abuse that might underlie the Commission's theory of harm in Google Search. The Commission's allegations of "self-preferencing" or "self-favouring" suggest an argument that Google abuses its alleged dominant position by engaging in discriminatory conduct. ${ }^{181}$ Implicit in the Commission's statements is an argument that Google treats its own comparison shopping service more favourably and thus differently in comparison to how it treats rival comparison shopping services regarding display of results and application of penalties, and this can be remedied by the

175. Statement of the Federal Trade Commission Regarding Google's Search Practices In the Matter of Google Inc, FTC File Number 111-0163, 2 (Jan. 3, 2013), https://www.ftc.gov/system/files/documents/ public_statements/295971/130103googlesearchstmtofcomm.pdf [hereinafter FTC Google Statement].

176. Id. at 2 .

177. Id.

178. German Monopolies Comm'n, supra note 107, at 62.

179. Id.

180. Id.

181. Fact Sheet, supra note 7. 
equal treatment of Google Shopping and rival comparison shopping sites by Google. ${ }^{182}$

According to Article 102(c)TFEU, abuse may consist in "applying dissimilar conditions to equivalent transactions with other trading parties, thereby placing them at a competitive disadvantage." 183 Discrimination requires - by definition - there to be (at least) two distinct transactions that are treated dissimilarly (similarly) albeit being equivalent (non-equivalent). ${ }^{184}$ Although the list of practices in Article 102TFEU is not exhaustive and the CoJ has in the past, in the context of tying, applied Article 102(d)TFEU to a situation which was clearly excluded by the wording of that provision on the basis of the list not being exhaustive, where the practice in question is one of the practices listed in Article 102TFEU itself, the normal practice for the EU Courts and the Commission would be to base their interpretation of that particular prohibition on the provision itself. ${ }^{185}$ If the alleged abuse is discrimination, then not complying with the conditions found in Article 102(c)TFEU that stipulate when discrimination can be abusive, would potentially breach the principle of legal certainty, a fundamental principle of EU law. ${ }^{186}$ For this reason, one must examine the conditions found in Article 102(c)TFEU to assess whether the

182. Id.

183. Nazzini, supra note 22, at 10.

184. For discrimination covering the treatment of non-equivalent transactions similarly, see Case 13/63, Italy v. Comm'n, 1963 E.C.R. 165, I[ 6.

185. See Pinar Akman, Article 82 Reformed? The EC Discussion Paper on Exclusionary Abuses, J. Bus. L. 816 (Dec. 2006) (arguing that where the practice in question is explicitly prohibited as an abuse in Article 102TFEU, the Commission and the EU Courts should base their interpretation of that particular abuse on the wording of the prohibition itself). See C-333/94 P, Tetra Pak International SA v. Comm'n, 1996 E.C.R. I-5951, II 37 (stating that the relevant case in question where the CoJ failed to do so is Tetra Pak II where the Court found that Article 102(d)TFEU can be infringed by an act of tying even if there are natural or commercial links between the tying and the tied product despite the clear wording of Article 102(d)TFEU to the contrary).

186. See, e.g., Case C-94/05, Emsland-Staerke GmbH v. Landwirtschaftskammer Hannover, 2006 E.C.R. I-2619, II 43 (and the cases cited therein on legal certainty being a fundamental principle of EU law); Case C201/08, Plantanol GmbH \& Co KG v. Hauptzollamt Darmstadt, 2009 E.C.R. I-08343, II 46; see Case 348/85, Kingdom of Denmark v. Comm'n, 1987 E.C.R. 5225, II 19 (explaining that legal certainty is a fundamental principle of EU law). Moreover, the list of practices in Article 102TFEU would lose all meaning as examples of abusive practices if they are not even applicable as stipulated in cases where the conduct in question is listed in the provision in terms of the requirements for it to be abusive. Such an interpretation would render superfluous the explicit statutory language (i.e., render it "mere surplusage") and is difficult to defend even under a teleological approach since concerning discrimination, like the other examples in Article 102(2)TFEU, the drafters of the Treaty have expressly indicated the requirements and scope of the operation of that prohibition, meaning that there is no gap to which the Court/Commission could extend the application of Article 102TFEU using a teleological approach. The EU Courts usually favour the teleological method of interpreting the Treaty rules. David J. Gerber, The Transformation of European Community Competition Law?, 35 HARV. INT'L L. J. 97, 109, 116-17 (1994). The teleological approach enables the court to extend the statutory provisions to situations that were not contemplated at the time of enactment, thereby ensuring the code's application to changing social and economic conditions. Gerard Carney, Comparative Approaches to Statutory Interpretation in Civil Law and Common Law Jurisdictions, 36 StATUTE L. Rev. 48, 52 (2015). The rule against "mere surplusage" is a canon of interpretation in common law meaning that a statute should not be interpreted in a way that will render a word superfluous. See, e.g., Astoria Fed Sav. \& Loan Ass'n v. Solimino, 501 U.S. 104,112 (1991) (explaining if the alleged abuse is that of discrimination, then the conditions found in Article 102(c)TFEU should be satisfied before a finding of an infringement can be made and the Commission should not be able to use the non-exhaustive nature of the list of practices to justify finding abusive a practice of discrimination that does not fit the requirements of Article 102(c)TFEU). 
conduct under investigation in Google Search satisfies them. ${ }^{187}$ Thus, the rest of this Subsection will examine the constituent elements of Article 102(c)TFEU, namely, the existence of transactions with other trading parties (i); the requirement of competitive disadvantage (ii); applying dissimilar conditions to equivalent transactions (iii); the relevance of a downstream/upstream market and vertical integration for a finding of abusive discrimination (iv); and, objective justification and lack of an exclusionary effect as potential factors that would prevent discriminatory conduct from being abusive $(v) .{ }^{188}$

\section{Transactions with Other Trading Parties}

The first question concerning the applicability of Article 102(c)TFEU in Google Search is whether there are such "transactions with other trading parties" that would place the conduct in question within the scope of Article 102(c)TFEU. ${ }^{189}$ There are two sub-issues within this question. The first is whether the use of the term "other trading parties" excludes a finding of abusive discrimination where the discrimination occurs between the dominant undertaking itself and a trading party. ${ }^{190}$ The second is the significance of the concept of "trading parties." 191 Regarding the first sub-issue, given that Article 102(c)TFEU explicitly requires discrimination to put "other trading parties" at a "competitive disadvantage" as a result of applying dissimilar conditions to equivalent transactions "with other trading parties," it appears difficult to argue that the prohibition can be applied to discrimination between one's self and others. Indeed, in the context of Google Search it has been remarked that for Google's conduct to be abusive, it is necessary to identify a legal rule which imposes on a dominant undertaking a duty to treat its rivals on nondiscriminatory terms. ${ }^{192}$ Such a rule arguably cannot be derived from the general prohibition of discrimination under Article 102(c)TFEU because that provision prohibits discrimination vis-à-vis "other trading parties" meaning that the discrimination must occur between parties other than the dominant undertaking itself. ${ }^{193}$ The second, perhaps more critical, sub-issue is the necessity of there being "transactions" with "trading parties" subjected to discrimination before such conduct can be abusive. In the context of Google Search, this is significant because Google is a two-sided business, but it is not a three-sided business. ${ }^{194}$ The argument put forward is that the websites that would like to appear in Google's search results are not trading partners of Google because Google seeks

187. Astoria Fed Sav. \& Loan Ass'n v. Solimino, 501 U.S. 104, 112 (1991).

188. Id.

189. Id.

190. Id.

191. Id.

192. Nazzini, supra note 22, at 307. In this vein, see also Pablo Ibáñez Colomo, Exclusionary Discrimination under Article 102TFEU, 51 COMMON MKT. L. REV. 141 (2014).

193. Nazzini, supra note 22.

194. Michael A. SAlinger \& Robert J. LeVinson, The Role for Economic Analysis in the FTC's Google Investigation, SPRINGER SCIENCE+BUS. MEDIA N.Y. 31 (2013), https://www.law.northwestern.edu/ researchfaculty/searlecenter/events/internet/documents/Salinger_Economics_of_Google_and_Antitrust_Case_ Searle_conference_version.pdf. 
to attract users, not websites. ${ }^{195}$ In fact, even this categorisation of Google's business may be a simplification: a German court found that Google only has a trading relationship with the advertisers and does not have such a relationship even with the users of Google Search. ${ }^{196}$ The suggestion that the comparison shopping sites are Google's trading parties with whom Google has a transactional relationship - which is a necessary requirement for the application of Article 102(c)TFEU - raises two questions the answers to which reveal that there is unlikely to be any such transactional relationship.

The first question is what these sites provide to Google and what Google provides in return that could create a transactional relationship between these sites and Google as trading parties. Without a contract by which these sites may advertise on Google Search in return for a fee, what Google provides to these sites appears to be free display of the sites on its general organic result pages which can lead to traffic to these websites. As for what the websites provide to Google in return for the free display, which could lead to the creation of a trading/business relationship, the answer appears to be nil. This explains why a German court noted that (specialist) websites which appear in search results "free ride" on Google's search engine services and seek (and receive) free promotion of their sites by Google. ${ }^{197}$ Regarding Google Search, there are legally no "transactions" between Google and comparison shopping sites and the latter sites are not Google's trading parties because there is no trade between them. Admittedly, in BdKEP the Commission rejected the view that "trading partners" should be construed narrowly as "contracting parties." 198 However, it did so by noting that "[m]ere business contacts between the dominant undertaking and its "trading partners" are generally considered to be sufficient." 199 This decision has not been appealed, and therefore, whether the EU Courts would accept such a broad understanding of "transactions with trading parties" is unknown. Moreover, the Commission's characterisation still requires there to be at the very least "business contacts" between the dominant undertaking and the allegedly discriminated-against-trading-parties, which suggests that there should at least be the provision of a service by the dominant undertaking to those parties and some sort of return for its provision. ${ }^{200}$ This is not the case in Google Search as Google does not provide a service to comparison shopping sites or any other sites that (wish to) appear, without payment, on the general result pages in response to a search conducted on the search engine. This is not because Google is in such an unusual, novel type of business that Article 102(c)TFEU as stipulated would fail to cover any aspect of Google's business. Similar to traditional businesses, Google does have "trading

195. Id.

196. Verband Deutscher Wetterdienstleister eV v. Google, Reference No. 408 HKO 36/13 (Apr. 4, 2013), Court of Hamburg, http://deutschland.taylorwessing.com/documents/get/150/court-order-google-weatherinbox-english-unofficial-translation.pdf.

197. Id.

198. Commission Decision Draft COMP/38.745 of Oct. 20, 2004 on the German Postal Legislation Relating to Mail Preparation Services, II 92, http://ec.europa.eu/competition/elojade/isef/case_details.cfm?proc_ code $=1 \_38745$ [hereinafter Mail Preparation]

199. Id. If 92.

200. See, e.g., id. $\operatorname{TII} 3,8,90$ (regarding the provision of service in return for a fee). 
parties": the advertisers which enter into a commercial relationship with Google and pay to advertise on Google's search result pages.

The second question regarding the suggestion that Google provides a service that would render the websites that (might) appear on the general result pages Google's trading parties is that of what the terms and conditions of the provision of that service are. Notably, Google does not make any legally relevant promises to any of the websites the links to which might appear on the general result pages: the only set of terms and conditions that Google appears to use are those directed to the users of its various services. ${ }^{201}$ The fact that Google's (and other search engine's) web crawlers index the millions of websites on the Internet does not create a "business contact" that could be interpreted as a trading relationship between Google (or other search engine operators) and the potentially infinite number of websites on the Internet. ${ }^{202} \mathrm{~A}$ web crawler crawling a website is similar to a user visiting a website and neither of these actions can in itself create "business contact" or a "transactional relationship" between "trading parties" as required by Article 102(c)TFEU. One could ask whether allowing the crawlers to visit a website in question could constitute the subject matter of what a website provides (i.e., consideration in common law jurisdictions) in return for Google being able to display the information about that website on search result pages. This, again, is unlikely to be a correct legal characterisation of the situation because the websites and the information contained therein which the crawlers gather are publicly and freely available. Consequently, it is difficult to argue that the act of visiting a website in itself creates a transactional/trading-party relationship between a given visitor and the website. ${ }^{203}$ Holding otherwise would amount to arguing that every time a potential customer enters a shop on the street, they enter into a transactional/trading-party relationship with that shop even if they are only browsing. This interpretation is clearly commercially unrealistic and legally

201. Terms of Service, GoOGLE, http://www.google.co.uk/intl/en/policies/terms/regional.html (last visited Oct. 14, 2017).

202. Web crawlers are a type of software that discover the publicly available webpages on the Internet, follow the links on these pages and bring the data back to Google so that Google can index the information about words and their locations. See Crawling and Indexing, GoogLE, http://www.google.co.uk/insidesearch/ howsearchworks/crawling-indexing.html (last visited Oct. 14, 2017) (stating that once a user conducts a query on Google, the algorithms look up the search terms of the query in the index to find appropriate pages).

203. In common law, for a promise to be legally binding as a contract, the promise has to be supported by consideration (unless it is made in a deed). Consideration is traditionally defined as either some right, interest, profit or benefit accruing to one party, or some forbearance, detriment, loss or responsibility given, suffered or undertaken by the other. Currie v. Misa (1875) LR 10 Ex 153. Moreover, consideration must be at the request of the other party. London Borough of Southwark LBC v. Logan (1997) 29 HLR 40, 45. Furthermore, consideration would not be valid where the act or forbearance would have been accomplished by the promisee anyway (i.e. even if the promise had not been made). See EdWIN PEEL, Treitel's Law OF ConTract 86 (13th ed. 2011). Some civil law jurisdictions also have concepts similar to consideration such as "cause" that would be required for a promise to be legally binding as a contract. HALSON, supra note 157, at 161, n. 5. In the context of Google Search neither Google nor any given website provides a service to the other at the request of one another or in return for one another's provision of a service. Similarly, if it is held that Google and the websites that appear on the general result pages do provide something of value to one another which would create a transactional/trading-party relationship between them, it would be difficult to argue that they would not have provided this thing of value otherwise. The difficulty of conceptualising the existence of a contract aids in appreciating the difficulty of conceptualising a trading relationship between a search engine and a given website. 
unlikely in the brick-and-mortar example; it would be just as incorrect in the virtual, website context. It appears, then, that there is no relationship between a search engine and the websites that (might) appear on the general result pages, without payment, that could be meaningfully conceptualised as a transactional/trading-party relationship or business contact. ${ }^{204}$

\section{Competitive Disadvantage}

Another factor that needs to be examined before a finding of abusive discrimination under Article 102(c)TFEU can be made concerns the requirement of "competitive disadvantage." The Commission and the Courts have, in the past, adopted a broad definition of "competitive disadvantage," almost reading this requirement out of the provision in their practice. ${ }^{205}$ For example, the Commission in BdKEP noted that "competitive disadvantage" can cover not only the situation whereby the customer of the dominant undertaking is disadvantaged in relation to other customers of the dominant undertaking, but also the situation whereby the customer is disadvantaged vis-à-vis the dominant undertaking itself. ${ }^{206}$ For the Commission, the latter type of discrimination does not require a competitive relationship between the two comparator groups. ${ }^{207}$ However, two points are noteworthy. First, no matter how liberally the competitive disadvantage requirement is interpreted, the finding of abusive discrimination itself is still based on the premise that there is a separate, vertical market on which the dominant undertaking and the disfavoured competitors are active and compete, as was also the case in $B d K E P{ }^{208}$ This will be returned to below in the discussion of whether there is such a vertically related market in Google Search. Second, the treatment of the requirement of competitive disadvantage appears to have changed in the more recent EU-level jurisprudence which has somewhat read the requirement back into the provision. This is welcome, since as argued by this Author elsewhere, the requirement of competitive disadvantage is the factor that distinguishes discrimination that can

204. Nazzini, supra note 22, at 10.

205. Pinar Akman, To Abuse, or Not to Abuse: Discrimination Between Consumers, 32 EUR. L. REV. 492 , 498 (2007).

206. See Mail Preparation, supra note 198, II 93 (explaining the Commission also found that a third type of discrimination, namely exploitative discrimination between customers who are not competing on the same market is also covered by Article 102(c)TFEU). This type of discrimination also does not require a competitive relationship between the comparator groups. Because the argument in Google Search is that the comparison shopping sites are being excluded from the market as a result of Google's favouring of its own comparison shopping service and not that Google is treating some "customers" better than others, the exploitative type of discrimination is not deemed to be relevant for the purposes of the current article.

207. Mail Preparation, supra note 198, II 93. For some other cases in which the requirement of competitive disadvantage was not strictly applied, see, e.g., Case C-18/93, Corsica Ferries Italia Srl v. Corpo dei Piloti del Porto do Genova, 1994 E.C.R. I-1783; Case 85/76, Hoffmann-La Roche \& Co AG v. Comm'n, 1979 E.C.R. 461; Commission Decision COMP/C-1/36.915, supra note 20.

208. See Mail Preparation, supra note 198, III 45, 51 (explaining this was the market for mail preparation services, a separate market from the market on which Deutsche Post had a monopoly, namely the market for basic postal services). 
be a competition issue from that which cannot be. ${ }^{209}$ In British Airways, the CoJ held that in order for Article 102(c)TFEU to be applicable,

[T] here must be a finding not only that the behaviour of an undertaking in a dominant position is discriminatory, but also that it tends to distort that competitive relationship, in other words to hinder the competitive position of some of the business partners of that undertaking in relation to the others .... ${ }^{210}$

Moreover, according to the Court, the consequence of Article 102(c)TFEU, in conjunction with then-Article 3(1)(g)EC (now Protocol 27) is that the commercial behaviour of a dominant undertaking should not distort competition on an upstream or downstream market, i.e. between suppliers or customers of that undertaking. ${ }^{211}$ This means that the co-contractors of that undertaking must not be favoured or disfavoured in the area of competition which they practise amongst themselves. ${ }^{212}$ These holdings of the CoJ are not only significant for pointing out that the Commission must establish that the discrimination by a dominant undertaking hinders the competitive position of some of its business partners in relation to others, they reiterate that the provision requires (i) a vertical relation between the dominant undertaking and the parties being discriminated against/in favour of which can be categorised as downstream/upstream to one another; (ii) the existence of a relationship of "cocontractors," "business partners," "supplier/customer" between the dominant undertaking and the parties being discriminated against/in favour of. In the context of Google Search, as discussed above, it is almost certain that Google does not have a contracting or partnership or supply relation with the comparison shopping sites (or any sites that do or could appear on general result pages in response to a query as long as the results are not paid for as advertisements). As will be discussed below, it is also highly questionable that separate markets can be identified that are in a vertical relation to one another.

More recently than British Airways, the CoJ held in Kanal 5 that the placement of some parties at a "competitive disadvantage" is indeed necessary for proving a breach of Article 102(c)TFEU and the parties in question should be competing on the same market. ${ }^{213}$ One must emphasize that it is not just a disadvantage that is required but a competitive disadvantage. ${ }^{214}$ Any reduced profits would be a disadvantage but do not necessarily affect an undertaking's ability to compete; the objective of Article 102TFEU is not to protect individual interests in a given level of surplus. ${ }^{215}$ Regarding Google Search, as the comparison shopping sites can still compete effectively on the alleged (but debatable) relevant market of "comparison shopping" even without the free promotion they receive from Google, because they have other means of

209. AKMAN, supra note 27, at 241 .

210. Case C-95/04P, British Airways v. Comm'n, 2007 E.C.R. I-2331, II 144.

211. Id. $\llbracket 143$.

212. Id.

213. Case C-52/07, Kanal 5 Ltd v. Föreningen Svenska Tonsättares Internationella Musikbyrå (STIM) upa. 2008 E.C.R. I-9275, IIII 46, 48.

214. Miguel de la Mano et al., Article 102, EU L. Of COMPETITIOn 330, 531 (3d ed. 2014).

215. Id. at 531-32; O'DONOGHUE \& PADILLA, supra note 55, at 802. 
promoting themselves (through online and offline advertising, social media, (e)mail campaigns, partnership with retailers/merchants, etc.), it is not possible to argue that they are put at a competitive disadvantage even if the loss of free traffic from Google may be a disadvantage (assuming that there is such a loss of traffic). It is also noteworthy that any loss of such free promotion and traffic on the part of comparison shopping sites would constitute a gain in the form of free promotion and potentially, traffic for sites which appear in the results instead of the comparison shopping sites, including Amazon, eBay, relevant retailers, etc. Given that Amazon specifically is one of Google's main rivals, particularly concerning product search, this also points out the potential lack of harm to competition that might result from Google's practices in question. ${ }^{216}$

\section{Applying Dissimilar Conditions to Equivalent Transactions}

For Article 102(c)TFEU to be applicable, another requirement is that there must be "equivalent" transactions to which the dominant undertaking applies "dissimilar conditions." On the basis of the position that Google is vertically integrated regarding its generalist search engine and specialist comparison shopping services, one commentator has noted that it is clear that the internal cost structure of a vertically integrated undertaking cannot be considered equivalent to a sale to a non-vertically integrated third party; vertical integration makes the transaction in question non-equivalent. ${ }^{217}$ Indeed, the most obvious reason for finding that two transactions are not equivalent has been noted to be different costs involved for the supplier in two transactions. ${ }^{218}$ Furthermore, it has been noted that even a vertically integrated dominant undertaking cannot be required to extend any efficiency-enhancing measures that benefit its downstream division to all its customers. ${ }^{219}$ Thus, not benefitting one's downstream customers in the same way that one benefits one's own downstream division cannot be deemed to apply "dissimilar conditions" to the customers' operations by the dominant undertaking. According to some commentators, the discriminatory supply of an inferior input can only be abusive when it prevents equally efficient downstream rivals of a vertically-integrated undertaking which provides an essential input to its downstream competitors and which deliberately

216. See Claire Cain Miller \& Stephanie Clifford, Google Struggles to Unseat Amazon as the Web's Most Popular Mall, N.Y. TIMES (Sept. 9, 2012), http://www.nytimes.com/2012/09/10/technology/google-shoppingcompetition-amazon-charging-retailers.html?_r=2\&ref=technology (explaining Google's lack of competition may explain behaviour); Hal Singer, Who Competes with Google Search? Just Amazon, Apple and Facebook, FORBES (Sept. 18, 2012, 9:28 AM), http://www.forbes.com/sites/halsinger/2012/09/18/who-competes-withgoogle-in-search-just-amazon-apple-and-facebook/. Google's Executive Chairman Eric Schmidt declared in 2014 that Amazon is Google's biggest search competitor. See Eric Schmidt, The New Gründergeist, GooGLE EUR. BLOG (Oct. 13, 2014), http://googlepolicyeurope.blogspot.co.uk/2014/10/the-new-grundergeist.html (finding that in 2012 a third of online users started their product searches on Amazon compared to 13\% who started their search on a search engine. In 2009, nearly a quarter of shoppers started their search on a search engine, whilst $18 \%$ started on Amazon).

217. Nazzini, supra note 22, at 10.

218. de la Mano et al., supra note 214, at 530.

219. Id. 
increases the efficiency of its own input and not the input supplied to the competitor. ${ }^{220}$ This is not the case in Google Search for several reasons.

First, Google cannot be said to control an essential input for the business of running a comparison shopping site; the provision of comparison shopping sites is not dependent on any such input from Google or any other search engine. Second, as discussed below, it is highly debatable whether Google is a vertically integrated undertaking that has an upstream search engine and a downstream comparison shopping service. Third, it is noteworthy that Google Shopping Commercial Unit displays links to merchant sites/retailers where the users can purchase the item for which they searched, through clicking on the link displayed within the Google Shopping Commercial Unit. Not displaying the links to comparison shopping sites in the same manner as Google displays links to merchants/retailers as part of the Google Shopping Commercial Unit cannot be deemed discriminatory and cannot be considered to be deliberately enhancing the efficiency of one's own input and not the input of the competitor: comparison shopping sites are not merchants/retailers and consumers cannot normally purchase products on these sites; consumers would still have to visit the merchant/retailer site to make a purchase after visiting the comparison shopping site. Consequently, for Google Search, displaying merchant/retailer site results in response to a query about a product that is available for sale is not "equivalent" to displaying results from comparison shopping sites for the same product. The former is clearly a more direct and efficient response to a user's product search, and a more convenient service to consumers who are interested in making a purchase since the latter involves the additional step of going through another website (i.e., the comparison shopping site) before the consumer will be directed to the merchant/retailer site where she can make a purchase. In fact, this is the case even if the consumer could directly purchase the item on the comparison shopping site in question - the transactional cost for the consumer would still be higher due to the necessity of visiting another website. Moreover, for Google, displaying results within the Google Shopping Commercial Unit is not equivalent to displaying results as part of the organic results, which may include links to comparison shopping sites because the former are revenue-generating, paid-for advertisements displayed in ad space, whilst the latter are not. Thus, the two types of results generated by two different types of relevance algorithms are fundamentally different and their differential treatment cannot be deemed discriminatory.

If the allegation of discrimination is based on the premise that there should be equivalent treatment of displaying merchant/retailer results in the Google Shopping Commercial Unit and the merchant/retailer results that would come up in the results of comparison shopping sites for the same query (i.e., that discrimination is between the merchant/retailer sites depending on whether they appear in Google Shopping Commercial Unit or in comparison shopping site results), it is again impossible to show "equivalent" transactions to which the dominant undertaking applies "dissimilar conditions." Such a proposition 
would imply that displaying the results rendered by Google's own algorithm is equivalent to displaying the results rendered by a comparison shopping site's algorithm. This is clearly incorrect since the algorithms in question are different. It would also imply that Google applies "dissimilar conditions" by relying on the accuracy and superiority of its own algorithm as opposed to the algorithms of comparison shopping sites, which does not make any business sense. It also does not make any legal sense to expect or require Google to treat the results of a comparison shopping site's algorithm equally to the results of its own algorithm: that requirement would not enhance but reduce competition between search providers which innovate and improve their algorithms to increase the accuracy, relevance, and therefore, the attractiveness of their offerings for users.

It is noteworthy that in Michelin I, while overturning the Commission's finding of abusive discrimination between Michelin dealers resulting from Michelin's system of rebates, the CoJ indicated that to prove abusive discrimination, the Commission has to establish that the differences in treatment of different dealers cannot be justified by "legitimate commercial reasons."221 In Google Search, Google's alleged differential treatment of Google Shopping and comparison shopping sites can be justified by the legitimate commercial reason that the practices in question require the application of different types of relevance algorithm. Google Shopping results displayed under Google Shopping Commercial Unit constitute ads (and are displayed in Google's ad space, which constitutes an opportunity cost for Google), whilst the results on the general search result pages are organic results that are not paid for. In other words, whereas the former generates revenue to Google, the latter does not (and in fact, the latter would not be provided but for the revenue generated by the former). The difference in the nature of the results rendered by different algorithms constitutes a legitimate commercial reason which can lead to the differential treatment of ads and organic results without this conduct being abusive in line with Michelin I.

\section{The Relevance of a Downstream/Upstream Market and Vertical Integration}

In competition law, discrimination is generally thought to result in either "primary" or "secondary" line injury to competition. ${ }^{222}$ "Primary line injury" concerns discrimination by a dominant firm harming its (horizontal) rivals through exclusionary effects. ${ }^{223}$ "Secondary line injury," in contrast, concerns the effects of discrimination on downstream markets where the customers of the dominant undertaking compete with one another or with third parties. ${ }^{224}$ In the 90.

221. See Case C-322/81, NV Nederlandsche Banden Industrie Michelin v Comm'n, 1983 E.C.R. I-3461, II

222. Price Discrimination: Robinson-Patman Violations, FTC: PROTECTING AMERICA's CONSUMERS, https://www.ftc.gov/tips-advice/competition-guidance/guide-antitrust-laws/price-discrimination-robinsonpatman (last visited Oct. 14, 2017).

223. JONES \& SUFRIN, supra note 124, at 397-98; O'DONOGHUE \& PADILLA, supra note 55, at 778.

224. JONES \& SUFRIN, supra note 124, at 398; O'DONOGHUE \& PADILLA, supra note 55, at 777-79. 
literature, Article 102(c)TFEU has been interpreted as being concerned only with discrimination causing secondary line injury on the basis of the use of phrase "transactions with other trading parties" which would exclude discrimination against rivals with whom the dominant firm does not have a direct transactional relationship. ${ }^{225}$ Some commentators have also argued that the requirement of "competitive disadvantage" in Article 102(c)TFEU makes the finding of a discriminatory abuse dependent on finding a downstream market on which the relevant firms compete. ${ }^{226}$ Several authors have consequently criticised the Commission's and the Courts' application of Article 102(c)TFEU to exclusionary practices which they argue should be dealt with under Article 102(b)TFEU (prohibiting the limitation of production, markets or technical development to the prejudice of consumers). ${ }^{227}$ It has been argued that although Article 102(c)TFEU has been applied in a few cases to exclusionary conduct where the only issue was discrimination, usually in favour of the dominant undertaking's own downstream operations and to the detriment of downstream rivals, who are both customers and competitors, in most cases exclusionary conduct involving discrimination has been analysed under the particular abuses concerned such as predatory pricing, margin squeeze or refusal to deal. ${ }^{228}$ This could cover several cases that involved discrimination by a non-vertically integrated undertaking where the practice, even if in nature discriminatory, was assessed in the particular context of the specific conduct such as rebates, refusal to deal, etc. ${ }^{229}$ Where the dominant undertaking is not vertically integrated and discriminates between its customers with whom it does not compete on any market, the incentives for distorting competition between such customers is unlikely to be strong in the absence of a potential effect on the competitive position of the horizontal rivals of the dominant undertaking. Indeed, findings of discrimination based only on differences in the prices or terms offered to similarly-situated customers have been "an extreme rarity under Article 102TFEU."230 Where no distortion of competition is expected as a result of

225. See O'DonoghuE \& PADILLA, supra note 55, at 779 and, more broadly, Jones \& SUFRIN, supra note 124, at 398; Santiago Martinez Lage \& Rafael Allendesalazar, Community Policy on Discriminatory Pricing: A Practitioner's Perspective, in WhAT IS AN ABUSE OF DOMINANT Position? 325, 341 (Claus-Dieter Ehlermann and Isabela Atanasiu eds., 2006); Damien Geradin \& Nicolas Petit, Price Discrimination Under EC Competition Law: Another Antitrust Doctrine in Search of Limiting Principles?, 2 J. COMPETITION L. \& ECON. 479, 487 (2006); see Damien Gerard, Price Discrimination Under Article 82(c) EC: Clearing up the Ambiguities, in Global Competition LAW CENTRE ResEARCH PAPERS ON ARTICLE 82 EC2, 132 (2005) (arguing that primary line injury should be dealt with under Article 102(b)TFEU); Michel Waelbroeck, Price Discrimination and Rebate Policies under EU Competition Law, InT'L ANTITRUST L. \& POL'Y: FordHAM CORP. L. 147, 160 (1996); Renato Nazzini, The Foundations of European Union Competition Law: The Objective and Principles of ARTicle 102, 250-51 (2011); DAmien Geradin, ANNE LAyne-FarRAR AND Nicolas Petit, EU COMPETITION LAW AND ECONOMICS 1, 305-07 (2012).

226. GERADIN \& PETIT, supra note 225, at 299.

227. See, e.g., id. at 307.

228. O'DonOGHUE \& PADILla, supra note 55, at 780.

229. See, e.g., Case C-497/99 P, Irish Sugar plc v. Comm'n, 2001 E.C.R. I-5333; Case C-95/04P, British Airways v. Comm'n, 2007 E.C.R. I-2331.

230. O'Donoghue \& Padilla, supra note 55, at 811. 
discrimination, it is possible that discrimination may actually increase welfare, for example, through increasing output. ${ }^{231}$

In cases where there is no potentially abusive practice other than discrimination, and that discrimination aims at harming the downstream competitors of a vertically integrated undertaking, such conduct can artificially raise rivals' costs. If the harm is serious enough, and the rivals are important to consumers, discrimination may also harm consumer welfare. ${ }^{232}$ Since the potential argument for an abuse of discrimination in Google Search is of this type, i.e., it involves the dominant undertaking discriminating in favour of its own downstream operations, ${ }^{233}$ the existence of a downstream market and Google being a vertically integrated undertaking present on the upstream and downstream markets become essential for assessing whether the facts of Google Search fall within the relevant case law.

Most cases concerning discrimination by a vertically integrated dominant undertaking involved former state monopolies whose markets were opened to competition where downstream rivals remained dependent on the vertically integrated dominant undertaking. ${ }^{234}$ Indeed, the cases of discrimination by a vertically-integrated dominant undertaking which was a (former) state or de facto monopoly and/or controlled an essential facility include many-if not all —of the cases that could be/have been used to support the position that the conduct in Google Search may be abusively discriminatory, such as Deutsche Bahn $;{ }^{235}$ Clearstream $;{ }^{236}$ GT-Link $;{ }^{237}$ ITT Promedia,${ }^{238}$ BdKEP $;{ }^{239}$ E.On $;{ }^{240}$ and $G D F .{ }^{241}$ In all these cases, there was a dominant undertaking, which in most cases was a monopoly, and which was treating a subsidiary/sister company more favourably than the downstream competitors of the dominant undertaking on a separate downstream market which concerned a separate service/product than

231. See, e.g., Mark Armstrong \& John Vickers, Price Discrimination, Competition and Regulation, $41 \mathrm{~J}$. INDUST. ECON. 335, 336 (1993) (according to economics, discrimination can either reduce or increase consumer welfare; its effects on welfare are therefore ambiguous); Gerard, supra note 225, at 105; Anne Perrot, Towards an Effects-Based Approach of Price Discrimination, in THE Pros AND CONS OF PRice DisCrimination 161, 168 (Swedish Competition Authority, 2005); see Benjamin Klein \& John S. Wiley Jr., Competitive Price Discrimination as an Antitrust Justification for Intellectual Property Refusals to Deal, 70 ANTITRUST L. J. 599, 610 (2003) (relying upon the fact that product differentiation is normal and pervasive in real-world markets, price discrimination — as a common type of discrimination — can be expected to be normal and pervasive as well: price discrimination arguably often exists in extremely competitive markets).

232. O'Donoghue \& PADILLA, supra note 55, at 803-04.

233. Id.

234. Id. at 810

235. Case T-229/94, Deutsche Bahn AG v. Comm'n, 1997 E.C.R. II-1689.

236. See Case T-301/04, Clearstream Banking v. Comm'n, 2009 E.C.R. II-3155 (noting that the main abuse in Clearstream was refusal to deal and discrimination was deemed to be a factor reinforcing the existence of the refusal to deal).

237. Case C-242/95, GT-Link A/S v. De Danske Statsbaner, 1997 E.C.R. I-4499.

238. See European Commission Press Release IP/97/292, Settlement Reached with Belgacom on the Publication of Telephone Directories-ITT Withdraws Complaint (Apr. 11, 1997), available at http://europa.eu/ rapid/press-release_IP-97-292_en.htm (showing that the Commission did not take a decision in this case because the complaint was withdrawn by ITT after Belgacom committed to changing its pricing policy).

239. Mail Preparation, supra note 198.

240. Commission Decision COMP/39.388, 2008 O.J. (L 36) 8

241. Commission Decision No. COMP/39.316, 2009 O.J. (L 57) 13; see Petit, supra note 22, at 3-4. 
the one over which the undertaking in question was dominant. ${ }^{242}$ It has, in fact, been noted in the literature that the issue of discrimination against rivals is most likely to arise in the case of liberalised utilities where the relevant markets are not yet fully competitive. ${ }^{243}$ It must, therefore, be emphasised that Google is not a monopoly on any of the markets that the Commission identified as the relevant markets (the markets for web search, search advertising, and comparison shopping) since it has competitors on all of these markets, which would distinguish Google Search from most-if not all-of the cases mentioned immediately above.

The cases discussed above emphasize several factors that need to be established by the Commission before Google Search can be fitted into the case law on discrimination under Article 102TFEU. ${ }^{244}$ First, the theory of discrimination against Google could only work if Google is found to be a vertically integrated undertaking active on more than one level of production/provision of services. $^{245}$ This would require proving that Google's search engine and other services such as comparison shopping are not only on different, separate markets, but also that they are in a vertical relation to one another. Otherwise, if Google is not a vertically integrated undertaking, for example, because Google's comparison shopping service is simply a feature of Google's search engine, then there is no discrimination between downstream operators or between downstream operators and Google's own operations because there are no such different operators to discriminate between. ${ }^{246}$ If Google is not vertically integrated, the theory of self-preferencing is unsustainable since there is no separate downstream Google operation to favour and there is no suggestion that Google discriminates between different

\footnotetext{
242. In Deutsche Bahn the subsidiary of Deutsche Bahn, the railway operator holding a statutory monopoly, was Transfracht, active in the carriage of maritime containers; in Clearstream the subsidiary of Clearstream which had a monopoly over providing clearing and settlement services for securities was Clearstream Banking Luxembourg active in the secondary clearing and settlement of securities in cross-border trade; in GT-Link the port operator (ie the Danish national railway operator) had a separate ferry service operating to/from the same port; in ITT Promedia Belgacom's (the Belgian national telecoms operator) downstream subsidiary was Belgacom Directory Services active on the market for publishing telephone directories; in $B d K E P$, Deutsche Post, the German national postal company, itself had operations on the separate, upstream market for mail preparation services; in E-On the electricity network operator E-On which was allegedly collectively dominant on the wholesale electricity market with others was also allegedly dominant on the separate market for the demand of secondary balancing power and had a subsidiary (E.On Netz) on that latter market which was a monopolist; in $G D F$, GDF Suez had allegedly a dominant position on the gas import and supply markets in the balancing zones of the GRTgaz transport network and allocated a significant portion of total capacity at the relevant terminal to its own trading division, GDF-B3G and Total arguably foreclosing competition on the separate, downstream gas supply markets.

243. O'DONOGHUE \& PADILlA, supra note 55, at 807; see Commission Decision COMP/C-1/36.915, supra note 20 (showing Deutsche Post-Interception of Cross-Border Mail as it involved Deutsche Post disadvantaging the position of its-horizontal — rival, British Post, by treating email differently from what Deutsche Post considered to be "genuine" international mail).

244. See Case T-229/94, Deutsche Bahn AG v. Comm'n, 1997 E.C.R. II-1689; Case T-301/04, Clearstream Banking v. Comm'n, 2009 E.C.R. II-3155; Case C-242/95, GT-Link A/S v. De Danske Statsbaner, 1997 E.C.R. I-4499; Commission Decision COMP/39.388, 2008 O.J. (L 36) 8; Commission Decision No. COMP/39.316, 2009 O.J. (L 57) 13.

245. See Colomo, supra note 192.

246. See FTC Google Statement, supra note 175, at 2-3.
} 
comparison shopping sites inter se, which implies that the theory of discrimination is untenable. ${ }^{247}$ Any theory of exclusion would then have to be built on a conceptual premise other than discrimination: the theory of distorting competition by discrimination in favour of one's self to disadvantage downstream rivals is dependent on there being a vertically integrated firm that is dominant on the upstream/downstream level and is leveraging its dominance into the downstream/upstream market. ${ }^{248}$ If there are no such separate operations on separate markets and there is no vertical integration, then the theory of leveraging market power through discrimination collapses. ${ }^{249}$ One cannot envisage building a theory of discrimination that would cause primary line injury to competition by harming Google's horizontal rivals either. Any discrimination by Google between comparison shopping sites would not hurt but effectively help Google Search's horizontal rivals such as Bing and DuckDuckGo, since the conduct would make these other search engines more attractive to those comparison shopping sites as alternative venues of generating traffic. $^{250}$ Thus, the allegations of discrimination can indeed only involve an allegation of secondary line injury to competition.

Whether Google Shopping could be deemed to be a separate service on a separate market from Google Search that is in a vertical relation to the search engine is indeed questionable. Although Google has been noted to be a "horizontal," or general purpose, search engine because it seeks to cover the Internet as completely as possible, which is distinct from "vertical" search engines that focus on narrowly defined categories of content such as shopping or travel:251 at a conceptual level, this distinction makes little sense. This is because, in terms of what users search for on any search engine, it is difficult to argue that some search queries are "general"/horizontal whilst some others are "specific"/vertical. A user who uses a search engine always seeks information on a specific, narrowly defined potential category of content. ${ }^{252}$ No user is interested in conducting a search on Google Search that would make the search engine bring up the entire content of the World Wide Web as a "generalist"/horizontal search engine. ${ }^{253}$ If Google Search did bring up the entire content of the worldwide web in response to a search query, it would make it a very poor search engine for not answering the specific query of the user. ${ }^{254}$ Arguing that certain websites whose scope is limited to providing answers to queries concerning certain categories of information and Google Shopping are in a vertical relation to Google Search is analogous to arguing that a supermarket is in a vertical relation to its bakery section and to all the bakeries in the vicinity. It is also analogous to argue that not only is the supermarket in a vertical relation to all the bakeries in the vicinity, but also to all the butchers, all the newsagents,

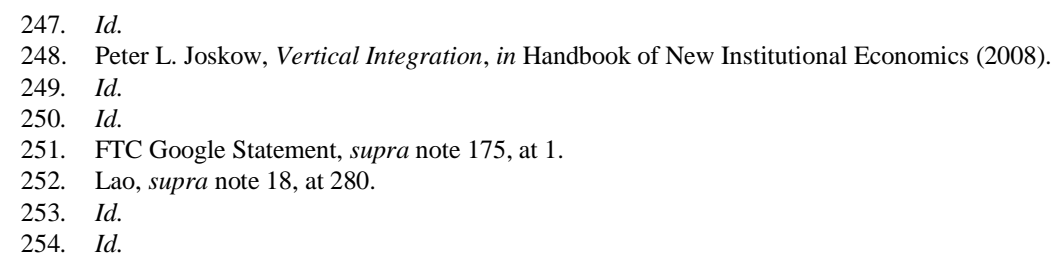


all the greengrocers, and all the boutiques if it sells clothing. This is clearly bizarre in the supermarket context, not least because if one took away all of the offerings found in these arguably "specialist" sections from the supermarket's offerings there would be nothing left that the supermarket could offer to customers. The operation of a supermarket in that sense is not that dissimilar to the operation of a search engine (except that the search engine does not sell anything to the users on the one side of the market, but sells advertising to the advertisers on the other side of the two-sided market, which makes the vertical integration argument even less tenable). ${ }^{255}$ The fact that a supermarket is able to provide customers with all these different offerings in different sections under one roof is what makes the supermarket a supermarket. These "specialist" sections are constituent elements of a supermarket. Moreover, arguing that a bakery, a greengrocer, or a butcher, is a downstream operation in relation to a supermarket would also be bizarre because the supermarket is already at the final level of the vertical production chain: the customers of the supermarket are final consumers which use the services of the supermarket. This is similar to the fact that the search engine service Google provides is provided to users who search for queries on Google Search. ${ }^{256}$ There is no intermediary, downstream level of service/operation between Google and the users for specialist types of queries; Google is at the end of the "production chain" if there is such a vertical production chain at all. ${ }^{257}$ The existence of such a chain is necessarily implied by the proposition that Google is a vertically integrated undertaking, which itself is necessary for the allegation of discrimination in favour of one's self and against one's downstream competitor to be sustainable since, without such vertical integration, there cannot be downstream customers and consequently, secondary-line injury to competition. ${ }^{258}$

The presentation of shopping results displayed in the Google Shopping Commercial Unit (and under Google Shopping) can be seen as an improvement of Google Search itself over the previous presentations of results by Google and has been deemed to be a "product design" feature by the FTC and some courts around the world. ${ }^{259}$ This suggests that Google Shopping is not a distinct operation of Google on a market separate from that on which the search engine operates, but a means of presenting the relevant results for a sub-group of users who search for a product on Google Search with the intention to make a

255. The fact that unlike a supermarket that sells bread, meat, and newspapers, and receives revenue in this way, Google does not itself sell any of the products that appear in the Google Shopping Commercial Unit (or under Google Shopping) makes the argument concerning lack of a downstream level of production/service even stronger in the search engine case than in the supermarket case.

256. Lao, supra note 18 , at 280.

257. Ben Edelman, Does Google Leverage Market Power Through Tying and Bundling?, 11 J. COMPETITION L. \& ECON. 365 (2015).

258. Id.

259. T.J.S.P.-18, Ap. Civ. No. 583.00.2012.131958-7, 05.09.2012 (Braz.); Verband Deutscher Wetterdienstleister eV v. Google, Reference No. 408 HKO 36/13, 3-4 (Apr. 4, 2013), Court of Hamburg, http://deutschland.taylorwessing.com/documents/get/150/court-order-google-weather-inbox-english-

unofficial-translation.pdf; FTC Google Statement, supra note 175, at 3. 
purchase. ${ }^{260}$ Furthermore, holding that Google Search is in a vertical, upstream relation to Google Shopping (and consequently to any other comparison shopping site) would open up the possibility of finding a search engine in a vertical relation and thus an upstream competitive position with an unlimited number of potential sites that may provide a service that makes up a subcategory of results that might come up on Google's general search result pages in response to a query. ${ }^{261}$ This would certainly "open the floodgates" and could have a chilling effect on innovation. ${ }^{262}$

The questionable categorisation of Google Shopping as a separate product/service in a vertical relation with Google Search and in competition with other such comparison shopping sites is also challenged by Google's business model. ${ }^{263}$ Google's revenue comes from advertisements placed on its website alongside or as part of search results (both of which expressly indicate these to be advertisements or sponsored results). ${ }^{264}$ This business model does not change according to whether Google provides the shopping results in response to a product query grouped and displayed together as the Google Shopping Commercial Unit (or Google Shopping) results or whether Google provides these results as text ads without grouping the shopping results. ${ }^{265}$ The results displayed within the Google Shopping Commercial Unit (and Google Shopping) are advertisements for the product in question similar to the advertisements displayed outside of the Google Shopping Commercial Unit (and Google Shopping) for the same (similar) product(s). ${ }^{266}$ Grouping shopping results together makes it easier for those users who, for example, search for "digital camera" with the intention to buy a camera, to select an advertisement that is of interest to them. ${ }^{267}$ Such grouping also makes it easier for users who are not interested in purchasing a "digital camera," but are interested in, for example, the history of digital cameras, to skip over the advertisements of cameras for sale. ${ }^{268}$ For users who are interested in purchasing cameras, this convenience may also increase Google's chances of receiving remuneration from the display of the advertisement, but this alone does not make the display of shopping results

\footnotetext{
260. FTC Google Statement, supra note 175 , at 3.

261. Lao, supra note 18 , at 286.

262. See Ultramares Corp. v. Touche, Niven \& Co., 174 N.E. 441, 442 (N.Y. 1931) (showing that the "floodgates principle" is an expression of recognition by courts (generally found in common law jurisdictions) that permitting a claim in one case would risk exposing the defendants to liability in countless claims for an indeterminate amount for an indeterminate time to an indeterminate class); Spartan Steel \& Alloys Ltd. v. Martin \& Co. (Contractors) Ltd. [1972] EWCA (Civ 3) 1 QB 27 (Eng.).

263. Brian J. Smith, Vertical vs. Core Search: Defining Google's Market in a Monopolization Case, 9 N.Y.U. J. L. \& BuS. 331, 357 (2012).

264. Id. at $337-38$

265. Id.

266. Google for Retail, GooGLE, https://www.google.com/retail/solutions/spark-shoppers-interest/ (last visited Oct. 14, 2017).

267. Create and Optimize Effective Shopping Campaigns: Google Best Practices, GoOGLE, https://support.google.com/adwords/answer/6167176?visit_id=1-636397984685580439-3379849634\&rd=1 (last visited Oct. 14, 2017).

268. Id.
} 
under the Google Shopping Commercial Unit a separate operation-let alone a separate relevant market - from the search engine. ${ }^{269}$

\section{Objective Justification and Exclusionary Effect}

Even if Google was found to be a vertically integrated undertaking by the Commission for the purposes of Google Search and the remaining conditions of Article 102(c)TFEU were satisfied, as noted above, objective justification is also always available to a dominant undertaking to defend its conduct. In fact, in Post Danmark I, the CoJ seems to have gone further than simply restating the availability of objective justification by holding that in the context of price discrimination "the fact that the practice of a dominant undertaking may ... be described as 'price discrimination,' . . . cannot of itself suggest that there exists an exclusionary abuse." 270 Although the CoJ has not elaborated on this statement, one could argue that discrimination without more does not constitute an exclusionary abuse under Article 102TFEU. ${ }^{271}$ This is different from stating the availability of an objective justification (which is currently a defence to be proven by the undertaking), because it suggests that without separately proving an exclusionary effect, discrimination does not constitute an abuse in the first place. Moreover, according to the Court, "[n]ot every exclusionary effect is necessarily detrimental to competition .... Competition on the merits may, by definition, lead to the departure from the market or the marginalisation of competitors that are less efficient and so less attractive to consumers from the point of view of, among other things, price, choice, quality or innovation."272 Nor does Article 102TFEU "seek to ensure that competitors less efficient than the undertaking with the dominant position should remain on the market." ${ }^{273}$ In Google Search, it is therefore fundamental to establish that any undertaking arguably being excluded from the market as a result of discrimination is not only as efficient as Google, but also has at least as attractive offers as Google's (and other competitors") to consumers in terms of price, choice, quality, or innovation. It is certainly debatable whether comparison shopping sites offer any additional value to consumers over and beyond what a search engine provides under one roof. ${ }^{274}$ More importantly, there has to be exclusion of these comparison shopping sites from the relevant market, which is factually disputed by the growth of some of these sites in the investigation period and by the fact

\footnotetext{
269. Id.

270. Case C-209/10, Post Danmark A/S v. Konkurrenceradet, 2012 EUR-Lex CELEX LEXIS 172, đI 30 (Mar. 27, 2012).

271. Case C-95/04P, British Airways v. Comm'n, 2007 E.C.R. I-2331, IIII 69, 86

272. Post Danmark, 2012 EUR-Lex CELEX LEXIS 172, II 22 (Mar. 27, 2012).

273. Id. 【 21.

274. See, e.g., James Grimmelmann, Some Skepticism About Search Neutrality, http://james.grimmelmann.net/essays/SearchNeutrality (calling these sites "junk" and "worthless," because all they do is to use existing content and place some of their own advertisements on it to "superficially resemble legitimate sites that actually provide something of value to users") (last visited Oct. 14, 2017).
} 
that such specialist sites have many other means of reaching consumers than through free promotion provided by Google Search results. ${ }^{275}$

Regarding the availability of an objective justification defence against a finding of discrimination in Google Search, the practice in question can be conceptualised as delivering efficiencies that benefit consumers. ${ }^{276}$ As the search engine provides answers to users' queries, doing so in a way that minimizes the costs of a search for a user is clearly an efficiency gain that benefits consumers. Displaying the Google Shopping Commercial Unit in response to a user's query, first, provides the user with a convenient display of product-related results grouped together, and second, saves the user who has the intention of purchasing a product from having to click through to another website (e.g. comparison shopping site) before the user can reach the merchant/retailer site to make a purchase. ${ }^{277}$ This, in turn, increases the efficiency of Google Search, because it enables it to provide those users interested in shopping with the relevant shopping results in the most convenient way possible, thereby increasing the usefulness and attractiveness of the search engine. ${ }^{278}$ In fact, "improvements in the quality of goods" is explicitly acknowledged by the Commission as an example of increasing efficiency that may satisfy the objective justification defence under Article 102TFEU. ${ }^{279}$ It is clear, therefore, that the conduct in Google Search can be objectively justified due to generating efficiencies that also benefit consumers.

\section{Tying}

Some commentators have raised the possibility that the conduct in question in Google Search can be conceptualised as "tying." 280 The argument is that the practice concerns the tying of Google content to search results or the tying of Universal Search with specialized search tools. ${ }^{281}$ Tying refers to a situation where customers who purchase one product (the tying product) are required to also purchase another product from the dominant undertaking (the tied product). ${ }^{282}$ Tying is prohibited under Article 102(d)TFEU which stipulates that "making the conclusion of contracts subject to acceptance by the other parties

275. See Amit Singhal, The Search for Harm, Google Official Blog (Apr. 15, 2015), https://googleblog.blogspot.co.uk/2015/04/the-search-for-harm.html (discussing the growth of comparison shopping sites and other specialized sites).

276. Google AdWords Help, Create and Optimize Effective Shopping Campaigns: Google Best Practices Official Guide to Building a Strategy for Your Shopping Campaigns, GoogLE, https://support.google.com/ adwords/answer/6167176?hl=en (last visited Oct. 14, 2017).

277. AdWords, GOOGLE, https://adwords.google.com/home/marketing-goals/drive-action/storevisits.html?subid=ww-ww-et-g-aw-a-helpcenter_1!02\#/subid=ww-ww-et-g-aw-a-helpcenter_1!02 (last visited Oct. 14, 2017).

278. Id.

279. Commission Guidance, supra note 31, II 30.

280. See, e.g., Edelman, supra note 257; Michael Luca, et al., Does Google Content Degrade Google Search? Experimental Evidence, Harvard Business School Working Paper 16-035 5, 7 (2015), http://www.hbs.edu/faculty/Publication\%20Files/16-035_2260fc69-1f63-466f-b4df-7957e77e2a3f.pdf; Lianos \& Motchenkova supra note 22, at 438.

281. Edelman, supra note 257; Luca, supra note 280; Lianos \& Motchenkova supra note 22, at 438.

282. Commission Guidance, supra note 31 , II 48. 
of supplementary obligations which, by their nature or according to commercial usage, have no connection with the subject of such contracts" may be an abuse. ${ }^{283}$ A literal reading of this provision would exclude Google Search from being a potential case of tying under Article 102TFEU since there is no contractual relationship between the users of the search engine and Google, by which Google contractually (or otherwise) obliges those who wish to use the search engine to also use its specialist services. ${ }^{284}$ Consequently, the only possible theory of tying in Google Search is that there is technical tying, a type of tying that has been found to be potentially abusive despite not explicitly being covered by Article 102TFEU. ${ }^{285}$ Technical tying occurs, according to the Commission, "when the tying product is designed in such a way that it only works properly with the tied product (and not with alternatives offered by competitors)."286 A literal reading of the Commission's definition would also exclude Google Search from the scope of abusive technical tying since Google Search cannot be said to work properly only with the tied product (e.g. Google Shopping Commercial Unit) and not with alternatives offered by competitors (e.g. with results of comparison shopping sites). ${ }^{287}$ However, since the guidance is limited to an expression of the Commission's enforcement priorities rather than constituting a statement of law, the rest of the section will explore whether there can be an issue of technical tying in Google Search. ${ }^{288}$

Given that technical tying in the absence of a contractual relationship is not covered by Article 102(d)TFEU, an assessment of the conditions stipulated in Article 102(d)TFEU will not be conducted here. ${ }^{289}$ Consequently, the relevant inquiry becomes that into the conditions established in the case law for tying to be abusive. There are four cumulative conditions for tying to be abusive: the tying and tied products are two separate products; the undertaking concerned is dominant on the market for the tying product; the undertaking concerned does not give customers a choice to obtain the tying product without the tied product;

283. Consolidated Version of the Treaty on the Functioning of the European Union art. 102, Oct. 26, 2012, 2012 O.J. (C 326) 47.

284. Id.

285. Commission Guidance, supra note 31, I[ 48

286. Id.

287. Gregory Voss, Angela Daly, Private Power, Online Information Flows and EU Law: Mind the Gap, 8 J. Intell. Prop. Info. TeCh \& Electronic COM. L. 89 (2017), https://www.jipitec.eu/issues/jipitec-8-12017/4535/JIPITEC_8_1_2017_Voss.pdf.

288. See Commission Guidance, supra note 31, II 3 (noting that Guidance is not a statement of the law).

289. Consolidated Version of the Treaty on the Functioning of the European Union art. 101(1)(e), Oct. 26, 2012, 2012 O.J. (C 326) 47 [hereinafter TFEU]. If such an assessment were conducted, then a potential argument that any tying in Google Search is not abusive could be based on the condition that the supplementary obligations are imposed on contracting parties which "by their nature or according to commercial usage, have no connection with the subject of such contracts." It would be difficult to argue - even assuming that there are contracts with users and supplementary obligations are imposed on users - that the display of Google Shopping results in response to a product search has no connection with the subject of conducting a search on a search engine. As noted above, the CoJ has held that Article 102(d)TFEU can apply to tying even if there was such natural or commercial links with the subject of the contracts. However, as mentioned previously, this Author has argued elsewhere that this approach is not correct or justifiable even under a teleological approach. 
tying forecloses competition. ${ }^{290}$ Some commentators have suggested that tying would be easier to prove than refusal to deal for the Commission in Google Search since once there is tying of two distinct products and the undertaking is dominant, a simple likelihood of anticompetitive effects may suffice to apply Article 102TFEU. ${ }^{291}$ As mentioned above, this Article assumes that the Commission's market definition and finding of dominance are correct, and will thus proceed to only discuss the remaining conditions. ${ }^{292}$ Consequently, the rest of this Subsection will examine (i) the requirement of two separate products/services; (ii) lack of customer choice to obtain the tying product without the tied product; (iii) foreclosure of competition and; (iv) objective justification.

\section{Two Separate Products/Services}

The first issue in Google Search is to establish that there are two separate products/services in question. Under the tying theory, Google's search engine is the "tying product" since it is the market for general search (as defined by the Commission) over which Google is dominant. ${ }^{293}$

According to the case law and the Commission's Guidance, the test for whether two products are distinct is to be assessed by reference to consumer demand. ${ }^{294}$ Some commentators have remarked that under EU competition law, for a product to be considered distinct, it is not necessary that it constitutes a relevant market and the existence of different sources of supply (particularly competing suppliers of the tied product) may indicate that the products are distinct. ${ }^{295}$ The suggestion is that the existence of a significant number of competitors present only in specialised (vertical) search may suggest that Universal Search and specialized search are distinct products. ${ }^{296}$ Similarly, regarding Google's additional services, it has been argued that the tying and tied products are distinct products because they offer different functionalities and are not interchangeable from a consumer's perspective. ${ }^{297}$ However, the accuracy of this position is debatable. For a user who is interested in purchasing a product, the search engine constitutes a tool for conducting a search with the expectation that the results will include those which would enable a purchase; ${ }^{298}$ thus, a

290. See Commission Decision 2007/53 of May 19, 2004, 50 O.J. (C 2004) 23, available at http://ec.europa.eu/competition/antitrust/cases/dec_docs/37792/37792_4177_1.pdf (relating to a proceeding pursuant to Article 82 of the EC Treaty and Article 54 of the EEA Agreement against Microsoft Corporation, Case COMP/C-3/37.792 II 794).

291. Lianos \& Motchenkova, supra note 22, at 439.

292. Kersting \& Dworschak, see supra note 18 (discussing the issue of market definition and the finding of dominance).

293. Edelman, supra note 257, at 370.

294. Commission Decision 2007/53, supra note 290, If 803; Case T-201/04, Microsoft Corp. v. Comm'n, 2007 E.C.R. II-3601, If 917; Commission Guidance, supra note 31, II 51.

295. Lianos \& Motchenkova, supra note 22, at 439.

296. Id.

297. Edelman, supra note 257, at 372 .

298. Search Engine Optimization, BoostABILITY, https://www.boostability.com/seo-services (last visited Oct. 14, 2017). 
comparison shopping site's offering and the search engine's offering for product search queries are interchangeable from the consumer's perspective. In fact, if they were not interchangeable, then it is difficult to see how the argument for potential exclusion would work (i.e., if the search engine services are not interchangeable for the services of the comparison shopping site, then the search engine cannot even theoretically exclude the comparison shopping sites). This reveals that a comparison shopping site provides a service that constitutes a subset of the functions that a general search engine entails. ${ }^{299}$ This does not make the different types of results that a general search engine provides (e.g., those that enable the user to purchase a digital camera and those that provide information on how a digital camera works) separate products/services for the search engine. It also cannot be argued that there is complementarity between the search engine and a comparison shopping site, which was suggested to be a reason for which Windows Media Player (WMP) and Windows OS could be considered as separate products. ${ }^{300}$ Similarly, it cannot be claimed-unlike in Microsoft - that the arguably separate products "clearly differ in terms of functionalities." "301 For a generalist search engine, showing results that display items to purchase in response to a product search query is not a complementary function; it is part of the essential function of the search engine since without these results, the search engine will have omitted a category of relevant results for that query. ${ }^{302}$ In Microsoft it was held by the GC that there was nothing preventing Microsoft from distributing WMP in the same way as it had distributed its previous player, which had been included on the Windows installation $C D$ and had to be installed by the users if they wished to use it. ${ }^{303}$ This is significantly different from the factual situation in Google Search and demonstrates that Google Shopping Commercial Unit cannot be deemed to be a separate product/service from Google's search engine; there is no other means available to Google to provide shopping results to a user who has a product search query on Google Search other than to display these as part of the general result pages. The display of shopping results is simply a functionality feature of the search engine for a certain type of query (i.e., product search) and forms part of the general results of Google Search. This is supported by the Commission's remark in the Guidance that "[t]wo products are distinct if, in the absence of tying or bundling, a substantial number of customers would purchase or would have purchased the tying product without also buying the tied product from the same supplier ...."304 In the context of Google Search, the Commission would have to prove that a substantial number of users who choose to use Google

299. See FTC Google Statement, supra note 175, at 1 (noting that vertical search engines present consumers with an alternative to Google for specific categories of searches); see also German Monopolies Comm'n, supra note 107, at 57 (finding that vertical search services compete with horizontal search services; German Monopolies Comm'n).

300. Case T-201/04, Microsoft Corp v. Comm’n, 2007 E.C.R. II-3601, II 922.

301. Id. I[ 926.

302. Nick Babich, Best Practices for Search Results, UX PLANET (Mar. 3, 2017), https://uxplanet.org/ best-practices-for-search-results-1bbed9d7a311.

303. Microsoft, 2007 E.C.R. II-3601 II 936.

304. Commission Guidance, supra note 31, II 51. 
Search to conduct, for example, product searches would prefer the search engine without the shopping results over a search engine with the shopping results. Further, it would have to be proven that, even though these users have chosen to conduct a product search on Google, they would rather obtain the relevant shopping results from another supplier. This would not only ignore the users' preference demonstrated by choosing Google Search, amongst other options, on which to conduct their search in the first place, but is factually unlikely to be correct, as demonstrated by the practices of the other search engines which display shopping results similar to Google Search in response to product searches. ${ }^{305}$ Similarly, in Google Search not only the alleged tied product, but also the alleged tying product are offered to users for free; ${ }^{306}$ it is highly unlikely that a user would prefer a less functional service over a more functional service when she does not pay for either version. ${ }^{307}$ In fact, this appears to have been even the case in Microsoft since the absence of demand for the version of the Windows OS without WMP - as imposed on Microsoft by the Commission as the remedy—raises serious doubts about the finding in Microsoft that there were two separate products (or that when given the choice, consumers prefer to obtain the tying product without also obtaining the tied product from the same supplier). ${ }^{308}$

The statement in the Commission's Guidance concerning the "presence on the market of undertakings specialised in the manufacture or sale of the tied product without the tying product" cannot be used to construct an argument that general search and specialist search results are two distinct products either. ${ }^{309}$ This is because such a focus on the supply side as opposed to the demand side in Google Search is not desirable or justified for several reasons. ${ }^{310}$ First, unlike in the case of consumables (as was the case in Hilti, to which the Commission refers in support of its statement in the Guidance) and aftermarkets, there is no discernible dependency between the tied product (comparison shopping services) and the tying product (the search engine) in Google Search. ${ }^{311}$ Second, if one were to decide that the Google Shopping Commercial Unit is a separate product from general search, then there would potentially be an infinite number of separate products on the basis of the infinite number of searches one can envisage on Google Search, which would lead to Google's liability for tying

\footnotetext{
305. See FTC Google Statement, supra note 175, at 2 (stating that other search engines have similar functions).

306. Mary Weinstein, The 10 Best Shopping Engines, SEARCH EngINE Watch (June 26, 2014), https://searchenginewatch.com/sew/study/2097413/shopping-engines.

307. Id.

308. See Christian Ahlborn \& David S. Evans, The Microsoft Judgment and Its Implications for Competition Policy Towards Dominant Firms in Europe, 75 ANTITRUST L. J. 887, 922 (2009) (remarking that between the date of the Windows OS being made available and the date of the oral hearing in Microsoft no Original Equipment Manufacturer (OEM) in the world chose to install it. Retailers bought 1,787 copies of the naked Windows OS, which constituted less than $0.005 \%$ of retail sales in Europe).

309. See Commission Guidance, supra note 31, đI 51 (referencing Case T-30/89, Hilti v. Comm'n, 1991 E.C.R. II-1439, I[ 67).

310. Ratko Vidakovic, Beyond Adwords: Demand Side Platforms Explained, MARKETING LAND (May 28, 2013, 9:05 AM), http://marketingland.com/beyond-adwords-an-intro-to-demand-side-platforms-44139.

311. Edelman, supra note 257.
} 
whenever Google displays results relating to these searches grouped together and it happens to be the case that there are specialist websites which only respond to searches of the same type. This would impose a serious-and unjustifiable - constraint on Google's ability to improve its own algorithm and design its own pages. ${ }^{312}$ It would also open the floodgates to claims of alleged tying on the basis of the mere fact that Google Search can respond to more search queries - arguably an indication of being a superior service - than some other sites with more limited scope. ${ }^{313}$ Third, if the objective of the EU competition rules is ultimately the enhancement of the welfare of consumers, then the criterion in deciding whether there is separate consumer demand for a given product is more appropriately based on consumer demand (rather than supply) and whether a substantial number of consumers would purchase the tying product without the tied product from the same supplier in the absence of a tie. ${ }^{314}$

\section{Lack of Customer Choice to Obtain the Tying Product Without the Tied Product}

Regarding the condition that the undertaking does not give customers a choice to obtain the two products separately, it would have to be proven that the tying product (i.e., Google Search) is not available without the tied product (i.e., the Google Shopping Commercial Unit). It has been argued that Google imposes a tie because " $[\mathrm{u}]$ sers can only obtain Google's search results together with whatever additional links Google elects to present. There is no way for users to avoid links to Google's additional services while still receiving Google search ...."315 This is arguably despite the fact that users are not forced to click on these links for additional services and could simply ignore them. ${ }^{316}$ The argument is that "prominence" matters; when users are presented with links to Google's services, users proceed accordingly. ${ }^{317}$ However, these arguments are open to challenge. First, users receive Google Search results without any grouped results being displayed in response to searches for which Google does not have relevant "specialist" results. ${ }^{318}$ Second, even for every product search, Google Search does not display the Google Shopping Commercial Unit since this display only takes place on the basis of the algorithm's relevance criteria:

312. Barry Schwartz, How Google Uses Machine Learning in its Search Algorithms, SEARCH ENGINE LAND (Oct. 18, 2016, 10:40 AM), http://searchengineland.com/google-uses-machine-learning-searchalgorithms-261158.

313. Adam Lella, comScore Releases February 2016 U.S. Desktop Search Engine Rankings, COMScORE (Mar. 16, 2016), https://www.comscore.com/Insights/Rankings/comScore-Releases-February-2016-USDesktop-Search-Engine-Rankings.

314. Romain Henro, Tying Under European Competition Rules, INSTITUT D’ÉTUDES POLITIQUES DE TouLouse 1, at 39 (2012), https://memoires.sciencespo-toulouse.fr/uploads/memoires/2012/DECR/memoire_ HENRIO-ROMAIN.pdf.

315. Edelman, supra note 257, at 371 .

316. Id.

317. Id. at 371-72.

318. See, e.g., Annex 1 (displaying the results of a search conducted on Google (UK) for the search term "world university rankings"-without using quotation marks-which did not lead to the display of any sponsored or advertisement listings or specialist Google features. The search was conducted on Nov. 20, 2015). 
there have to be relevant Google Shopping results that can be displayed in response to the user's particular query. ${ }^{319}$ Therefore, the suggestion that Google Search is not available without Google's added features is factually incorrect; for given queries, generic results are provided without any added features such as Google Shopping results, etc. ${ }^{320}$ Consequently, to argue that there is a tie, one would have to base that argument on specific types of queries. ${ }^{321}$ For example, one would have to argue that for shopping queries, the search engine is never available without the Google Shopping Commercial Unit. However, the implication of this is that one would have to establish the search engine's dominance per query (or per query type) and also demonstrate that, for example, there is never a product search that would not return some affiliated Google feature such as the Shopping Commercial Unit (which, as mentioned above, is factually incorrect). Not only would it be a challenge to prove that a "relevant market" exists for specific search queries or for specific types of search queries, if this was to be done, it would also have to be established that Google is dominant for that particular type of search query since if there is no dominance in the tying product, there cannot be abusive tying. ${ }^{322}$ Yet, it is clear that users have many options for finding answers to such queries and an assessment of dominance would have to include every site and app (and possibly the offline means) to which users could turn for answers. ${ }^{323}$ This factual difference also distinguishes Google Search from Microsoft since in the latter, once a consumer purchased a PC with the Windows OS, the PC was delivered with WMP preinstalled by the Original Equipment Manufacturer (OEM) with no possibility to uninstall; ${ }^{324}$ there was categorically no technical availability of using the

319. See, e.g., Joshua D. Wright, Defining and Measuring Search Bias: Some Preliminary Evidence, 12 14 (2011) GEO. MASON L. \& ECON. https://www.law.gmu.edu/assets/files/publications/working_papers/ 1214DefiningandMeasuringSearchBias.pdf (discussing in an empirical study the discovery on the basis of a random sample of 1,000 search queries which found that Google does not refer to its own content in over $90 \%$ of queries in the first position of results and refers to its own content in the first position when other search engines do not in only $6.7 \%$ of queries); see also Annex 2 (showing a product search-spa vouchers-for which the search engine does not display the Shopping Commercial Unit even though one can find relevant shopping results under the separate Google Shopping feature. The search was conducted on Nov. 20, 2015).

320. About Search Features, GoOGLE, https://developers.google.com/search/docs/guides/search-features (last visited Oct. 14, 2017).

321. Google Shopping, SEARCH ENGINE LAND, http://searchengineland.com/library/google/googleproduct-search (last visited Oct. 14, 2017).

322. Guidance on the Commission's enforcement priorities in applying Article 82 of the EC Treaty to abusive exclusionary conduct by dominant undertakings, 2009 O.J. (C 45/02).

323. A user study found Amazon to be the first stop for online shoppers and that a third of all online purchases were influenced or prepared by product search on Amazon (Germany) as opposed to under 15\% on Google (Germany). ECC Koeln Online Experts, Amazon ist Deutschlands größter Showroom-ECC Köln und hybris veröffentlichen neue Cross-Channel-Studie (May 5, 2015), http://www.ecckoeln.de/ News/Amazon-istDeutschlands-gr\%C3\%B6\%C3\%9Fter-Showroom-\%E2\%80\%93-ECC-K\%C3\%B6ln-und-hybris-

ver\%C3\%B6ffentlichen-neue-Cross-Channel-Studie. See, e.g., Jason Del Rey, 55 Percent of Online Shoppers Start Their Product Searches on Amazon, ReCode (Sept. 27, 2016, 3:06 PM), https://www.recode.net/ 2016/9/27/13078526/amazon-online-shopping-product-search-engine (finding that fifty-five percent of people in the U.S. begin their online shopping on Amazon while only twenty-eight percent start on Google).

324. 2007 J.O. (L32/23). 
Windows OS (the tying product) without the WMP (the tied product) on these PCs sold through the OEMs. ${ }^{325}$

The suggestion that prominence of links suggests a tie also ignores the possible argument that users who click on Google's links may do so not (just) because they are prominent but because they believe that Google Search provides high quality results in response to searches and therefore, their clicks represent their preferences. If the users indeed prefer Google's links, then they cannot be deemed to be "coerced" into using Google's added features. ${ }^{326}$ Furthermore, a Google Search results page never consists of an otherwise blank page with Google's own affiliated feature links. ${ }^{327}$ These links — some of which are simply advertisements such as those within the Google Shopping Commercial Unit - are accompanied by a list of organic results. ${ }^{328}$ Features of rivals can appear in the organic results, and in any case, the mere existence of the organic results - for which there is no payment or Google's "favouring" of its own services - always provides alternatives and additional choice to users. The equivalent factual scenario can be thought to be similar to PCs with Windows OS that arrive preinstalled with WMP also listing other media players available on the market on the desktop without, however, having any of these preinstalled on the PC. Interestingly, this was exactly the commitment that was offered and accepted in Microsoft (Tying), which concerned Microsoft's alleged abuse of tying Internet Explorer to Windows OS. ${ }^{329}$ To eliminate the Commission's competition concerns, Microsoft committed to provide a "browser choice screen" which would list other browsers available for users to download (as opposed to preinstalling these other browsers whenever Internet Explorer was preinstalled on a PC). ${ }^{330}$ Given that any search on Google Search by its nature provides a list of relevant (organic) alternatives to whichever special feature of Google the results may also display, it is difficult to argue that there is a "tie" that can foreclose the market for that special feature. It is also difficult to suggest that the consumers are deprived of the choice to obtain the tying product without the tied product. ${ }^{331}$

325. See Commission Decision 2007/53 of May 19, 2004, 50 O.J. (C 2004) 23 If 829, http://ec.europa.eu/competition/antitrust/cases/dec_docs/37792/37792_4177_1.pdf (discussing the technical impossibility of uninstalling WMP and how the great majority (75\%) of Microsoft's sales of client PC operating systems were made through OEMs); see also Case T-201/04, Microsoft Corp. v. Comm'n, 2007 E.C.R. II-3601 9ศ 904, 946 (explaining how, under Microsoft's licensing system, OEMs had to license the Windows OS with WMP pre-installed).

326. See Microsoft, 2007 E.C.R. II-3601 865 (explaining why "coercion" is relevant in the context of abusive tying since the GC has characterized the lack of choice to obtain the tying product without the tied product as "coercion" in Microsoft).

327. How Search Works, GoOGLE, https://www.google.com/search/howsearchworks/ (last visited Oct. 14, 2017).

328. Nicholas Economides, Microsoft's Mistakes Show Why Google Needs to Settle with the EU, MASHABLE (June 29, 2017), http://mashable.com/2017/06/29/google-should-settle-eu/\#K_25pWwMqPqa.

329. United States v. Microsoft Corp., 253 F.3d 34 (D.C. Cir. 2001).

330. Case C-3/39.530, Comm'n v. Microsoft Corp., 2009, http://ec.europa.eu/competition/antitrust/cases/ dec_docs/39530/39530_2671_3.pdf .

331. See Lianos \& Motchenkova, supra note 22, at 438 (suggesting this is a condition of tying to be found abusive). 


\section{Foreclosure of Competition}

The existence or lack of a tie in Google Search is closely related to the final condition of tying, namely that tying forecloses competition. ${ }^{332}$ Conduct will be abusive only if it is capable of restricting competition. ${ }^{333}$ In Microsoft, the Commission held that there were good reasons not to assume that tying in itself constitutes conduct, which by its very nature is liable to foreclose competition. ${ }^{334}$ This is because the Commission decided that unlike in traditional tying cases where the foreclosure effect for competitors was demonstrated by the bundling of the two products, in Microsoft the users could, and to an extent did, obtain third party media players through the Internet, sometimes for free. ${ }^{335}$ According to the Commission, this fact necessitated an analysis of the effects of tying on competition. ${ }^{336}$ In Google Search the fact that both of the allegedly separate products are free to use, that product design changes of the kind at issue are not "by its very nature" liable to foreclose competition and that there is no issue of turning Google Commercial Shopping Unit into "the platform of choice for complementary content and applications which in turn risks foreclosing competition in the market for the tied product" 337 suggest that the Commission should argumentum a fortiori conduct an effects-based assessment of foreclosure and not find foreclosure on the basis of simple tying (assuming that a tie could be established). ${ }^{338}$

In Microsoft, the foreclosure effect was linked to Microsoft's unparalleled advantage of distribution of its product which ensured ubiquity of WMP on client PCs which provided a disincentive for users to utilize third-party media players and for OEMs to preinstall such players on PCs. ${ }^{339}$ Further, other methods such as downloading, or bundling it with other software, were found to be inefficient and ineffective means of distributing software in comparison to preinstalling WMP on Windows. ${ }^{340}$ In this context, a significant issue in Microsoft was network effects: installing WMP on Windows - holding a market share of ninety percent on the PC operating systems market-led to the ubiquity of WMP and that in turn meant that content providers and software developers were more likely to use the WMP format to the detriment of the competitors and their technologies, which in turn led to increased popularity of WMP for users. ${ }^{341}$ This differs significantly from the factual situation in Google Search. Other than the fact that there are generalist search engine competitors of Google, Google's

332. Mark Thoma, iTunes, iPods, and Product Tying Arrangements, ECONOMISTS VIEW (Apr. 27, 2006, 12:24 AM), http://economistsview.typepad.com/economistsview/2006/04/itunes_ipods_an.html.

333. Case T-201/04, Microsoft Corp v. Comm'n, 2007 E.C.R. II-3601 If 867.

334. Commission Decision 2007/53, supra note 290.

335. Id. II 841.

336. $I d$.

337. See id. II 842 (discussing the foreclosure concern being related to WMP the platform of choice).

338. Lianos \& Motchenkova, supra note 22, at 439 (suggesting that once there is tying of two distinct products and the undertaking is dominant, a simple likelihood of anticompetitive effects may be sufficient evidence for the application of Article 102TFEU).

339. Case T-201/04, Microsoft Corp v. Comm'n, 2007 E.C.R. II-3601, I[ 1054.

340. Commission Decision 2007/53, supra note 290, IIII 872-876.

341. Id. IIII 880, 883-944; see also, Microsoft, 2007 E.C.R. II-3601, II 1061. 
alleged tying cannot prevent the competitors (i.e., comparison shopping sites) from reaching users by simply displaying the Google Shopping Commercial Unit to users. ${ }^{342}$ The competitors and their services are available for users to access them directly and these competitors have many more means of reaching users than receiving free traffic from Google Search. ${ }^{343}$ Moreover, the competitors continue to receive free traffic from Google Search when their websites are relevant to a user's query on the basis of Google's algorithm. ${ }^{344}$

Another important factor in Microsoft regarding foreclosure was that Microsoft's tying interfered with the normal competitive process which would benefit users in terms of quicker cycles of innovation; Microsoft reduced "the talent and capital invested in innovation of media players, not least its own." 345 Microsoft's conduct affected "a market which could be a hotbed for new and exciting products springing forth in a climate of undistorted competition." 346 In contrast, commentators have argued that comparison shopping sites do not provide any such innovative services. ${ }^{347}$ In fact, it is even debatable that the Commission's comments regarding WMP as a "hotbed for new and exciting products" were accurate given the technological developments of the last decade, which should serve as a warning sign that regulators are unlikely to be able to predict how competition might develop in dynamic industries. ${ }^{348}$ Furthermore, unlike in Microsoft where Microsoft's conduct prevented OEMs from choosing one of WMP's competitors as the only media player to install on new PCs, ${ }^{349}$ in Google Search not only are users free to exclusively use competitor comparison shopping sites whilst still using Google Search, Google's general result pages themselves, provide users with alternative shopping choices in the organic results displaying links to Amazon, eBay, retailers, etc. ${ }^{350}$ The existence of alternatives like Amazon, eBay, and the like, also suggests that there is no issue of reducing innovation on the relevant markets. Considering factors such as downloading other media players not being a realistic alternative to using the media player that comes pre-installed on the PC, ${ }^{351}$ in Google Search not only are users free to exclusively use competitor comparison shopping sites whilst still using Google Search, Google's general

342. Berin Szoka \& Adam Marcus, The Next Digital Decade: Essays on the Future of the INTERNET 3, 9-29 (2010), http://www.nyu.edu/projects/nissenbaum/papers/The-Next-Digital-Decade-Essayson-the-Future-of-the-Internet.pdf.

343. Geoffery Manne, The EU's Android Antitrust Complaints are Contrived, WIRED MAG. (Nov. 11, 2016, 7:00 AM), https://www.wired.com/2016/11/eus-android-antitrust-complaints-contrived/.

344. What is SEO/Search Engine Optimization?, SEARCH ENGINE LAND, http://searchengineland.com/ guide/what-is-seo (last visited Oct. 14, 2017).

345. Commission Decision 2007/53, supra note 290, IIII 980-81.

346. Id. II 981 .

347. See, e.g., Grimmelmann, supra note 274, at 450 (commenting on the business models and value of comparison shopping sites).

348. David Jon Phillips, Why Antitrust Regulators Underestimate Competition, CHI. BooTH R. (Mar. 1, 2016), http://review.chicagobooth.edu/magazine/spring-2016/why-antitrust-regulators-underestimatecompetition.

349. Case T-201/04, Microsoft Corp v. Comm'n, 2007 E.C.R. II-3601, I[ 1046.

350. Charity Stebbins, The "Best" Way to Outrank Amazon, Conductor SPOTLight (May 14, 2015), https://www.conductor.com/blog/2015/05/the-best-way-to-outrank-amazon/.

351. Microsoft, 2007 E.C.R. II-3601, II 1050. 
result pages themselves provide users with alternative shopping choices in the organic results displaying links to Amazon, eBay, retailers, etc. The existence of alternatives like Amazon, eBay, etc. also suggests that there is no issue of reducing innovation on the relevant markets. Factors such as downloading other media players not being a realistic alternative to using the media player that comes pre-installed on the $\mathrm{PC}^{352}$ or end-user inertia ${ }^{353}$ or insecurity of unsophisticated users concerning downloading another media player ${ }^{354}$ which were relevant for assessing foreclosure in Microsoft are unlikely to exist in Google Search. An Internet user who is sophisticated enough to purchase a product online and who is potentially going to use a comparison shopping site in the process will presumably be aware of the existence of websites other than Google Search. Unlike a given PC being operated by only a single operating system, there are numerous shopping websites on the Internet that an average Internet user can visit directly. ${ }^{355}$ Similarly, such a consumer is more than likely to have mobile Internet which provides additional alternatives for shopping in the form of apps, as well as for other "specialist" queries such as travel and navigation. No matter what the market share of Google is on search - assuming that search is a relevant market, which is doubtful - Google Search is not the only way to search, let alone access the Internet (unlike the Windows OS being the only way to operate a PC on which it is the preinstalled operating system). ${ }^{356}$

\section{Objective Justification}

As with all other abuses, objective justification is applicable to rebut a finding of abusive tying as well. In this context, it is useful to consider the potential remedy, consumer harm and objective justification together. This is because if a finding of abusive tying is made, the remedy would normally be the requirement to "untie" the bundled products. ${ }^{357}$ In Google Search, this is likely to be along the lines of ordering Google not to develop and/or display any specialist features such as the Google Shopping Commercial Unit on the general result pages since otherwise it is difficult to envisage how the alleged tie may be ended. However, such a remedy has the potential to harm consumers by preventing Google from innovating because it would limit the options available

\footnotetext{
352. Id. I[ 1050.

353. Commission Decision 2007/53, supra note 290, II 870.

354. Id.

355. See Mike Cassidy, Survey: Amazon is Burying the Competition in Search, BloomReACH Blog (Oct. 6, 2015), http://bloomreach.com/2015/10/survey-amazon-is-burying-the-competiton-in-search/ (exemplifying a specific shopping website); Bill Siwicki, Money20/20 Report: New GPSShopper/Comscore Survey Reveals Mobile Shopping and Mobile Payments Insights, GPSSHOPPER BLOG (Oct. 26, 2015), http://blog.gpshopper.com/market-research/money20/20-report-new-gpshopper/comscore-survey-revealsmobile-shopping-and-mobile-payments-insights; Brian Solomon, Shopping Apps Are Now The Fastest Growing Thing in Mobile, FORBES (Jan. 6, 2015), http://www.forbes.com/sites/briansolomon/2015/01/06/shopping-appsare-now-the-fastest-growing-thing-in-mobile/.

356. Vangie Beal, The History of Windows Operating Systems, WebopediA (Mar. 24, 2016), http://www.webopedia.com/DidYouKnow/Hardware_Software/history_of_microsoft_windows_operating_sys tem.html.

357. Luca, supra note 280 , at 16-35.
} 
to Google for displaying search results and be tantamount to requiring Google to give up on a product improvement. ${ }^{358}$ If this is not taken into account in the context of establishing abuse, for example, while establishing whether there is anticompetitive foreclosure, then it should at least be considered in the assessment of an objective justification in Google Search. In its investigation into similar practices, the FTC has, for example, found that Google's design changes were a "quality improvement" and Google likely benefited consumers by prominently displaying its specialist content on its search result pages. ${ }^{359}$ Thus, even if despite all the issues discussed above concerning tying, a case of abusive tying could be made in Google Search, the consumer benefits from the tie would need to be assessed to establish whether they can outweigh the anticompetitive effects in question. On the basis of available facts, it is most likely that such benefits would outweigh any effects of the conduct on competitors.

\section{Normative ASSESSMENT OF THE ALLEGED AbUSE}

The discussion of the three main existing types of potential abuse in Section II has demonstrated the formidable difficulties with fitting Google Search into the existing frameworks for these abuses. Without seriously disrupting the existing parameters of these abuses as established by the current jurisprudence under Article 102TFEU (and thereby, potentially breaching the principle of legal certainty), the facts of Google Search cannot be fitted under any of these established categories of abuse. ${ }^{360}$ This is because the facts raise fundamental problems for the case law, such as how there can be a refusal to deal when there is strictly speaking no refusal; how there can be discrimination between trading parties when there is no trading-party relationship between the dominant undertaking and the relevant parties; how there can be a tie when there are not separate products/services and when the alleged tying product is available without the alleged tied product under certain circumstances, etc. ${ }^{361}$ Consequently, a normative assessment of whether the facts of Google Search should be found abusive gains fundamental importance. This Section will conduct such a normative assessment under one principled conceptualisation of "abuse."

For a normative assessment, one might think that a good starting point would be the objectives of Article 102TFEU, since these could shape the ideal application of the provision to a novel set of facts. ${ }^{362}$ Unfortunately, the objectives of Article 102TFEU are not settled and are subject to debate. ${ }^{363}$ Faced with the criticism that its approach to unilateral conduct under Article 102TFEU

358. Id.

359. FTC Google Statement, supra note 175, at 2.

360. See Press Release, supra note 1 (describing the facts of the antitrust investigation).

361. Id.

362. Nazzini, supra note 22.

363. See AKMAN, supra note 27, ch. 3, 4 (discussing welfare and fairness as two possible objectives of Article 102TFEU). 
is formalistic, not sufficiently based on economic effects and serves to protect competitors rather than competition, ${ }^{364}$ the Commission started a review of its approach in early 2000s, which culminated in the Guidance Paper on Enforcement Priorities. According to the Guidance, in applying Article 102TFEU to exclusionary conduct by dominant undertakings, the Commission will focus on those types of conduct that are most harmful to consumers. ${ }^{365}$ The Commission will, therefore, direct its enforcement ensuring that markets function properly and that consumers benefit from the efficiency and productivity which results from effective competition between undertakings. ${ }^{366}$ Further, the Commission is mindful that what really matters is protecting an effective competitive process and not simply protecting competitors, which may mean that competitors who deliver less to consumers in terms of price, choice, quality and innovation will leave the market. ${ }^{367}$ Commentators have remarked that with the adoption of the Guidance, consumer welfare and efficiency are now at the heart of Article 102TFEU. ${ }^{368}$

Whether or not consumer welfare and efficiency have become the guiding principles for the Commission's enforcement, the EU Courts have not been sufficiently consistent in their judgments concerning the objectives and application of Article 102TFEU in individual cases to establish the precise objectives of the provision. ${ }^{369}$ Some commentators note that at least recently, the EU Courts have revealed a consistent tendency to stress competition, efficiency and consumer welfare as the key objectives of Article 102TFEU. ${ }^{370}$ Other commentators disagree, particularly on the basis of the recent judgment of the GC in Intel which they argue to reject an effects-based approach to Article 102TFEU serving the aim of enhancing consumer welfare and efficiency. ${ }^{371}$

364. But see Eleanor M. Fox, Monopolization and Dominance in the United States and the European Community: Efficiency, Opportunity, and Fairness, 61 Notre DAME L. ReV. 981, 1004 (1986); Per Jebsen \& Robert Stevens, Assumptions, Goals and Dominant Undertakings: The Regulation of Competition Under Article 86 of the European Union, 64 AnTITRUST L. J. 443 (1996); Brian Sher, The Last of Steam-Powered Trains: Modernising Article 82, 25 EuR. COMPETITION L.R. 243 (2004); John Kallaugher \& Brian Sher, Rebates Revisited: Anti-Competitive Effects and Exclusionary Abuse under Article 82, 25 EUR. COMPETITION L.R. 263 (2004); Denis Waelbroeck, Michelin II: A Per Se Rule Against Rebates by Dominant Companies?, J. COMPETITION L. \& ECON. 149 (2005).

365. Commission Guidance, supra note 31 , II 5.

366. Id.

367. Id. II 6.

368. See O'DonOGHUE \& PADILla, supra note 55, at 5 (arguing elsewhere that the Guidance fails to fully and properly adopt a consumer welfare standard in terms of setting out the Commission's enforcement priorities); AKMAN, supra note 27, at 629.

369. See also AKMAN, supra note 27, at 129-43 (assessing the case law).

370. Richard Whish \& DAVID BAILEY, CoMpetition L. 207 (8th ed. 2015).

371. See, e.g., Nicolas Petit, Intel, Leveraging Rebates and the Goals of Article 102TFEU, 11 EUR. Competition J. 26, 52 (2015); Wouter P.J. Wils, The Judgment of the EU General Court in Intel and the SoCalled "More Economic Approach" to Abuse of Dominance, 37 World COMPETITION: L. \& ECON. REV. 405, 418, 437 (2014); James S. Venit, Case T-286/09 Intel v. Commission-The Judgment of the General Court: All Steps Backward and No Steps Forward, 10 EuR. COMPETITION J. 203, 206 (2014); Patrick Rey \& James S. Venit, An Effects-Based Approach to Article 102: A Response to Wouter Wils, 38 WORLD COMPETITION: L. \& ECON. REv. 3, 18 (2015); Damien Geradin, Loyalty Rebates after Intel: Time for the European Court of Justice to Overrule Hoffmann La Roche, 11 J. COMPETITION L. \& ECON. 579, 581-82 (2015); Paul Nihoul, The Ruling of the General Court in Intel: Towards the End of an Effect-Based Approach in European Competition Law?, 5 J. Eur. Competition L. \& Pract. 521, 530 (2014); see Luc Peeperkorn, Conditional Pricing: Why the General 
Given the controversy surrounding the rationale underpinning Article 102TFEU which has not been resolved by the EU Courts, ${ }^{372}$ the normative discussion of whether a given set of facts should breach Article 102TFEU has to be based on a conceptualization of abuse developed elsewhere. The current Author developed such a concept of abuse elsewhere, which will underlie the discussion in this Section. ${ }^{373}$ Under this conceptualization of abuse, there are three cumulatively necessary and sufficient conditions for a given conduct to be abusive. ${ }^{374}$ These are exploitation, exclusion and a lack of an increase in efficiency. ${ }^{375}$ The rest of this Section will elaborate on this conceptualisation of abuse and its requirements (A); apply this framework to the facts of Google Search (B); and, discuss the issue of the remedy in case of a finding of infringement in Google Search since the potential remedy has significant implications for establishing whether the conduct in question should constitute abuse in the first place (C).

\section{A. The Concept of Abuse and its Requirements}

The first requirement of the particular conceptualization of abuse being used for the normative assessment is "exploitation." This requirement results from a reading of Article 102TFEU itself which, at face value and on the basis of historical analysis, ${ }^{376}$ is concerned only with the exploitation of the customers/suppliers of the dominant undertaking. ${ }^{377}$ In fact, it was never questioned whether Article 102TFEU covered exploitative abuse; the only debate was whether it covered exclusionary abuse at all. ${ }^{378}$ Although most of the existing case law on Article 102TFEU concerns exclusionary conduct, ${ }^{379}$ the main objection to an undertaking with market power is indeed its ability to exploit its position in a way that would not be possible for an undertaking on a competitive market. ${ }^{380}$ It is noteworthy that the requirement of exploitation results from the provision of Article 102TFEU itself and therefore remains necessary for that provision to be infringed irrespective of what the objectives of the provision may be stipulated to be by the Commission and the EU

\footnotetext{
Court is Wrong in Intel (and What the Court of Justice can do to Rebalance the Assessment of Rebates), $\mathrm{N}^{\circ} 1$ 2015 ConCURRENCES REv. 43, $43-44$ (2015) (showing commentators suggestions that Case T-286/09, Intel Corp v. Comm'n, ECLI:EU:T:2014:547, 2014 (repudiating an outcome-orientated, effects-based approach to Article 102TFEU whilst disagreeing on whether this is a good or bad development of the case law).

372. Petit, supra note 371, at 29-30.

373. See AKMAN, supra note 27 (focusing on chapter 8).

374. Id. at 300 .

375. Id.

376. See generally Akman, supra note 53 (providing historical analysis of the EU competition rules on the basis of the travaux préparatoires relating to the negotiations of the Treaty).

377. Nazzini, supra note 22.

378. See Case 6/72, Europemballage Corporation and Continental Can Company Inc v. Comm'n, 1973 E.C.R. 215, If 26 (ruling Continental Can that Article 102TFEU is not only aimed at practices which may cause damage to consumers directly, but also at those which are detrimental to them through their impact on an effective competition structure).

379. See generally Akman, supra note 170 (analysing the case law surrounding Article 102TFEU).

380. JONES \& SUFRIN, supra note 124 , at 367.
} 
Courts. ${ }^{381}$ Having said that, within an effects-based and consumer-welfareorientated approach, exploitation can and should be used as the test of harmful effects of conduct that would qualify the conduct as abusive. ${ }^{382}$ Indeed, another reason why exploitation should be deemed necessary to establish abuse is that it is exploitation that shows harm to someone other than the competitors of a dominant undertaking in the context of Article 102TFEU, particularly given the possibility that exclusionary effects can be established on the basis of harm to competitors alone under the existing jurisprudence. ${ }^{383}$ In this context, exploitation can be defined as the receiving of advantages by the dominant undertaking to the disadvantage of its trading partners that would not be possible but for the undertaking's dominance. ${ }^{384}$

The second condition of abuse is that the exploitative conduct should also harm or restrict competition which can be phrased as it being "exclusionary." The requirement of exclusion is derived not from Article 102TFEU itself, ${ }^{385}$ but from the fact that the rule is found under Rules on Competition in the Treaty and the then-Article 3(f)EEC, which stipulated that the activities of the Community included the "institution of a system ensuring that competition in the common market is not distorted." 386 This provision is now found in Protocol 27 which states that the internal market "includes a system ensuring that competition is not distorted." 387 The requirement in Protocol 27 that competition is not distorted can be used to incorporate the condition of harm to competition (i.e., exclusion of competition) to interpret the concept of abuse in Article 102TFEU as only covering exploitation that results from or is in some other way related to harm to competition. ${ }^{388}$ Such exclusion and consequent harm to competition can comprise horizontal or vertical foreclosure (i.e., the exclusion of direct competitors or of customers of the undertaking). ${ }^{389}$ This should relate to the exclusion of undertakings at least as efficient as the dominant undertaking,

381. Akman, supra note 170 , at 610 .

382. AKMAN, supra note 27 , at 302.

383. Id.

384. Id. at 303 .

385. This Author respectfully disagrees with the interpretation that Article 102(b)TFEU prohibits exclusionary conduct as argued by some commentators. See e.g., O’DonOGHUE \& PADILlA, supra note 55, at 240. Article 102(b)TFEU prohibits "limiting production, markets or technical development to the prejudice of consumers." As such, it does not stipulate anything about exclusion or foreclosure; production, markets or technical development can be limited to the prejudice of consumers (i.e., exploit consumers) by the unilateral acts of a dominant undertaking without any exclusion or foreclosure of competition or competitors. Notably, while establishing that Article 102TFEU also covers exclusionary conduct, the CoJ used the examples in paragraphs (c) and (d) of Article 102TFEU and not (b). Case 6/72, Europemballage Corp. \& Continental Can Co. v. Comm'n, 1973 E.C.R. 215, 9 26. This is not to say that the CoJ's overall interpretation in Continental Can was correct; this Author has argued elsewhere that this interpretation was incorrect and confused two things: the issue of whether Article 102TFEU applies to mere exclusion and the issue of whether harm to competition (in the shape of exclusion) is necessary for the exploitative practices listed in Article 102TFEU to be abusive. AKMAN, supra note 27, at 309.

386. AKMAN, supra note 27, at 307-08. With the Treaty of Maastricht, Article 3(f)EEC was amended by deleting the words "the institution of" and became Article $3(\mathrm{~g}) \mathrm{EC}$ (and later became Article $3(1)(\mathrm{g}) \mathrm{EC}$ with the entry into force of the Treaty of Amsterdam in 1999).

387. Protocol (No 27), 2008 O.J. (L 115) (EU).

388. AKMAN, supra note 27, at 309-10.

389. Id. at 312-13. 
unless the Commission/claimant can prove that the exclusion of not-yet-asefficient competitors can harm competition in a given case. ${ }^{390}$

The third requirement for conduct to be abusive is that it does not lead to an increase in efficiency; unilateral conduct that leads to a (non-trivial) increase in efficiency and thus has an efficiency explanation should not be found abusive. ${ }^{391}$ The assessment of efficiency should be made comparing the situation with the allegedly abusive conduct in place and the situation without the dominant undertaking's conduct in place, taking into account the alternative conduct that the undertaking would possibly adopt if the investigated conduct is found abusive. ${ }^{392}$ The requirement of efficiency not only enables an approach conforming to the original intent behind Article 102TFEU, it also ensures that conduct that is otherwise normal and legitimate business practice is not prohibited. ${ }^{393}$ A consequence of this requirement is that if a certain practice is available to and commonly practiced by non-dominant undertakings as well, then it should mean that such conduct is not abusive; abusive practices are those that are only possible as a result of the position of dominance that the undertaking enjoys. ${ }^{394}$

\section{B. Application of the Framework to the Facts in Google Search}

\section{Exploitation}

To establish whether there is exploitation in Google Search, one must focus on the effects of the alleged conduct on the trading partners of Google. As mentioned above, ${ }^{395}$ there is some debate as to who the trading partners/customers of Google are. It is clear that advertisers are the trading partners of Google due to being in a contractual relationship with Google ${ }^{396}$ and according to some, they are the only trading partners of Google. ${ }^{397}$ There are also strong arguments for accepting that the potentially infinite number of websites the links to which might appear on the general result pages in response to a search on Google Search cannot be deemed to be the trading partners/customers of Google. ${ }^{398}$ The question whether the users of Google Search are potential trading partners/customers of Google is one that requires further elaboration. However, for the sake of argument and to enable a more

\footnotetext{
390. Id. at 315 .

391. Id. at 316.

392. Id.

393. Id.; see also Akman, supra note 170 (for the original intent as demonstrated by a study of the travaux préparatoires).

394. AKMAN, supra note 27, at 319. This also implies that the "special responsibility" of dominant undertakings is to not distort competition by way of abusing their positions and thus, dominant undertakings do not have a special responsibility over and beyond that of not abusing their positions of dominance.

395. AKMAN, supra note 27.

396. See, e.g., OLG Apr. 4, 2013, 408 HKO 36/13, http://deutschland.taylorwessing.com/documents/get/ 150/court-order-google-weather-inbox-english-unofficial-translation.pdf.

397. Id.

398. AKMAN, supra note 27.
} 
encompassing discussion of exploitation, it will be assumed for present purposes that a case could be made that the users are trading partners/customers of Google

The first question is then whether the advertisers are exploited by Google's alleged practice of its own specialist services. As noted by one commentator, the Commission's investigation appears to be less focused on the potential to increase prices of ad spaces to advertisers than on the failure to actively promote other comparison shopping websites. ${ }^{399}$ This is despite the fact that even if the issue of foreclosure were addressed, there would still be two other issues to deal with, one of which being whether Google would be in a position to increase prices as a result of its conduct. ${ }^{400}$ Given that the service is free to users, the question concerning the ability to increase prices becomes that of whether Google exploits the advertisers by, for example, charging supra-competitive prices for ads as a result of its alleged favouring its own specialist services. Some commentators have suggested that the alleged abuse in Google Search may indeed involve exploitation of advertisers through excessive prices, price discrimination, etc. ${ }^{401}$

In Google Search, an argument of exploiting the advertisers runs into several problems. The first and fundamental point is that advertisements on Google are chosen through an auction; it is the advertisers themselves who bid for the ad space on the basis of their willingness to pay. ${ }^{402}$ Whether or not a given ad is displayed depends on how much a given advertiser is willing to pay for a given search query and the relevance of the ad for that query. ${ }^{403}$ This means that even if a given advertiser's maximum bid for a given search term is lower than the rival's bid, the former advertiser's ad may appear above the latter's due to higher relevance. ${ }^{404}$ Moreover, an advertiser only pays for an ad once a user clicks through the link. ${ }^{405}$ Given this factual context, it is difficult to envisage how Google's alleged prominent display of the Google Shopping Commercial Unit (which comprises ads with images, price information, etc.) can exploit advertisers as a result of disfavouring the results of competing comparison shopping sites. ${ }^{406}$ Furthermore, proving exploitation of advertisers would also require proving that Google is not sufficiently exposed to competition in the sale of ad spaces. ${ }^{407}$ This would necessitate demonstrating that the alternatives available to advertisers such as advertising on other search engines, social

\footnotetext{
399. Renda, supra note 16 , at 35.

400. Id. The second is whether the conduct eliminates competition from all "as efficient" actual and potential competitors. This will be discussed below.

401. See Lianos \& Motchenkova, supra note 22, at 442-43.

402. See generally About Google AdWords, GoOGLE, https://support.google.com/adwords/answer/ 2497976 (last visited Oct. 14, 2017).

403. Google uses Ad Rank to decide which ad to display and in which order in response to a query. This is determined by the bid amount, the components of Quality Score (expected click-through rate, ad relevance and landing page experience), and the expected impact of extensions and other ad formats. See Ad Rank, GoOGLE, https://support.google.com/adwords/answer/1752122 (last visited Oct. 14, 2017).

404. About Google AdWords, supra note 402.

405. Id.

406. Statement 15/4780, supra note 5

407. See generally Renda, supra note 16, at 35 (demonstrating that Google may not be sufficiently exposed).
} 
media, mobile apps or even on offline media do not apply competitive pressure on Google in terms of attracting advertisements. It is also noteworthy that Google's business model itself creates a competitive alternative to the advertisements since the organic results - that are always displayed in response to the same search query that triggers the display of advertisements on the basis of relevance - are not paid for and essentially constitute free promotion for the websites that appear in the organic results. ${ }^{408}$ This also points out that the alleged demotion of comparison shopping sites on the general result pages, even if true, could not in itself lead to the exploitation of advertisers by Google because the space that is saved by any such demotion is taken up by other organic results which provide alternatives for users. Finally, given that exploitation refers to taking advantage of customers in a manner that would not be possible but for the dominance of the undertaking, the fact that other search engines (which would not be dominant even if Google were) adopt similar practices towards displaying specialist ads, text ads, and organic results on their pages ${ }^{409}$ suggests that the conduct is not exploitative. The conduct in question, therefore, does not seem to have an impact on the position of advertisers vis-à-vis Google that could be deemed exploitative.

If the conduct in question were found to have exploitative effects on advertisers, there would still be a question of whether this is the relevant type of exploitation under Article 102TFEU. This is because, as argued elsewhere, the interests of final consumers and (other) customers of the dominant undertaking may not always be aligned. ${ }^{410}$ This distinction becomes particularly important if a policy choice is made, for example, by the Commission to adopt a (properly defined) consumer welfare standard in its enforcement. ${ }^{411}$ Under such a consumer welfare standard, the "exploitation" that ultimately renders conduct abusive should be deemed to be that of the final consumer. ${ }^{412}$ It is this question of whether final consumers (i.e., users) are exploited by Google's alleged conduct in Google Search that this Article now turns to.

The second possible type of exploitation is that of users of Google Search, assuming that a trading relationship could be said to exist between them and Google. The relevant question is whether the alleged display of Google Shopping results more prominently than the results of comparison shopping sites exploits users. This is a difficult argument to sustain because both the generalist

\footnotetext{
408. See AdWords: SEO vs. PPC?, GoOGLE, https://adwords.google.com/home/resources/seo-vs-ppc.html (last visited Oct. 14, 2017).

409. See FTC Google Statement, supra note 175, at 2 (finding that other search engines have similar functions) (last visited Oct. 14, 2017).

410. See Pinar Akman, “Consumer" Versus "Customer”: The Devil in the Detail, 37 J. L. \& Soc'Y 315 (2010) (discussing how and when these interests might differ).

411. Currently, the Commission's "consumer welfare" standard is a "customer welfare" standard because the term "consumer" is not used to refer to end-users (final consumers) but all customers of the undertaking involved including intermediate customers. See, e.g., Guidelines on the Application of Article 81(3) of the Treaty, 2004 O.J. (C 101) 97, II 84; Commission Guidance, supra note 31, at 10. As demonstrated by the examination of the travaux préperatoires the reference to "consumers" in Article 102(b)TFEU is also a reference to "customers" and not necessarily final consumers. AKMAN, supra note 27, at 297.

412. AKMAN, supra note 27 , at 305 .
} 
results and the specialist results are provided for free to the users. ${ }^{413}$ Furthermore, any exploitation is disputed by the factual findings of the FTC which suggest that users have benefitted from Universal Search (namely, Google displaying Google Shopping results prominently as well as organic results in response to a product search). ${ }^{414}$ Given that any space vacated by not displaying a comparison shopping site is taken up by alternatives to those sites including sites where the users can directly make a purchase and a large part of these are organic results for which Google receives no payment, ${ }^{415}$ it appears also too difficult to argue that users will pay higher prices for the items that they might purchase after clicking on links within the Shopping Commercial Unit (even if the ads in this space cost more for advertisers than ads in comparison shopping sites). ${ }^{416}$ A reduction in the quality of the general result pages due to Google's prominent display of Google Shopping Commercial Unit (e.g., due to Google receiving higher remuneration for a less relevant result) could be seen as a potential exploitation of users, but is tempered by the fact that it is the relevance of results that attracts both the users and the advertisers to the search engine in the first place. ${ }^{417}$ Thus, the reduction in the relevance of results would lead users to conduct fewer searches on Google Search or to switch to another search engine. ${ }^{418}$ Such a strategy of leveraging market power from general search to specialist search has also been remarked to be not profitable to Google for being "economic nonsense'; by diverting users from general search to its specialist services, Google would be giving up on a monopolist's advertising profit on the lost searches (given the allegation that Google is dominant on the general search market) to gain market share on a more competitive market (i.e., the market for

413. There is an emerging literature arguing that consumers pay for various free services on the Internet by their data. See, e.g., Ariel Ezrachi \& Maurice E. Stucke, Virtual Competition: The Promise and Perils of the Algorithm-Driven Economy (2016); John M. Newman, Antitrust in Zero-Price Markets: Foundations, 164 U. PA. L. REV. 149 (2015). This literature is not immediately relevant to this article as it is not an issue in Google Search and thus, will not be discussed further. However, for the argument that monetization of consumer data to offer "free" services benefit consumers, see, e.g., D. Daniel Sokol \& Roisin E. Comeford, Antitrust and Regulating Big Data, 23 GEO. MASON L. REV. 1129 (2016).

414. FTC Google Statement, supra note 175, at 2.

415. Id. at 1 .

416. In any case, whether there is a potential increase in the price of the product concerning which the search was conducted would ultimately depend on the state of competition on the market for a given product and could not be established in the abstract or in general for all product searches.

417. See Ratliff \& Rubinfeld, supra note 18, at 531.

418. See generally Ratliff \& Rubinfeld, supra note 18, at 531. Ratliff and Rubinfeld remark that consumers would become aware of any diminution in the relevance of Google's results in both absolute and relative senses. In the absolute sense, if Google leads them to a low-value vertical search service, consumers would realize that the Google search that led them there was also of low value irrespective of whether they are aware of better vertical search services. Id. If consumers do not have a different and more negative experience when they are led to an assumed lower-quality vertical search service than when led to an assumed higher-quality one, then this would indeed call into question the assertion that one was actually lower quality than the other. Id. In the relative sense, consumers would become aware if Google's vertical search service was of lower-quality when they become aware of higher-quality vertical search services that Google disfavoured. Id. They would become aware of such services even if they exclusively use Google because general search is not the only means by which consumers can learn about vertical search services. Id. For the position that if Google lowered the quality of search results it would lose users to competitors such as Yahoo!, Bing, etc. See also German Monopolies Comm'n, supra note 107, at 56. 
comparison shopping), thereby lowering its total profits. ${ }^{419}$ All in all, the first condition of abuse fails to be satisfied.

\section{Exclusion}

The second requirement of abuse, namely exclusion of competition from competitors at least as efficient as the dominant undertaking that constitutes harm to competition appears not to be met in Google Search either. The relevant exclusionary conduct allegation is that certain specialist websites lose traffic due to not being ranked as prominently as they were before Google started prominently displaying its own Shopping results with the consequence that they are excluded from the comparison shopping market. ${ }^{420}$ Foremost, it has to be noted that there is no outright exclusion of Google's specialist (vertical) competitors from the general result pages (just like there is no coercion of consumers to choose results higher up in the results). ${ }^{421}$ Thus, if the loss of traffic is the cause of the alleged exclusion, it needs to be taken into account that provided that their results are relevant, these specialist sites still receive free traffic from Google Search. ${ }^{422}$ Moreover, given that many - if not most — of the comparison shopping sites in question have stayed in business despite the alleged diversion of traffic for nearly a decade, ${ }^{423}$ it is highly questionable whether there is any actual or potential exclusion. An alternative explanation for those sites which have not stayed on the market might be found in the changing preferences of consumers regarding online shopping and the rising prominence of merchant platforms such as Amazon as well as the normal effects of competition. ${ }^{424}$

Second, what matters is harm to competition, and not the effect of conduct on certain competitors for the sake of preserving their competitive positions. Commentators have noted that a requirement imposed by competition law to consider purely external effects on competitors (i.e., the effects of Google's technological or business decisions on the profits of other websites) would be perverse as competition itself necessarily imposes negative externalities on competitors (in the form of reduced profits and lower prices that benefit consumers). ${ }^{425}$ It has to be reiterated that what the competitors lose is essentially a form of free promotion by Google, hence the characterisation by the German Court of their relation to Google Search as free-riders. ${ }^{426}$ Furthermore, in

419. Robert H. Bork \& J. Gregory Sidak, What Does the Chicago School Teach about Internet Search and the Antitrust Treatment of Google?, 8 J. COMPETITION L. \& ECON. 663, 676-77 (2012).

420. Renda, supra note 16, at 2-3, 8 .

421. Wagner-von Papp, supra note 16, at 642-643.

422. Renda, supra note 16 , at 45.

423. As noted above, Google introduced Universal Search in 2007. For a historical overview, see supra note 16 .

424. See Michael R. Baye, Babur De los Santos \& Matthijs R. Wildenbeest, The Evolution of Product Search, 9 J. L. ECON. \& POL'Y 201, 202, 211-18 (2013) (discussing consumers' changing preferences and the comparison shopping sites losing their popularity over the last decade).

425. SALINGER \& LEVINSON, supra note 194, at 31.

426. OLG Apr. 4, 2013, 408 HKO 36/13, http://deutschland.taylorwessing.com/documents/get/150/ courtorder-google-weather-inbox-english-unofficial-translation.pdf. 
Google Search the alleged conduct in question continues to generate free traffic to the websites displayed under the organic results and these are also competitors of Google for users conducting a product search such as Amazon, various retailers, etc. Indeed, the FTC has found that although changes to Google's algorithm may have resulted in traffic loss to the demoted comparison shopping sites, the same changes can be viewed as improving the overall quality of Google's search results because the first page now presents users with a greater diversity of websites. ${ }^{427}$ Thus, even if some competitors may have been harmed, competition is unlikely to have been harmed because of the numerous options still available to users wishing to search for and purchase items online and the numerous websites still receiving free traffic from Google Search. Given that both the EU Courts and the Commission have stipulated that effective competition may lead to the departure from the market of less efficient undertakings who deliver less to consumers in terms of price, choice, quality, innovation, etc., without this being anticompetitive under Article 102TFEU, ${ }^{428}$ the failure of some comparison shopping sites does not in itself represent the type of harm to competition that the EU competition rules seek to prevent.

\section{Lack of an Increase in Efficiency}

The third requirement of abuse also does not appear to be met in Google Search. As already alluded to above, the move from the ten-blue-links to Universal Search by Google and its competitors is considered to be an improvement in the provision of the search engine service which increased the efficiency of the service to users by improving quality through innovation (i.e., dynamic efficiencies). ${ }^{429}$ Google's display of its own content has been found to be an improvement in the quality of Google's search product by the FTC. ${ }^{430}$ Commentators also seem generally to agree that Universal Search is seen as an improvement by consumers in their experience. ${ }^{431}$ The introduction of Universal Search, which required Google to refine its assessment of the intent behind a search and then provide a link to the best available information for that intent regardless of its form, is perceived as an important intermediate step toward the ultimate goal of providing information directly. ${ }^{432}$ Providing information directly to users' complicated queries, such as, "show me flights under $€ 300$ for places where it's hot in December and I can snorkel," which no search engine can currently answer, appears to be the ultimate goal of Google, which would present a further improvement in the search engine service

427. FTC Google Statement, supra note 175, at 2-3.

428. Commission Guidance, supra note 31, II 6; Case C-209/10, Post Danmark A/S v. Konkurrenceradet, 2012 EUR-Lex CELEX LEXIS 172, II 22 (Mar. 27, 2012).

429. FTC Google Statement, supra note 175, at 2.

430. Id. at 3 .

431. See, e.g. Renda, supra note 16, at 34-35; Lao, supra note 18, at 310; Daniel A. Crane, Search Neutrality as an Antitrust Principle, 19 Geo. MASON L. REV. 1199, 1205 (2012); Ryan Singel, Times Case for Gov Regulation of Google Search is Weak, WIRED (July 16, 2010), http://www.wired.com/2010/07/nyt-googleregulation; Bork \& Sidak, supra note 419, at 673; SALINGER \& LEVINSON, supra note 194, at 18.

432. SALINGER \& LEVINSON, supra note 194, at 22. 
provided to users. ${ }^{433}$ Thus, it is clear that the conduct in question is a legitimate business practice that increases the efficiency and attractiveness of the search engine and ultimately benefits consumers through innovation. All in all, none of the conditions of the particular conceptualisation of abuse under investigation is met on the basis of the available facts in Google Search.

\section{The Potential Remedy}

The potential remedy in Google Search presents one of the most significant challenges in the Commission's investigation. This is because it remains unclear whether there is an appropriate remedy that can be imposed by the Commission. Under Article 7, Regulation 1/2003, where the Commission finds that there is an infringement of Article 102TFEU, it may by decision require the undertaking concerned to bring such infringement to an end. ${ }^{434}$

For this purpose, the Commission may impose on the undertaking any behavioural or structural remedies which are proportionate to the infringement and necessary to bring the infringement effectively to an end .... Structural remedies can only be imposed either where there is no equally effective behavioural remedy or where any equally effective behavioural remedy would be more burdensome for the undertaking concerned than the structural remedy. ${ }^{435}$

Thus, any remedy to be imposed has to be effective, apply in relation to the infringement that has been established and be proportionate to that infringement. ${ }^{436}$ The principle of proportionality means that the burdens imposed on an undertaking to bring an infringement of competition law to an end must not exceed what is appropriate and necessary to attain the objective sought, namely re-establishing compliance with the rules. ${ }^{437}$

On the basis of the allegations, the remedy in Google Search is potentially that of "treating all comparison sites in the same manner as Google treats its own comparison shopping service by subjecting them all to the same algorithm." 438 As noted before, the SO took the preliminary view that to remedy the conduct, Google should treat its own comparison shopping service and those of rivals in

433. See Schmidt, supra note 216 ("[T] he goal of a search engine is to deliver relevant results to users as quickly as possible. Put simply, we created search for users, not websites. And that's the motivation behind all our improvements over the last decade.").

434. See Council Regulation 1/2003, supra note 1, art. 7 (describing how the Council will find and terminate infringement).

435. Id.

436. See Commercial Solvents, 1974 E.C.R. 223, III 45-46 ("It stated that that limitation was counterbalanced by competition as regards the quality of the services supplied to customers, which was not normally possible in the absence of an adequate profit margin covering the higher costs entailed by such services."); Magill, 1995 E.C.R. 743, II 93.

437. Magill, 1995 E.C.R. 743, II 93.

438. Fact Sheet, supra note 7 ("The Statement of Objections takes the preliminary view that in order to remedy the conduct, Google should treat its own comparison shopping service and those of rivals in the same way. This would not interfere with either the algorithms Google applies or how it designs its search results pages. It would, however, mean that when Google shows comparison shopping services in response to a user's query, the most relevant service or services would be selected to appear in Google's search results pages."). 
the same way. ${ }^{439}$ This suggests that the expectation is for Google to subject all comparison shopping sites to the same algorithm as Google Shopping (Commercial Unit), namely the algorithm that Google applies to advertisements that generate revenue to Google even though the comparison shopping sites in question would not be paying for any ad space on Google's general result pages. ${ }^{440}$ Notably, the former Commissioner expressly indicated that imposing such a strict equal treatment obligation (i.e., that Google should apply the same algorithm to rank all search results including its own) would not be indispensable to remedy the concern in question and would not be proportionate, implying that it would not be justified under EU competition rules. ${ }^{441}$ The former Commissioner further noted that requiring Google to treat its own services in the exact same way as those of its competitors would mean that, depending on the results of the algorithm, Google's own services might not appear on its own page. ${ }^{442}$ According to the former Commissioner, this would "certainly be an unprecedented constraint imposed on a company by an antitrust authority" and would not be in the users' best interest. ${ }^{443}$

Other than the question of whether such a remedy of equal treatment can be achieved and effectively supervised in practice, ${ }^{444}$ it is unclear whether, in Google Search, there is a potential remedy, the imposition of which can be legally justified and makes commercial sense.

The first issue concerns what such a remedy of subjecting comparison shopping sites to the same algorithm that Google subjects Google Shopping (Commercial Unit) would entail. Such a remedy could require Google to display the merchant results that the competitor shopping sites would display in response to a particular product search. ${ }^{445}$ However, there are several problems with such a remedy. First, it is inconsistent with the way that search engines operate and compete with one another since the competition between search engines takes place through the display of their own results, not results of others.

439. Id.

440. The prospect of comparison shopping sites paying for such display was vehemently rejected by some of the complainants. See ICOMP, ICOMP Response to the European Commission's RFI in Relation to Google's Revised Proposed Commitments-Text of 21 October 2013, 5 (2013), http://www.i-comp.org/fr/wpcontent/uploads/sites/6/2013/12/ICOMP_rfi.pdf.

441. Almunia Sticking to His Guns in Google Antitrust Case, EurActiv (Mar. 13, 2014), http://www.euractiv.com/innovation-enterprise/almunia-keeps-tough-line-google-news-534114; Google Settlement Won't Create a New "Revenue Stream," EU Commission Says, MLEX (Mar. 12, 2014), www.mlex.com/EU/Content.aspx?ID=512749.

442. Joaquín Almunia, We Discipline Google, FrANKFURTER AllgemeIne (May 13, 2014), www.faz.net/aktuell/feuilleton/debatten/the-digital-debate/joaquin-almunia-we-discipline-google12937515.html.

443. Id.

444. Google applies around 500-600 changes to its algorithm every year. See Google Algorithm Change History, Moz, https://moz.com/google-algorithm-change (last visited Oct. 14, 2017). For example, in 2012, there were 665 improvements launched. See How Search Algorithms Work, GooGLE, https://www.google.com/ insidesearch/howsearchworks/algorithms.html (last visited Oct. 14, 2017). This in itself raises serious concerns about whether any remedy imposed on Google could be effectively achieved and supervised.

445. Almunia, supra note 442 ("[W]henever it promotes its own services, Google would also have to present the specialized [sic] services of three competitors in a way that is clearly visible to users. These rival links would also be displayed in a comparable visual format."). 
Second, it is unclear how Google could obey such a remedy. There are two options: first, Google may be required to show results of the comparison shopping sites on the basis of the algorithms that these sites themselves use; or, second, Google may be required to apply its own algorithm to the merchant offers available in the comparison shopping sites' inventories. ${ }^{446}$ Even if either of these options were technically possible without reducing the quality of search results for users by causing delays, both options would be tantamount to ordering Google to allow its competitors to monetize its page real estate by placing product offers in that space for which the rival has been paid for by advertisers. ${ }^{447}$ This would not only dampen competition, but also reduce the incentives to innovate of both Google and its competitors.

Irrespective of the question what exactly the remedy would entail, there is a second obvious problem concerning the remedy, as noted by the German Monopolies Commission: the operator of a search engine does not need to manipulate the search algorithm to take advantage of the preferential display of its own services since knowing the algorithm already enables the operator to design the websites for its own services in a way that would enable them to rank higher more easily in the generic search results. ${ }^{448}$ Thus, even if Google were to apply the same algorithm to Google Shopping and to the comparison shopping sites, simply by virtue of knowing the algorithm, it could ensure that Google Shopping ranks higher than a comparison shopping service. ${ }^{449}$ It must be noted that the German Monopolies Commission does not recommend the separation of general and specialised search services since it finds that this would be disproportionate. ${ }^{450}$ Moreover, such separation would impose on Google a compulsory reduction of the quality of its results for users since a free search engine service that presents universal results is more valuable to users than a free service that presents ten-blue-links. Furthermore, such separation would constitute divestiture. ${ }^{451}$ However, given that Google's specialist results are simply a subset of its general search results rather than separate operations, it is difficult to envisage what exactly Google could be asked to divest. There would potentially be no limit to such an imposed reduction in quality - since that would be ultimately what separation and divestiture involve-as the more search queries there are for which a competitor may have a website that represents a subset of queries that Google can answer, the more specialist results Google would have to refrain from displaying on its general search result pages. Not only would this be an unjustifiable intervention in Google's design choices over its proprietary content, such separation would also harm consumers by reducing

446. In this vein, see the options discussed (and ultimately found disproportionate) in_Streetmap.EU Ltd. v. Google Inc. [2016] EWHC 253, 162-76 (Eng.).

447. See, e.g., Metro SB-Großmärkte GmbH \& Co. KG v. Comm'n, 1986 E.C.R. 3021, IIII 55-56 (regarding the legitimate interest of a company in protecting the quality of its products); Pronuptia de Paris GmbH v. Pronuptia de Paris Irmgard Schillgallis, 1986 E.C.R. 353, II 27.

448. German Monopolies Comm'n, supra note 107, at 7.

449. See id. at 7 (stating that "knowing the algorithm already enables the operator to design the websites for its own services so that they rank higher more easily in the generic list of results.").

450. Id.

451. See id. (implying "the separation of general and specialised [sic] search services" would be "[a] divestiture"). 
the relevance and, thus, the quality of the results that they would receive for searches on Google Search.

A third problem with the potential remedy is that imposing an obligation that Google subjects its own shopping results and competitors' shopping sites to the same algorithm ignores the revealed preferences of users. Users who choose to conduct a search on Google, as opposed to another search engine or a comparison shopping site, can be presumed to do so out of preference given the availability of other options. Thus, making Google display the results of competitors in the same manner as it displays its own results-when the comparison shopping sites are available to access for anyone valuing their services - disregards the preferences of users who want to see Google's results. Moreover, it implies ignoring the preferences of users in order to make Google provide free promotion to its competitors. This entails questioning whether the consumers have the "right preferences," even though such paternalism is alien to competition law. ${ }^{452}$ Intervening without very good evidence that informed consumer choice is impossible in the circumstances of the case would result in the Commission overruling consumer preferences instead of protecting them against restrictions. ${ }^{453}$

A related fourth issue with the potential remedy is that given that the comparison shopping sites (and other sites) do receive free traffic from Google by being displayed in the organic results when relevant, the remedy inherently must involve more than the provision of free traffic. Indeed, the potential remedy implies the active promotion of comparison shopping sites by Google, for free, in the general result pages. This begs two questions: first, why any site should be promoted for free by Google when Google's free search engine service to users is funded almost exclusively by advertisers who pay for the space on the general result pages ${ }^{454}$ (i.e., the exact same thing that the competitors would be entitled to for free). Second, why comparison shopping sites deserve and are more entitled to this enhanced free promotion of their websites by Google any more than, for example, Amazon or eBay or a given merchant is. Such entitlement to enhanced promotion is a direct result of the Commission's definition of a relevant market as that of comparison shopping and its definition of that market in a particular way. ${ }^{455}$ If the relevant market is not that of comparison shopping or if the market of comparison shopping as defined by the Commission also included merchant platforms such as Amazon and eBay, then the remedy would involve little more than the Commission protecting the interests of comparison shopping sites as opposed to other sites like Amazon and

452. Wagner-von Papp, supra note 16, at 646.

453. Id. at 647 .

454. See Greg McFarlane, How Does Google Make Its Money?, InVESTOPEDIA (Nov. 22, 2012, 10:21 AM), http://www.investopedia.com/stock-analysis/2012/what-does-google-actually-make-money-fromgoog1121.aspx (providing an overview of how Google Search drives Google's revenue).

455. Commission Notice on the Definition of Relevant Market for the Purposes of Community Competition Law, 1997 O.J. (C 372) 5, II 7. 
thereby, distorting competition between competitors. ${ }^{456}$ However, market definition is an entirely artificial construct that has been called an incoherent process as a matter of basic economic principles. ${ }^{457}$ Real markets do not come defined. Market definition is an exercise that serves to establish the group of products that are sufficiently substitutable with one another. ${ }^{458}$ In Google Search, it is highly likely that comparison shopping services is either not a relevant market or if it is, it includes merchant platforms such as Amazon and eBay, which currently are not acknowledged as part of the relevant market by the Commission. ${ }^{459}$ As noted by one commentator, "there might be something wrong if policymakers systematically identify different competitors compared to those that the companies themselves consider to be their rivals." ${ }^{460}$ Notably, Amazon and eBay both consider themselves to be competing with general search engines as well as comparison shopping sites. ${ }^{461}$ Thus, the Commission's envisaged remedy may result in arbitrarily protecting some competitors-in fact, likely those less preferred by consumers - over others.

Fifth, the potential remedy involves Google practically paying for the promotion of its rivals by the use of Google's services. This is because Google earns revenue from the display of Google Shopping (Commercial Unit) results which are ads. ${ }^{462}$ The space in which Google might be ordered to treat its competitors in the same way as it treats Google Shopping is Google's ad space. ${ }^{463}$ Consequently, the remedy will entail Google treating the competitors' sites which do not involve any advertisement return to Google in the same way as revenue generating advertisements, thereby losing the potential revenue from paid-for advertisements in the same space, to promote the services of its competitors on its own property. This is equivalent to not only making Google

\footnotetext{
456. The case would be unsustainable if one included particularly Amazon as a player in the relevant market since the Commission would have to demonstrate that Amazon is likely to be excluded as a result of Google's conduct. A comScore study that found that product searches on Amazon grew $73 \%$ over one year (in 2012). See Singer, supra note 216.

457. Louis Kaplow, Why (Ever) Define Markets, 124 HARV. L. REV. 437 (2010).

458. A relevant "product market" comprises all those products/services which are regarded as interchangeable or substitutable by the consumer, by reason of the products'/services' characteristics, their prices and their intended use. See Commission Notice, supra note 455, II 7.

459. See, e.g., Renda, supra note 16, at 28 (noting that Amazon is clearly a competitor to Google's comparison shopping service); Lianos, supra note 22 (suggesting that Amazon may be a competitor in "product search").

460. Renda, supra note 16 , at 43.

461. See Amazon.com, Inc., Annual Report (Form 10-K) (Jan. 29, 2015), https://www.sec.gov/Archives/ edgar/data/1018724/000101872415000006/amzn-20141231x10k.htm\#s21F0250F132C18429D9452F1E3EE

59F5 ("[W]e have many competitors in different industries, including retail, e-commerce services, digital content and electronic devices, and web and infrastructure computing services."); eBay Inc., Annual Report (Form 10K) (Feb. 5, 2015) 10, 13-14 http://www.sec.gov/Archives/edgar/data/1065088/000106508815000054/ ebay201410-k.htm\#s7BBCEDF2F60 0306C7D072F1C7807C055 ("[Competitors] include, but are not limited to, retailers, distributors, liquidators, import and export companies, auctioneers, catalog and mail-order companies, classifieds, directories, search engines, commerce participants (consumer-to-consumer, business-toconsumer and business-to-business), shopping channels and networks.").

462. McFarlane, supra note 454.

463. Almunia, supra note 442 ("So whenever Google decides to offer what you [Mathias Döpfner, to whom the open letter is addressed] call "a new advertising window," it would be obliged to share it with its competitors, providing them with comparable space inside it.").
} 
promote competition against itself, but also making Google practically pay (an amount equivalent to the forgone revenue from not displaying a potentially revenue-generating ad in the same space) for such promotion. It is difficult to contemplate how such a remedy might be considered proportionate and necessary.

In summation, it is challenging to envisage exactly what could be legitimately required of Google to remedy its allegedly infringing conduct. The potential lack of an appropriate remedy should prompt the Commission to reconsider whether there is an infringement in the first place. It has indeed been remarked that at this stage in Google Search, it is difficult to imagine a remedy that would benefit consumers more than the "do nothing" option. ${ }^{464}$

\section{CONCLUSION}

This Article has conducted a positive and a normative assessment of whether the conduct in Google Search, as identified by the Commission, breaches Article 102TFEU. Regarding the positive law assessment, three of the most likely theories of abuse (i.e., refusal to deal, discrimination, and tying) have been considered. A thorough analysis of the provision of Article 102TFEU, as well as the case law thereon, reveals that fitting the publicly available facts of Google Search into one of these existing types of abuse is equivalent to fitting a square peg in a round hole. Without entirely disregarding some of the fundamental concepts and rules underlying the existing framework for these abuses, the facts of Google Search do not fit into these categories of abuse. A normative legal assessment of the conduct in question, the necessity of which arises from the list of practices in Article 102TFEU being indicative and from the lack of precedent in EU law, also reveals that these facts should not be fitted into the framework of Article 102TFEU. Under the conceptualisation of abuse adopted for this normative assessment, the requirements of abuse are not fulfilled: the facts in Google Search do not indicate the relevant type of exploitation, exclusion, or lack of an increase in efficiency resulting from the dominant undertaking's conduct. Coupled with the serious issues surrounding the potential remedy as well as the possibility that no appropriate remedy exists, Google Search clearly presents a testing challenge for the Commission.

Reaching the incorrect outcome in Google Search can lead to a chain of other incorrect interventions in Europe and beyond, as well as a reduction in incentives of other companies to take risks, invest and innovate. Commentators have indeed remarked that on the basis of an error-cost framework an antitrust action against Google is ill-advised and creates substantial risk for a false positive, which would chill innovation and competition in fast moving markets that currently benefit consumers. ${ }^{465}$ Arguably, antitrust authorities have historically not treated novel business practices or innovative practices kindly, and economics has tended to ascribe anti-competitive explanations to new forms

464. Renda, supra note 16 , at 42 .

465. Manne, supra note 16 , at 178. 
of conduct that are not-well-understood. ${ }^{466}$ Antitrust scrutiny of innovation is likely to be biased towards assigning a higher likelihood of anti-competitiveness to a given practice than later literature and evidence will suggest is reasonable or accurate. ${ }^{467}$ Not only is the theoretical literature on innovation and competition insufficient to instil any confidence in our ability to establish which antitrust policies would encourage innovation and result in consumer gains, but stakes are also higher in cases concerning innovation than in regular antitrust cases on the basis of the well-established link between economic growth and innovation. ${ }^{468}$

Google Search is an opportunity for the Commission to demonstrate its dedication to an enforcement objective that distinguishes harm to competitors from harm to competition and consumers under Article 102TFEU. Whether competition and consumers have been harmed by any of Google's alleged practices has to be established beyond a demonstration of harm to some competitors. As the publicly available facts stand, it appears unlikely that Google's practices under scrutiny have harmed or even can harm consumers. That a search on Google Search never returns an otherwise empty page with results from Google's own specialist services and related advertisements, but always involves free, organic results which in many cases generate traffic to Google's major competitors (such as Amazon) is an important fact to remember when establishing whether competition has been harmed. Any infringement decision in Google Search should, therefore, demonstrate that the case is not about who "is going to get their hands on" the potential revenue from advertisers, but is about protecting competition in order to ultimately benefit consumers. ${ }^{469}$

466. Id. at 183

467. Id.

468. Id. at $184-86$

469. See Attheraces Ltd. v. British Horse Racing Bd. Ltd., [2007] EWCA Civ 38, 214 (Eng.) (holding that this case concerning the supply of pre-race data to which bookmakers and broadcasters needed access for use in their business and which was allegedly supplied at excessive prices by the British Horseracing Board to Attheraces (ATR) (a broadcaster) under Article 102TFEU was "[d]espite its elaborate legal and economic arguments and the high levels of moral indignation, [a] case . . . about who is going to get their hands on ATR's revenues from overseas bookmakers."). See also id. at 215 (holding that since "the principal object of Article [102] of the Treaty is the protection of consumers, in this case the punters, not of business competitors . . [ [the Court] need[s] to look beyond ATR's immediate interests to the market served by ATR."). 


\section{ANNEX 1}

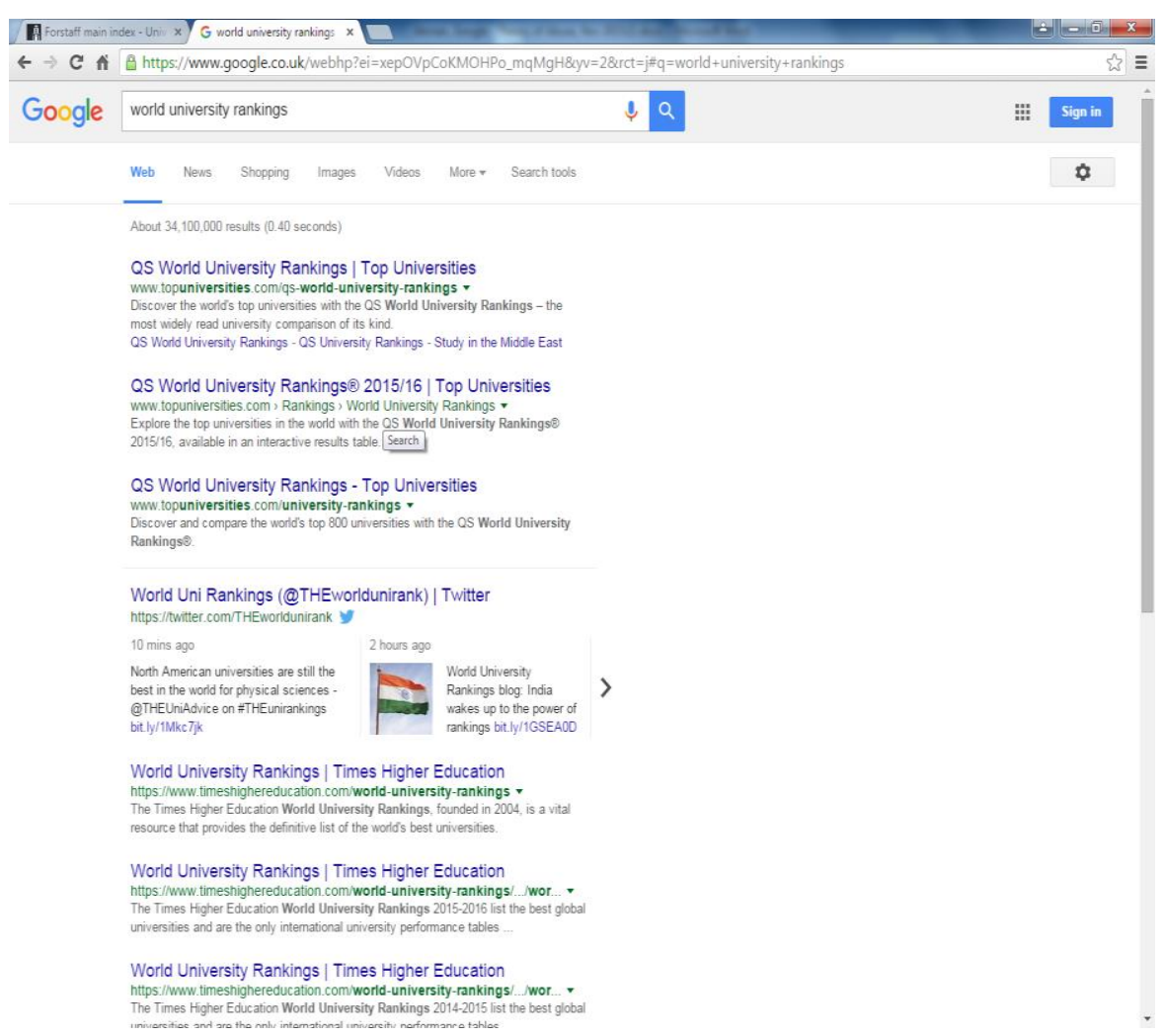


ANNEX 2

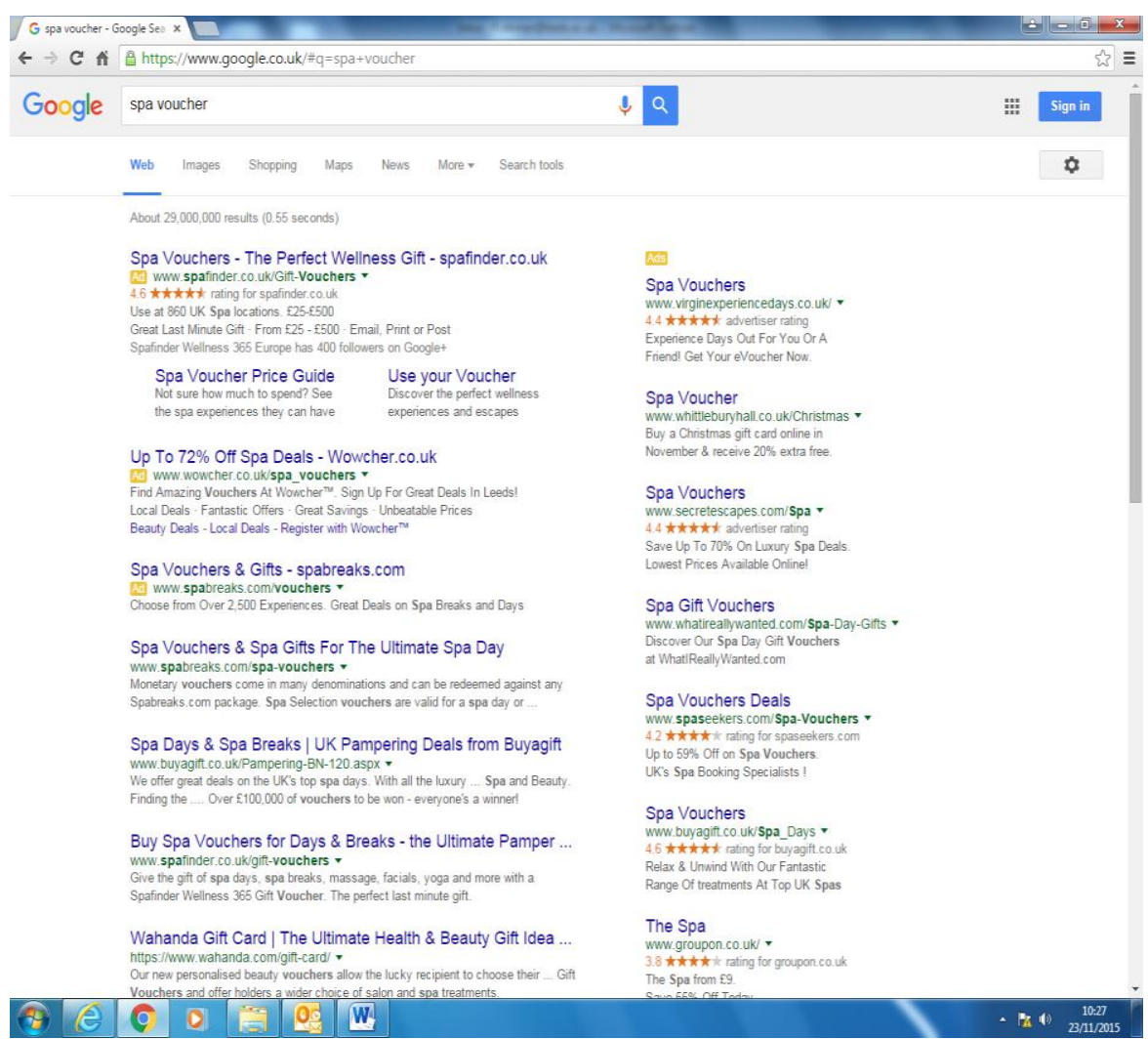


ANNEX 2 CONTINUED

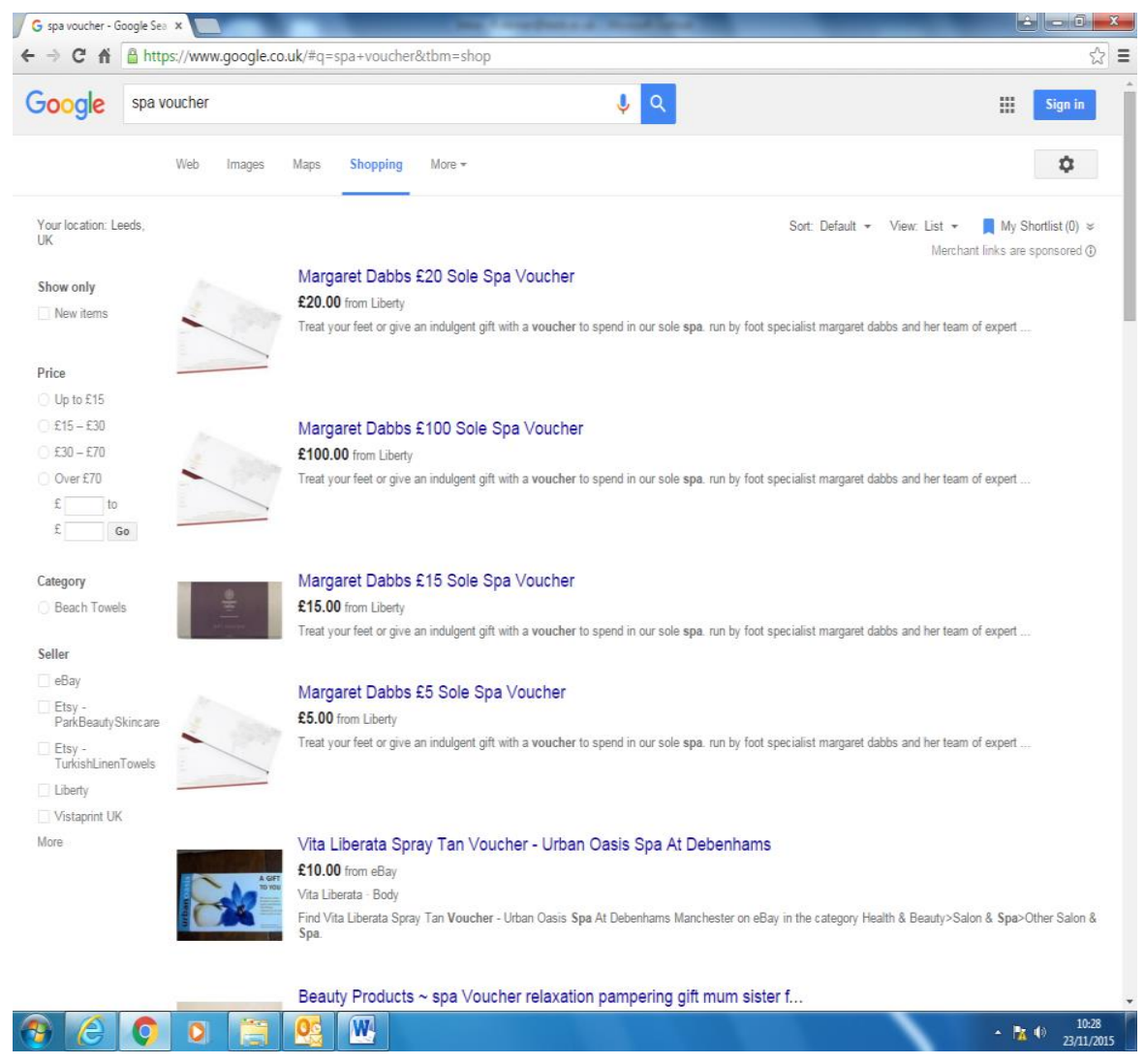

